\title{
Anatomy of Juravenator starki (Theropoda: Coelurosauria) from the Late Jurassic of Germany
}

\author{
Luis M. Chiappe, Los Angeles and Ursula B. Göhlich, Vienna
}

With 26 figures

ChiAppe, L. M. \& GöHLICH, U. B. (2011): Anatomy of Juravenator starki (Theropoda: Coelurosauria) from the Late Jurassic of Germany. - N. Jb. Geol. Paläont. Abh., 258: 257-296; Stuttgart.

\begin{abstract}
We provide a detailed study of the morphology of the holotype of Juravenator starki from the Late Jurassic of the Solnhofen area of southern Germany. The incompletely ossified surface of multiple bones and lack of several skeletal fusions indicate that Juravenator starki is based on an immature specimen. Nonetheless, numerous unique morphologies and bone proportions distinguish this taxon from Compsognathus longipes, the only previously named non-avian theropod dinosaur from the Late Jurassic of the Solnhofen Archipelago. Yet, its skeletal anatomy is most similar to that of Compsognathus and other theropods that have often been regarded as closely related to the lattersometimes within a monophyletic Compsognathidae. Juravenator is characterized by having a small size $(\sim 0.75$-meter-long in the holotype $)$ with few maxillary teeth, lack of a premaxillary-maxillary diastema, an antorbital fenestra subequal in length to orbit, an elongate scapula that is narrowest at its neck, a proportionally short humerus and high and abruptly tapered manual claws, and bowlike zygapophysial articulations in the mid-caudal vertebrae. Portions of the epidermis preserved mainly along the tail provide the only glimpse of the morphology of the skin of basal coelurosaurs, and structures newly revealed under UV light hint at the possibility of filamentous integumentary structures - akin to those interpreted as proto-feathers in other basal coelurosaurs - also covering the body of this dinosaur. The discovery of Juravenator has provided evidence of morphologies - from details of the skull to the epidermis - that are poorly known in other theropods interpreted as at or near the base of Coelurosauria, and thus contributes significantly to our understanding of the evolutionary history of this clade. The exquisitely preserved holotipic skeleton adds significantly to the meager record of small-bodied Late Jurassic theropods.
\end{abstract}

Key words: Juravenator, Theropoda, anatomy, taphonomy, preservation, Jurassic, Solnhofen Limestones.

\section{Introduction}

Small non-avian theropods of Late Jurassic age are rare worldwide (WEISHAMPEL et al. 2004). Only a handful of them exist in Europe and until recently, these dinosaurs were best represented by two incomplete skeletons of Compsognathus longipes (WAGNER 1861). Despite the historical significance of Compsognathus, the discovery of which played a key role in the evolutionary debate of the $19^{\text {th }}$ century (DESMOND 1982; Ostrom 1978; CHIAPPE 2007), the rather unspecialized morphology of "compsognathids" (Compsognathus and a series of alleged Late Jurassic-Early Cretaceous relatives - CURRIE \& CHEN 2001; Holtz et al. 2004; HwANG et al. 2004; NAISH et al. 2004; JI et al. 2007b; Gishlick \& GAuthier 2007) has complicated interpretations of this group's monophyly. In this paper, "compsognathids" are used without any 


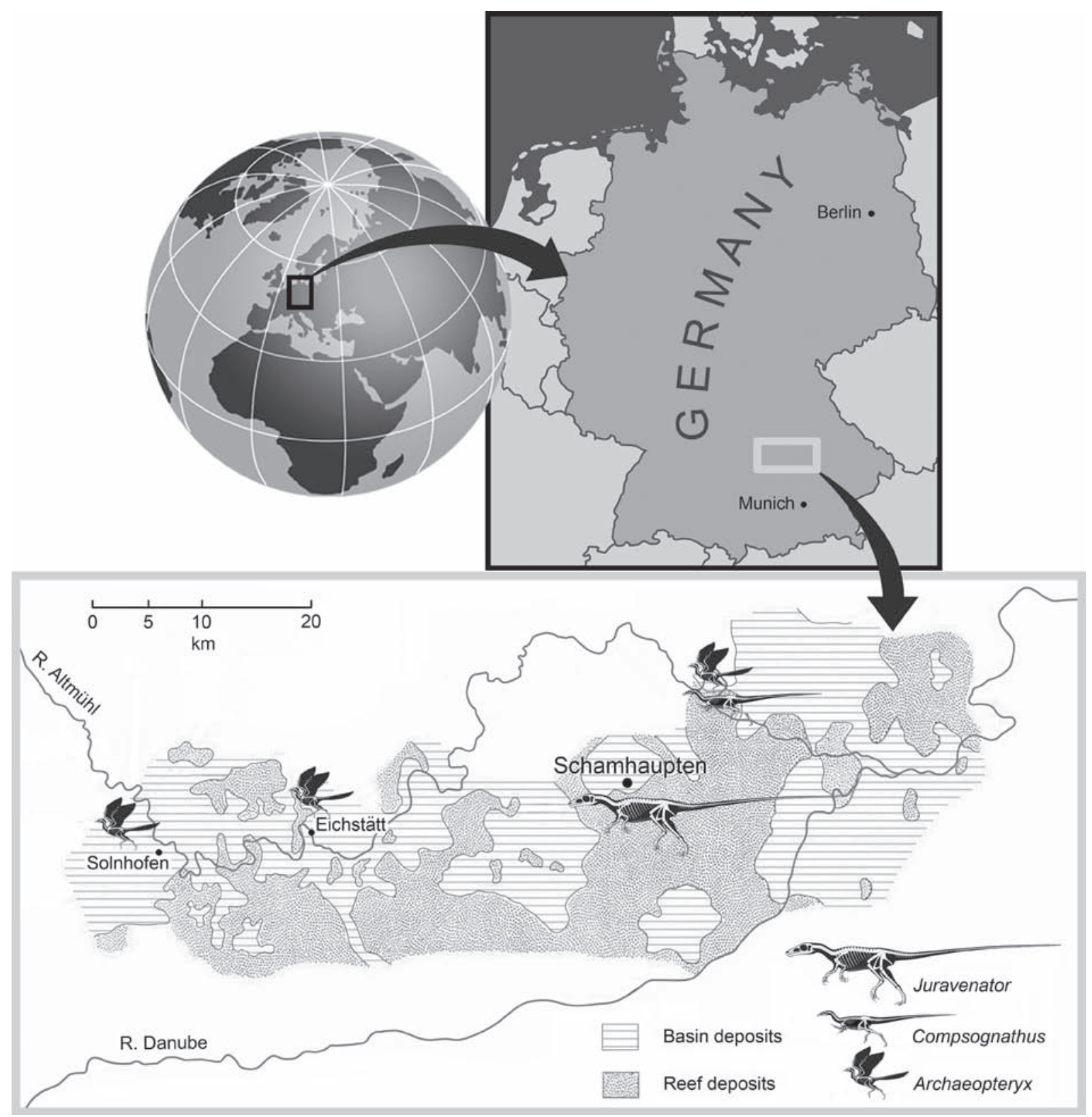

Fig. 1. Geographic location of Juravenator starki (JME Sch 200), Compsognathus longipes, and selected specimens of Archaeopteryx lithographica (reconstructions not to scale). Barred and mottled patterns indicate the approximate depositional areas during the Late Jurassic.

implication of the putative monophyletic nature of a group that includes Compsognathus longipes (Wagner 1861; Ostrom 1978; Peyer 2006), Huaxiagnathus orientalis (HwANG et al. 2004), Sinosauropteryx prima (Ji \& Ji 1996; CHEN et al. 1998; CURRIE \& CHEN 2001), Scipionyx samniticus (DAL SASSO \& SignORE 1998), and Juravenator starki (GöHLICH \&
Chiappe 2006) among other non-avian theropods usually regarded at or near the base of the coelurosaurian clade. The morphological diversity of these theropods has remained as a poorly understood chapter in the evolutionary history of Late Jurassic-Early Cretaceous theropod dinosaurs (CURRIE \& CHEN 2001; Holtz et al. 2004; Peyer 2006). However, 


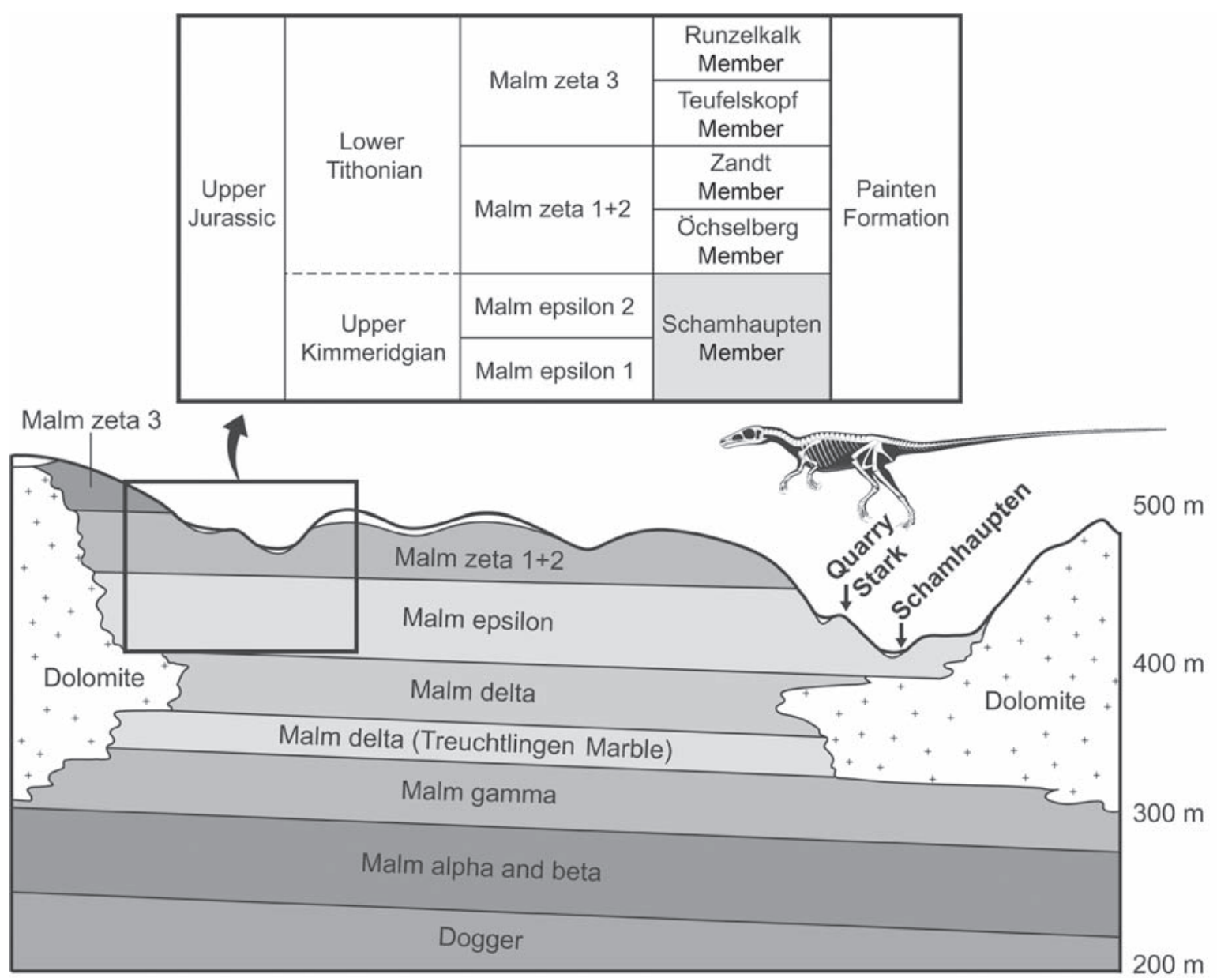

Fig. 2. Stratigraphic position of STARK Quarry (Schamhaupten Member) and Juravenator starki (JME Sch 200). Stratigraphic section and table modified after ViOHL \& ZAPP $(2006,2007)$.

these generally unspecialized theropods provide key evidence for understanding the morphological transformations that occurred near the base of Coelurosauria, an extremely diverse clade of dinosaurs that includes all living birds.

In 1998, ending a decade-long collecting program (1989-1998) by the Jura-Museum Eichstätt under the direction of GÜNTER VIOHL, volunteers KLAUSDieter and Hans-JoACHIM Weiss (Kelkheim-Fischbach) unearthed a small Late Jurassic theropod from the Franz STARK Quarry of Schamhaupten (district of Eichstätt, Southern Franconian Alb, Bavaria, Germany) (Fig. 1). The WeIss brothers first split a slab containing portions of the skull and cervicals, which led them to quarry the adjacent slabs. The specimen (JME Sch 200) was brought to the Jura-Museum Eichstätt for a multi-year preparation by PINO VöLKL, who revealed a nearly complete skeleton with traces of soft tissues (for more details on the history of discovery and preparation, see TISCHLINGER et al. [2006] and GöHLICH et al. [2006]). The specimen was preliminarily described and named Juravenator starki by GöHLICH \& CHIAPPE (2006). Based on several synapomorphies including the presence of a round orbit, some maxillary and dentary teeth without anterior serrations, and axial epipophyses not extending beyond the posterior rim of the postzygapophyses, GöHLICH \& CHIAPPE (2006) identified Juravenator as a coelurosaurian, and clustered this taxon with other basal coelurosaurians within Compsognathidae. As mentioned above, however, the monophyly of "compsognathids" and their relationships to other coelurosaurians, are far from settled. While a number of phylogenetic studies (e.g., HwANG et al. 2004; SENTER 2007; 
Xu et al. 2009; ChOINIERE et al. 2010) have recovered them as a monophyletic clade, taxa usually ascribed as "compsognathids" are distributed across the basal portion of the coelurosaurian tree in other studies (e.g., Butler \& UpChurCh 2007). Furthermore, cladistic analyses in which compsognathids are recovered as monophyletic usually limit the taxonomic sampling of these theropods to better known taxa such as Compsognathus, Sinosauropteryx, and Huaxiagnathus, but fail to include a variety of other taxa that have also been described as members of the same group (e.g., Mirischia asymmetrica, Sinocalliopteryx gigas) (MARTILL et al. 2000; NAISH et al. 2004; Ji et al. 2007a).

The phylogenetic relationships of Juravenator together with that of many other basal coelurosaurians (and the monophyly of "compsognathids") needs to be studied in light of more comprehensive cladistic analyses. This notewithstanding, the discovery of Juravenator resulted in an exceptionally well-preserved specimen - possibly the most complete nonavian theropod from Europe - and a startling new example of a small-bodied Late Jurassic carnivorous dinosaur. Juravenator thus provides important information for better understanding the role played by basal coelurosaurs in the evolutionary history of theropods. The present paper provides a detailed description of both the skeletal morphology and integumentary anatomy of this dinosaur.

Institutional abbreviations. - AMNH, American Museum of Natural History (New York); BSPG, Bayerische Staatssammlung für Paläontologie und Geologie (Munich); CAGS, Chinese Academy of Geological Sciences (Beijing); GMV, Geological Museum of China (Beijing); JME, JuraMuseum Eichstätt (Eichstätt); SMNK, Staatliches Museum für Naturkunde Karlsruhe (Karlsruhe).

\section{Geological setting}

During the Late Jurassic, southern Germany was largely submerged by a shelf sea wedged between two large islands to the north and the deeper Tethys Ocean to the south (BARTHEL et al. 1990). A series of limestone-filled basins developed within this shallow sea; one of them was the small $\left(\sim 35 \mathrm{~km}^{2}\right)$ Schamhaupten Basin (Southern Franconian Alb), in which limestones were deposited amid a large complex of dolomitic reefs (Renesto \& Viohl 1997; Zeiss 2001; Viohl \& ZAPP 2006, 2007) (Figs. 1-2).

The skeleton of Juravenator (JME Sch 200) is contained in the strongly silicified, laminated limestone that outcrops at the FrAnZ STARK Quarry of Schamhaupten. VIOHL \& ZAPP $(2006,2007)$ identified this silicified plattenkalk as belonging to the Late Kimmeridgian Schamhaupten Subformation, which is considered to be part of the Painten Formation. Based on recent biostratigraphic studies (ZEISS 2001; VIOHL \& ZAPP 2006, 2007; SCHWEIGERT 2007), the top limestones at Stark Quarry are dated as uppermost Kimmeridgian (Beckeri Zone, Ulmense Subzone) (Fig. 2), thus slightly older than the neighboring Solnhofen Lithographic Limestones (Solnhofener Plattenkalk) the celebrated deposits that have yielded both Compsognathus and Archaeopteryx (WELLNHOFER 2008).

The Schamhaupten plattenkalk (which is different than the Solnhofen plattenkalk) comprises two main types of beds: bindstones and detrital carbonates. Most articulated fossils are contained within bindstones, while detrital carbonates most typically yield shells and isolated skeletal elements (VIOHL \& ZAPP 2006) - Juravenator is embedded in a 3.5 -cm-thick bindstone belonging to section layer E3 (see VIOHL \& ZAPP 2006: fig. 5, 2007: fig. 4). Containing more than 200 taxa, the Schamhaupten plattenkalk has preserved a great variety of fossil plants, nano- and microfossils, invertebrates, and vertebrates (VIOHL 1999; VIOHL \& ZAPP 2006). Fish are the most abundant vertebrates but a variety of reptiles - among these, the turtles Solnhofia and Eurysternum, the sphenodontid Leptosaurus, and Juravenator (RENESTO \& VIOHL 1997; VioHL 1999, 2006, 2007) - are also well-represented. The fact that most Schamhaupten fossils are of marine origin suggests good connections to the Tethys Ocean but the remains of terrestrial taxa also indicate the existence of nearby islands.

The exceptional preservation illustrated by the richness of articulated fossils - fish, reptiles, crustaceans, sea urchins with in situ spines, and others designates the Schamhaupten plattenkalk as a Konservat Lagerstätte, although one in which organisms in different stages of decay are also preserved. This extraordinary preservation has been recently explained by the taphonomic model of VIOHL \& ZAPP (2006, 2007). These authors suggest that a stratified salinity developed within the Schamhaupten Basin: its bottom zone was hypersaline, anaerobic or dysaerobic, and thus lethal, while its upper water column was suitable for marine life. The hostile nature of the basin's bottom suggests the absence of benthonic scavengers, although VIOHL \& ZAPP $(2006,2007)$ interpreted the proliferation of microbial mats as responsible for the generation of bindstones by trapping sedi- 


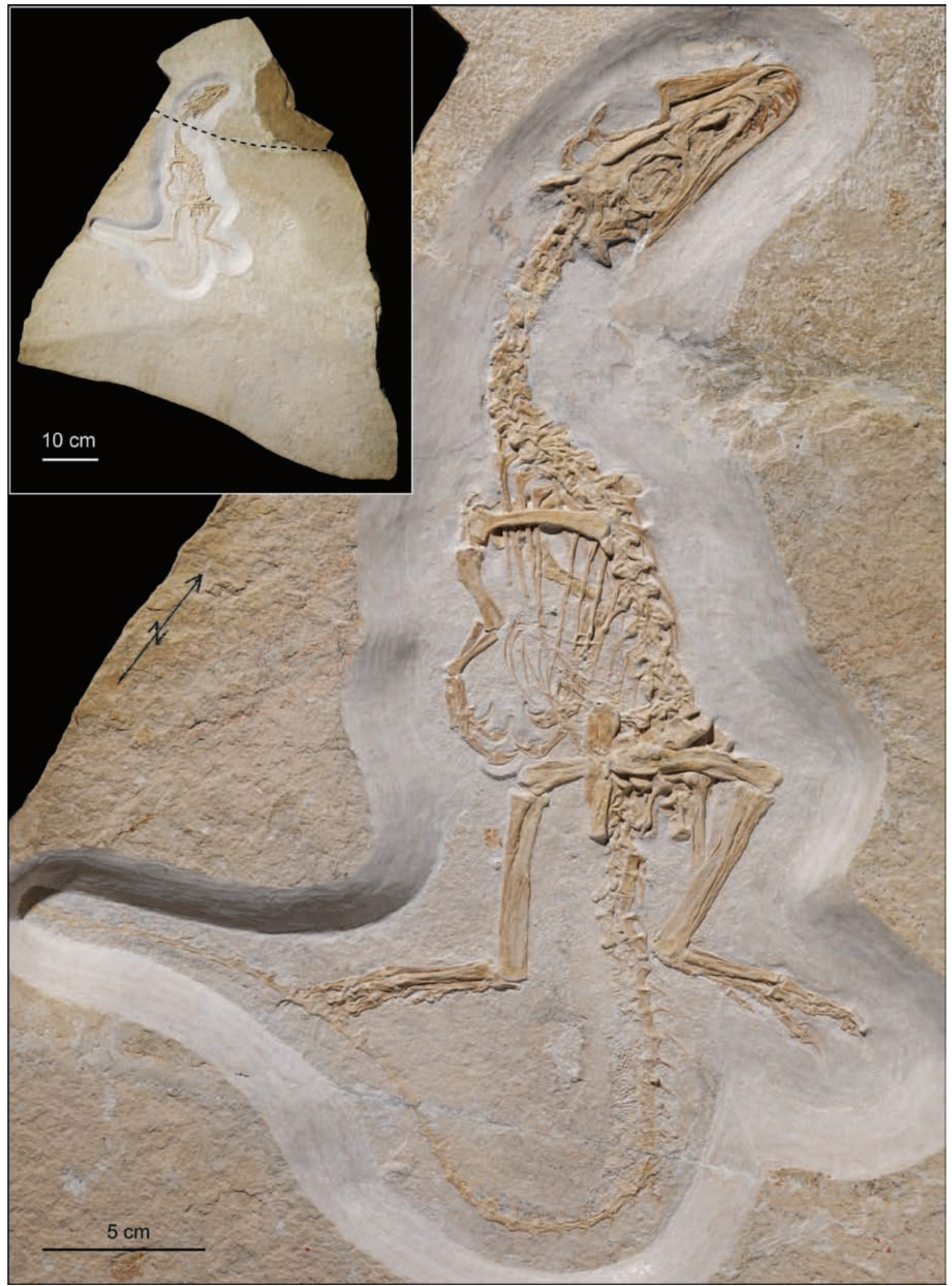

Fig. 3. Photograph under normal light of the skeleton of Juravenator starki (JME Sch 200). Dashed line on inset highlights the boundaries of the two blocks in which the specimen was collected. 


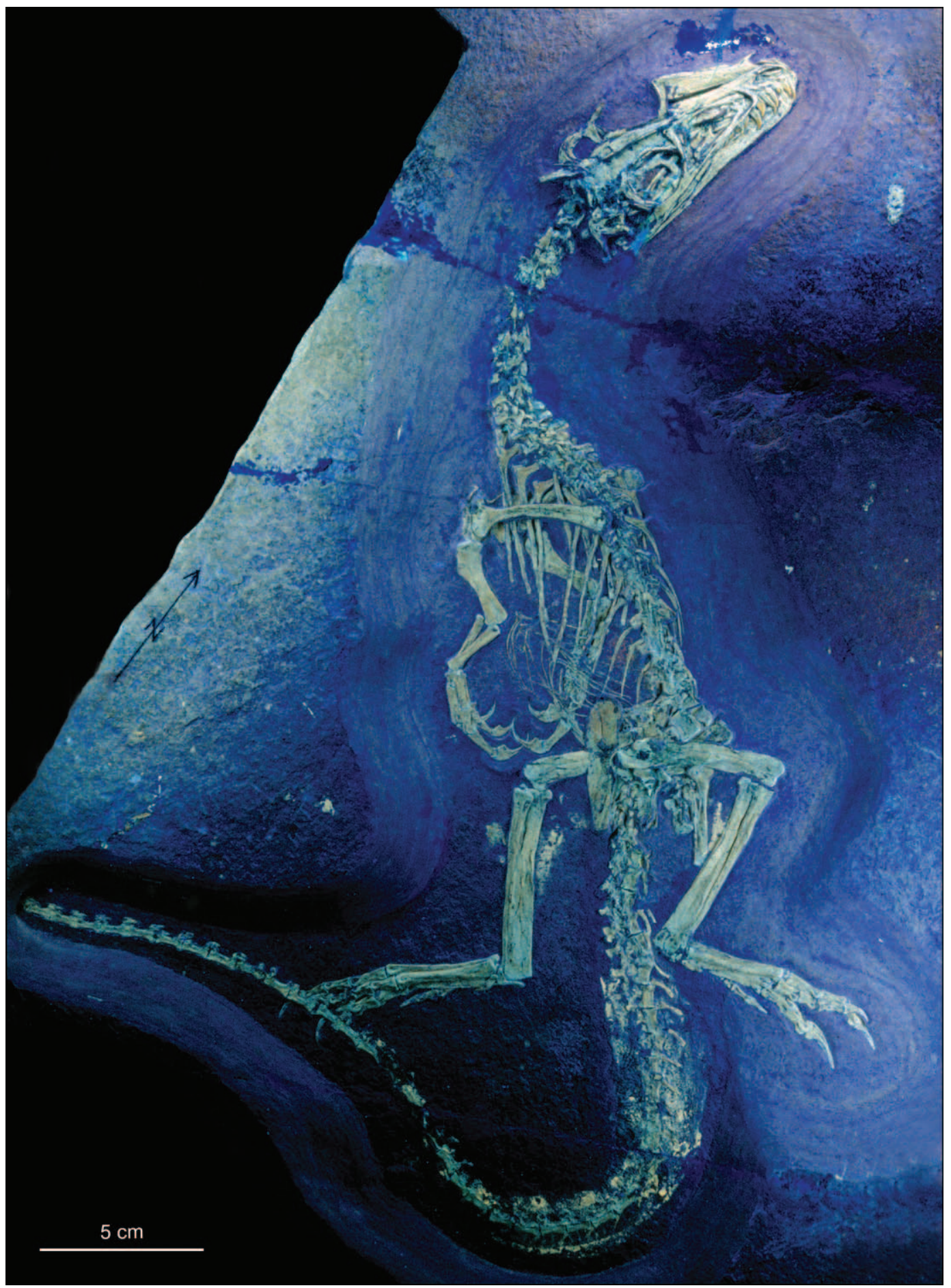

Fig. 4. Photograph under ultraviolet light of the skeleton of Juravenator starki (JME Sch 200).

ment and for the extraordinary preservation of Schamhaupten by rapidly sealing the sunken corpses.

\section{Taphonomy of Juravenator}

Instead of having the typical opisthotonic posture of many fossil amniotes (MARshall FAUX \& PADIAN 
2007), the skeleton of Juravenator (Figs. 3-5) exhibits two distinct torsions: at the level of the neck and most unusually, in front of the pelvis. While the skull and tail are primarily exposed in right lateral view, the torso shows its left lateral side. The pelvic bones are somewhat disarticulated - the ilia are displaced and exhibit their right sides - and the hindlimbs are splayed ventrally, each showing its laterocaudal surface.

The completeness and extensive articulation of the skeleton of Juravenator strongly suggests that the carcass floated for a very short period of time before it sunk into the hostile bottom of the basin soon after the animal's death. Explaining the unusual death posture of the skeleton is, however, more problematic. Nowhere in the skeleton is there apparent evidence of predation that can explain the observed rotation of the pelvis with respect to the torso. The inferred bottom conditions point at the absence of benthonic scavengers that could have disrupted the skeleton and even the presence of very small marine woodlouses (Isopoda) (Fig. 6) - that probably scavenged the corpse before it settled on the basin's bottom - can hardly explain the aforementioned rotation. All this suggests that the peculiar torsion of the skeleton of Juravenator is most likely the result of taphonomic factors. A possible scenario might be that the carcass settled into the basin's floor with the head lying on its left side, the torso leaning towards its right side with the right forelimb tucked under the body, the pelvis in a more upright position, and the legs splayed. If so, the complete rotation between torso and pelvis may be explained by the strong compaction of the bindstones during diagenesis (VIOHL \& ZAPP 2006).

\section{Systematic paleontology}

\author{
Dinosauria Owen, 1842 \\ Theropoda MARsh, 1881 \\ Tetanurae GAUTHIER, 1986 \\ Coelurosauria v. Huene, 1914
}

\section{Juravenator starki GÖHLICH \& CHIAPPE, 2006}

Holotype: JME Sch 200, a nearly complete and articulated skeleton - preserving portions of soft tissue - missing only the distal third of its tail (Figs. 3-5). The specimen was collected in two main blocks that were glued together during preparation (Fig. 3). Some parts of the skull and neck were collected as slab and counterslab and subsequently glued together and prepared from one side.

Horizon and locality: Silicified, laminated limestone, Late Jurassic (Upper Malm, Late Kimmeridgian, Beckeri
Zone, Ulmense Subzone) in the local stratigraphy (ZeIsS 2001; SCHWEIGERT 2007) (Fig. 2). JME Sch 200 was collected from the Stark Quarry, a quarry owned by the Stark family and situated a few hundred meters west of the village of Schamhaupten (district of Eichstätt, Southern Franconian Alb), Bavaria, Germany (Fig. 1).

Diagnosis: Small basal coelurosaur (a clade encompassing Passer domesticus and all taxa sharing a more recent common ancestor with it than with Allosaurus fragilis) with a large skull proportionally longer than in Compsognathus longipes (skull: femur and skull: presacral vertebrae ratios are 1.5 and 0.47 , and 1.1 and 0.25 in Juravenator and $C$. longipes, respectively), low number of maxillary teeth (less than 10 in Juravenator, 10 in Ornitholestes hermanni, 12 in Sinosauropteryx prima, 15 in C. longipes), absence of a premaxillary-maxillary (diastema present in Scipionyx samniticus), distinct indentation on the dentigerous margin of the maxilla (between second and third teeth), an antorbital fenestra subequal in length to orbit (antorbital fenestra is nearly half the orbit in S. prima, Ornitholestes hermanni, and S. samniticus and subequal to the orbit in C. longipes and basal tyrannosauroids [XU et al. 2004, 2006; SERENO et al. 2009]), long scapula (humerus:scapula and scapula:femur ratios are 0.63 and 0.81 in Juravenator, 0.86 and 0.60 in S. prima, and 1 and 0.54 in C. longipes, respectively), of which the narrowest portion is at the neck as opposed to near the mid-shaft, and short feet (metatarsal III: femur is 0.59 in Juravenator and approximately 0.75 in $S$. prima and C. longipes [CURRIE \& CHEN 2001]). Juravenator is also unique among other basal coelurosaurs in having longer and more slender teeth, a concave rostral margin of the jugal process of the postorbital, humeri with very short and triangular-shaped deltopectoral crests, manual claws that are very high proximally and that taper abruptly around their midpoints, and arched, bow-like zygapophysial articulations in the mid-caudal vertebrae. We regard these unique features as autapomorphies of Juravenator starki.

\section{Anatomical description}

The specimen shows features indicating an early ontogenetic age - the surface of its bones is intensively scarred by small pits and grooves, thus revealing a pattern of incomplete periosteal formation (e.g. Horner 1997; SANZ et al. 1997; ChIAPPE et al. 1998; Codorniú \& Chiappe 2004) (Fig. 7). Evidence of immaturity is also present in the lack of fusion between sacral vertebrae and presence of open neurocentral sutures, visible on many caudal vertebrae (BROCHU 1996). Based on the preserved length of the axial skeleton and the estimated length of the missing distal third of the tail, GöHLICH \& CHIAPPE (2006) projected the length of the holotype of Juravenator starki to $0.75-.80 \mathrm{~m}$. This value was considered to be a slight underestimation by THERRIEN \& HENDERSON (2007), who based on a least-square regression of 


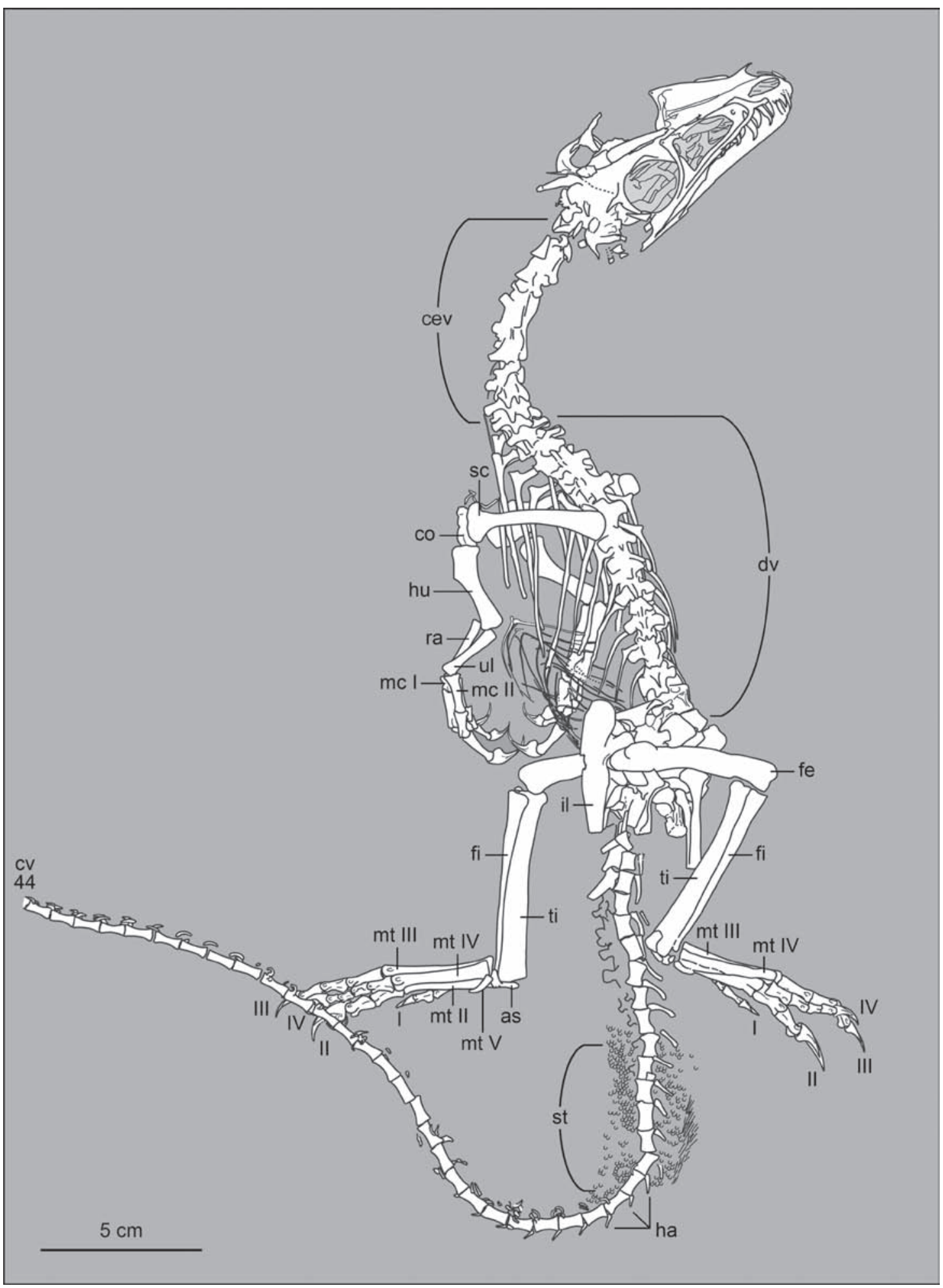

Fig. 5. Interpretive drawing of the skeleton of Juravenator starki (JME Sch 200). Abbreviations: as, astragalus; cev, cervical vertebrae; co, coracoid; cv 44, caudal vertebra 44; dv, dorsal vertebrae; fe, femur; fi, fibula; ha, haemal arches; hu, humerus; il, ilium; mcI-II, metacarpals I-II; mt II-V, metatarsals II-V; ul, ulna; ra, radius; sc, scapula; st, soft-tissue; ti, tibia; I-IV, pedal digits I-IV. 


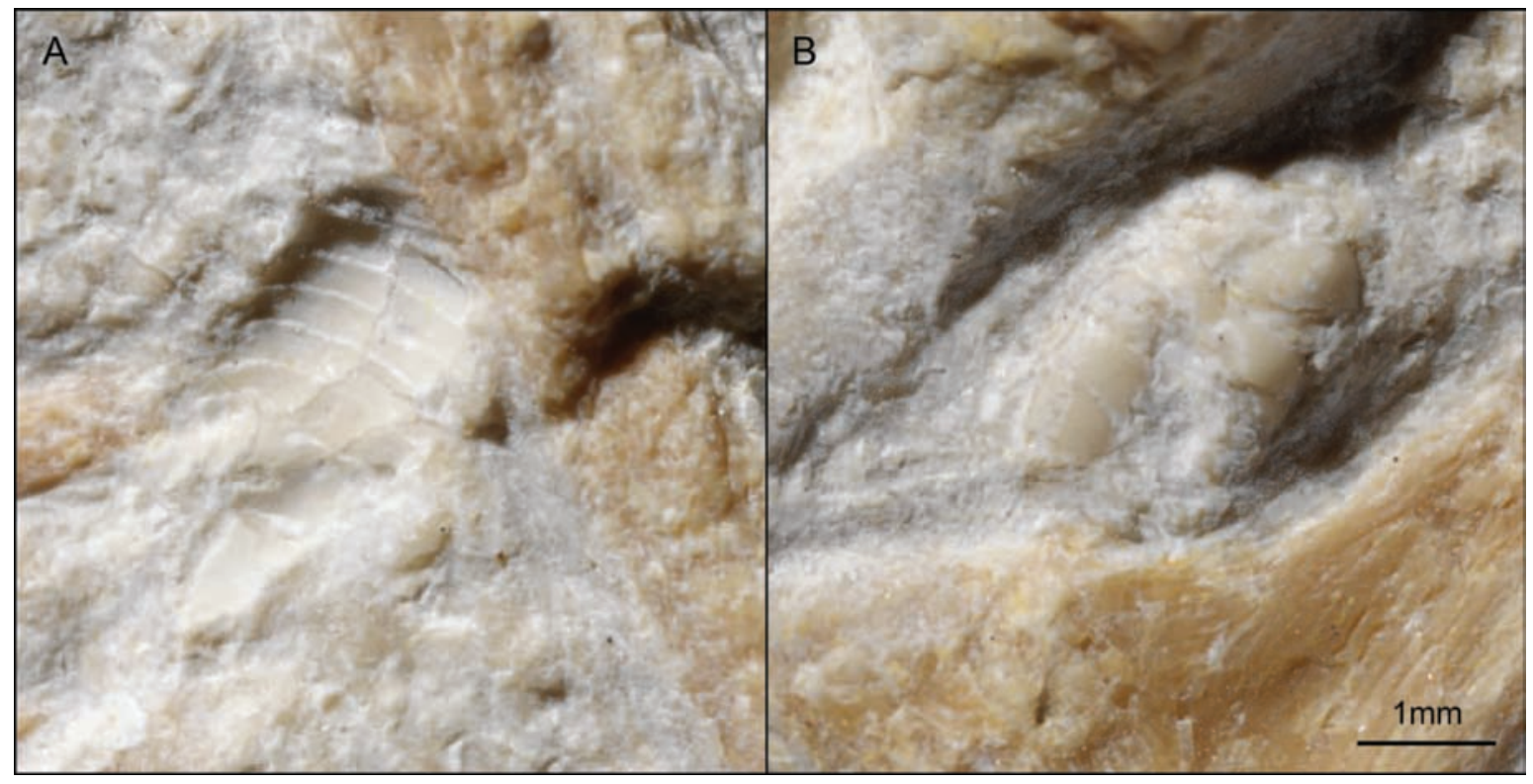

Fig. 6. Close-up of isopods preserved as impressions (A) or three-dimensionally (B) within the skeleton of Juravenator starki (JME Sch 200).

theropod skulls calculated the length of this specimen as slightly over $1 \mathrm{~m}$. The latter may well be accounted for by the relatively large skull of the holotype, but regardless of the difference between calculations based on actual skeletal length and those based on least-square regressions, the juvenile nature of the holotype indicates that the adults of this species must have substantially exceeded both projected lengths. Detailed osteological measurements are given in the Appendix.

\subsection{Skull}

Cranial bones. - The skull (Fig. 8) is large in proportion to the skeleton (more than 1.5 times the length of the femur) (Figs. 3-5). The rostrum is moderately long - the distance between the lacrimal and the rostrum's tip is $53 \%$ of the skull length - and excavated by a large antorbital fossa.

The right premaxilla is preserved in lateral view and the nasal process of its counterpart is exposed dorsal to the rostral half of the former. The body of the premaxilla is rectangular, longer than it is high, and bears short maxillary (subnarial) and nasal (internarial) processes, which have relative lengths more like those of Compsognathus (OSTROM 1978; PEYer 2006), Scipionyx (Dal Sasso \& Signore 1998), Sinosauropteryx (CHEN et al. 1998; CURRIE \& CHEN
2001), and the basal tyrannosauroid Dilong paradoxus (Xu et al. 2004) than the long processes of Huaxiagnathus (HwANG et al. 2004) (Figs. 8-9). The nasal process of the premaxilla extends along the rostrodorsal margin of the snout, bordering dorsally the elliptical external nares, for about half the length of the nares (Fig. 7). The maxillary process extends caudally beyond the caudal end of the nasal process and it appears to be thicker than the latter, a condition similar to that in Sinocalliopteryx (JI et al. 2007a) and opposite to that in Sinosauropteryx (CURRIE \& CHEN 2001). These two processes are also less caudally divergent than in Sinosauropteryx, more similar to Sinocalliopteryx (Ji et al. 2007a), Huaxiagnathus (Hwang et al. 2004), Scipionyx (DAL SASso \& SignORE 1998), and Compsognathus (MNHM CNJ 79, Michard 1991) (Fig. 8). There are at least three premaxillary teeth - the last one broken at its base but we cannot rule out the presence of a fourth and most anterior tooth (Figs. 7, 10). Similar uncertainties have been expressed for other "compsognathids": Ostrom (1978) reported a minimum of three premaxillary teeth in Compsognathus longipes (BSPG AS I 563) but PEYER (2006) highlighted the presence of four alveoli in the French Compsognathus (MNHM CNJ 79). CURRIE \& CHEN (2001) were not definitive whether four or five premaxillary teeth are present in Sinosauropteryx (although they believed four to be the 


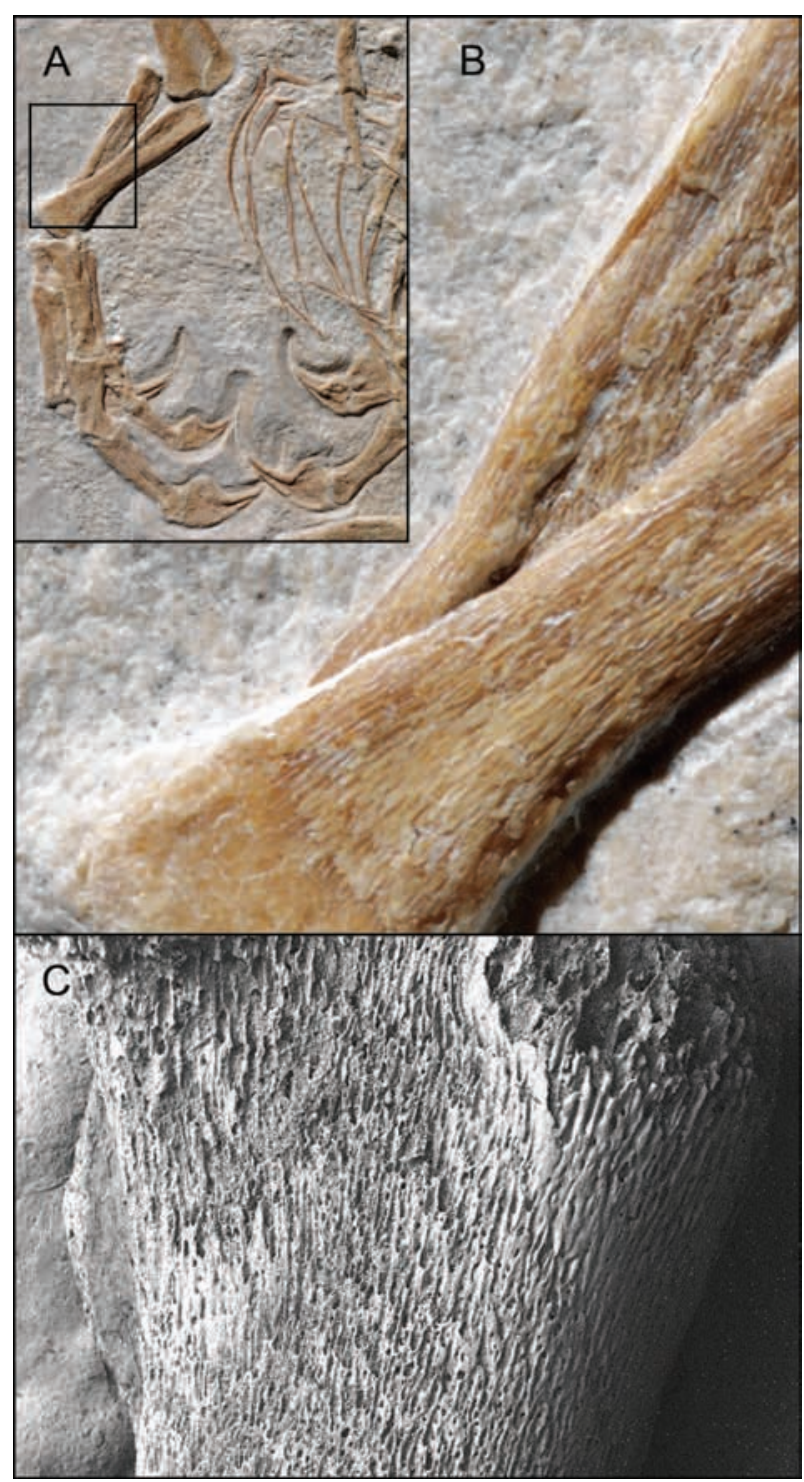

Fig. 7. Detail of the surface of the left ulna-radius of Juravenator starki (JME Sch 200) (A, B) as compared to that of a neonate modern bird (C, from SANZ et al. 2001). Note the intensively scarred surface of the periosteum.

number), and HwANG et al. (2004) were indeterminate between three and four. In Scipionyx - presumably also closely related to Compsognathus (DAL SASSO, pers. comm.) - there are five premaxillary teeth, but only four in the large compsognathid Sinocalliopteryx (Ji et al. 2007a).

The right maxilla is exposed in lateral view; what appears to be a displaced small portion of the dorsal ramus of the left maxilla is attached to the side of the left nasal. The maxilla is largely excavated by an antorbital fossa that contains a large antorbital fenestra and a small maxillary fenestra (Fig. 7). The maxillary region anterior to the antorbital fossa is very short - shorter than the length of the body of the premaxilla - a condition shared with Scipionyx (DAL SASSO \& SignORE 1998). The extent to which this feature is related to the early ontogenetic age of the holotypes of Juravenator and Scipionyx is uncertain. However, the condition of these taxa contrasts with the extension of the maxilla in front of the antorbital fossa of Huaxiagnathus (more than three times the length of the premaxillary body; HwANG et al. 2004: fig. 2), Dilong and Sinocalliopteryx (more than twice the length of the premaxillary body; XU et al. 2004; JI et al. 2007a), Sinosauropteryx (more than 1.5 times the length of the premaxillary body; CURRIE \& CHEN 2001: fig. 3A), and apparently Compsognathus, in which the region anterior to the antorbital fossa is slightly longer than the length of the premaxillary body (Fig. 8). The anterior suture of the maxilla - its contact with the premaxilla and nasal - is sinusoid. As in Huaxiagnathus and Sinosauropteryx, this margin is excluded from the external nares by the contact of the premaxilla and nasal (Fig. 8). Ostrom (1978) reported that the maxilla of Compsognathus formed the caudal margin of the external nares; however, this cannot be verified in either of the two specimens (BSPG AS I 563; MNHM CNJ 79). Three maxillary teeth fit the dentigerous margin anterior to the antorbital fossa - comparisons with other "compsognathids" are hampered by poor preservation, however two teeth appear to be present in Scipionyx and at least three teeth fit this portion of the maxilla of Sinocalliopteryx. The maxillary of Juravenator preserves an additional five teeth along the dentigerous margin beneath the thin ventral border of the antorbital fossa - the last tooth is centered along this margin (Figs. 7, 10). Thus, the maxilla of Juravenator bears at least, and possibly not more than, eight teeth. The number of maxillary teeth varies greatly among other "compsognathids" and other basal coelurosaurs: at least six are present in Sinocalliopteryx (Ji et al. 2007a), seven seem to exist in Scipionyx (DAL SASSO, pers. comm.), a minimum of eight are present in both Sinosauropteryx (GMV 2124; pers. obs.) and Huaxiagnathus (HwANG et al. 2004), 10 in Ornitholestes (OSBORN 1916), 13 in some basal tyrannosauroids (XU et al. 2006; SERENO et al. 2009), and 14 were reported for Compsognathus (PEYER 2006) (Fig. 11). In Juravenator, the maxillary teeth are not separated from those in the premaxilla by a diastema. Ostrom (1978) reported the presence of a 


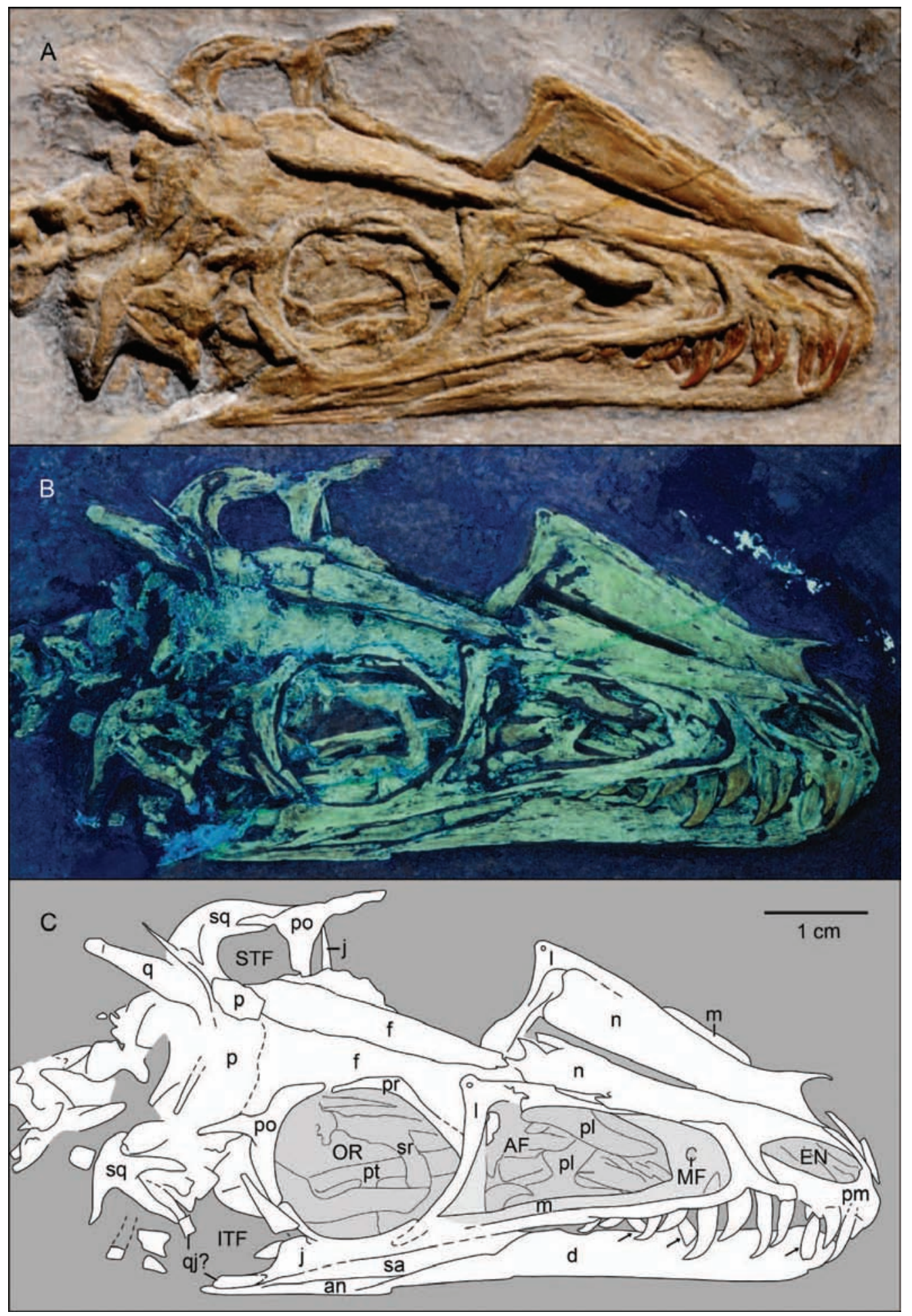

Fig. 8. Photograph of the skull of Juravenator starki (JME Sch 200) under normal (A) and ultraviolet (B) light, and interpretive drawing (C). Abbreviations: an, angular; AF, antorbital fenestra; d, dentary; EN, external naris; $f$, frontal; ITF, infratemporal fenestra; j, jugal; 1, lacrimal; m, maxilla; MF, maxillary fenestra; $n$, nasal; OR, orbit; $p$, parietal; pl, palatine; pm, premaxilla; po, postorbital; pr, prefrontal; pt, pterygoid; q, quadrate; qj, quadratojugal; sa, surangular; sq, squamosal; sr, sclerotic ring; STF, supratemporal fenestra. Arrows point at dentary teeth. 


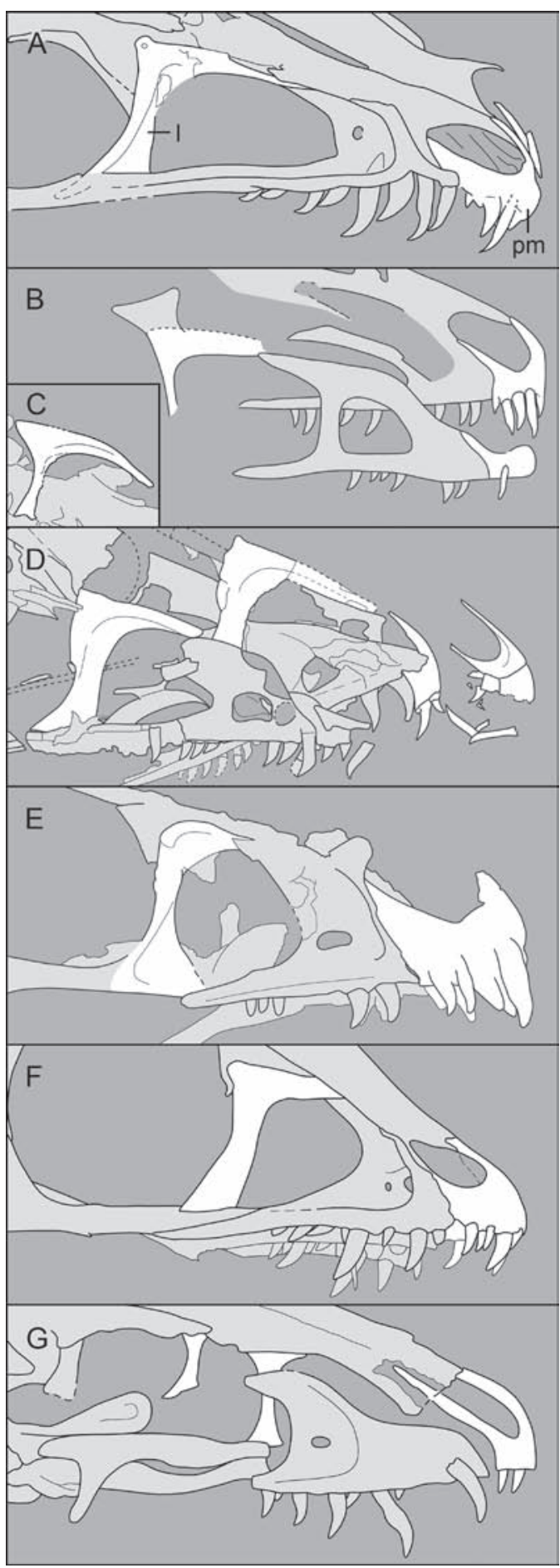

Fig. 9. Comparisons of the premaxilla and lacrimal of Juravenator starki (A), Sinosauropteryx prima (B, based on Currie \& Chen 2001; C, based on GMV 2124), Compsognathus longipes (D, based on PEYER 2006), Ornitholestes hermanni (E, based on AMNH 619), Scipionyx samniticus (F, based on Dal SASSO \& Signore 1998), and Huaxiagnathus orientalis ( $\mathrm{G}$, based on HwANG et al. 2004). Abbreviations: 1, lacrimal; pm, premaxilla. Drawings not to scale. premaxillary-maxillary diastema in the holotype of Compsognathus longipes (BSPG AS I 563), however PEYer (2006) has argued that such a feature (absent in MNHM CNJ 79) may be a preservational artifact. Our examination of BSPG AS I 563 failed to corroborate Ostrom's claim; as he pointed out, the ends of the premaxilla and maxilla are poorly preserved. A diastema is absent in Sinosauropteryx (CURRIE \& CHEN 2001), Ornitholestes (OsBorn 1916), Scipionyx (DAL SASSO \& Signore 1998), and Huaxiagnathus (HwANG et al. 2004), and it is most likely that this feature was also absent in Sinocalliopteryx and Compsognathus (Fig. 11). A distinct indentation is present on the anterior dentigerous margin of Juravenator, between its second and third maxillary teeth (Figs. 8, 10). This feature appears to be somewhat exaggerated by bone weathering, but we believe it to be real and unique to Juravenator among "compsognathids". Posterior to this indentation, the ventral margin of the maxilla in lateral view is straight throughout the extension of the tooth row, becoming slightly concave behind the last tooth. On the caudoventral corner of the maxilla, the contact between this bone and either the lacrimal or the jugal cannot be distinguished.

The maxilla does not seem to form part of the dorsal margin of the antorbital fossa; this margin appears to be formed solely by the nasal and lacrimal (Fig. 8). There is no evidence indicating that the antorbital pneumaticity extended into the nasal - this bone appears to just form the dorsal margin of the antorbital fossa. A thin maxillary sheet - the medial lamina of the ascending ramus of the maxilla - lines the anterior fourth of the antorbital fossa. The center of this portion is punctuated by a round maxillary fenestra; however, due to poor preservation, the existence of a promaxillary fenestra cannot be determined. A narrow portion of bone extends from the base of the medial lamina of the ascending ramus caudoventrally as a long inset that defines the ventral margin of the antorbital fenestra.

The nasals are exposed in laterodorsal (right element) and dorsal (left element) views. These bones form the caudal and dorsocaudal margins of the external nares (Fig. 8). The internarial process of the nasal extends for about two-thirds the length of the nares. The premaxillary process of the nasal forms a broad arch, the base of which forms the caudal margin of the nares, and its tip runs between the premaxilla and the maxilla. The main body of the nasal becomes gradually wider towards the caudal end of the bone. The lateral and medial margins are straight, and 
Fig. 10. Reconstructions of the skulls of Juravenator starki (A), Compsognathus longipes (B, based on PEYER 2006), Scipionyx samniticus $(\mathrm{C}$, based on DAL SASSO \& SignORE 1998), and Ornitholestes hermanni (D, based on AMNH 619). Hatched areas indicate missing portions of the skull. Drawings not to scale.

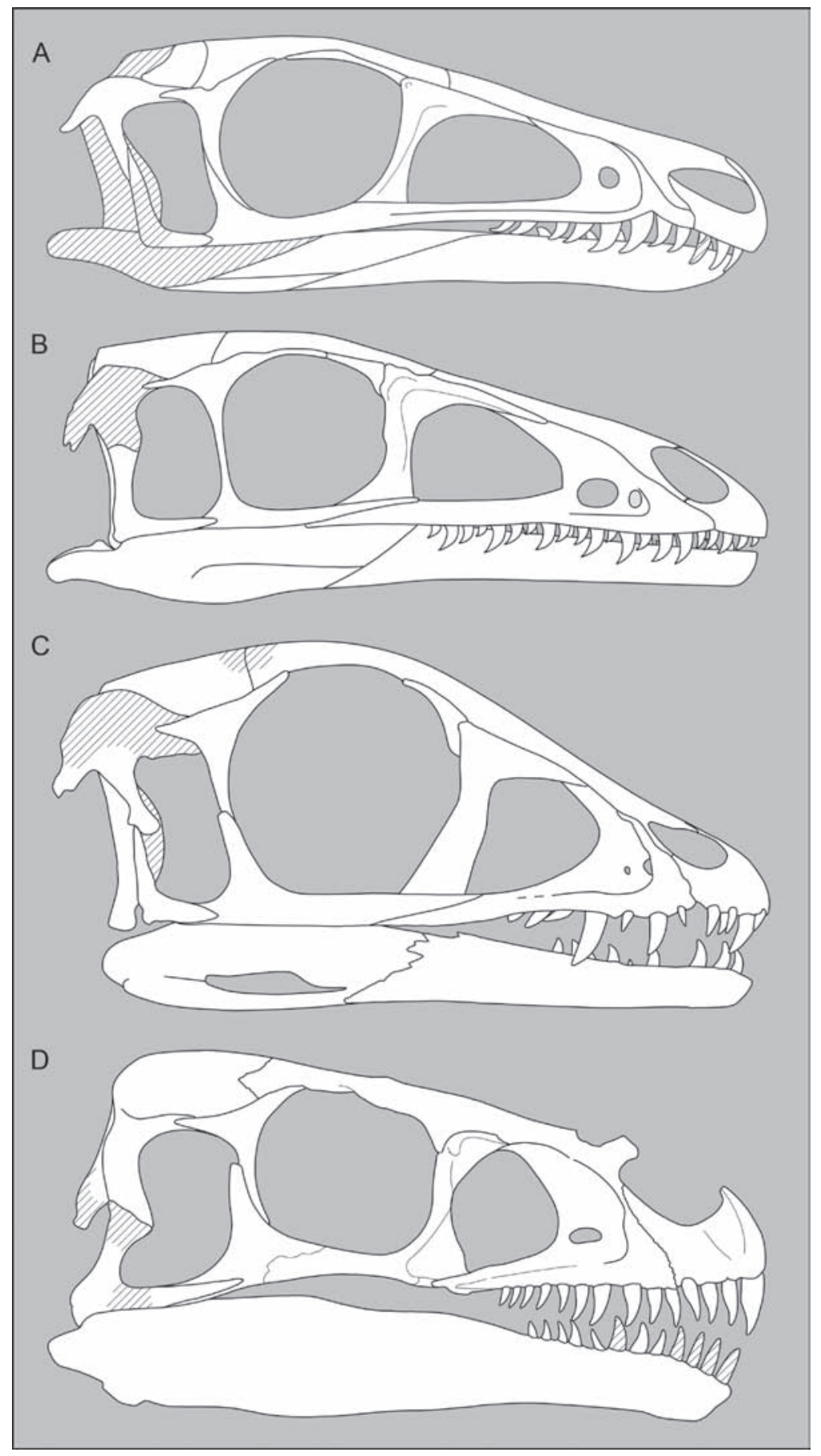

the latter forms a long suture with its counterpart. Dorsally, the surface of the nasal is essentially flat, although the central portion of the lateral edge is slightly swollen. The caudal end of this bone contacts the frontal in a more or less transversally oriented suture, although the precise shape of this suture is not clear.
The lacrimals are exposed in both lateral (right element) and medial (left element) views. This bone has the shape of an inverted " $L$ " and as in other "compsognathids", it lacks any evidence of a "horn" or dorsal protuberance (Fig. 8). The inverted "L" shape of this bone more closely resembles the lacrimals of Scipionyx (DAL SASso \& Signore 1998) and Comp- 


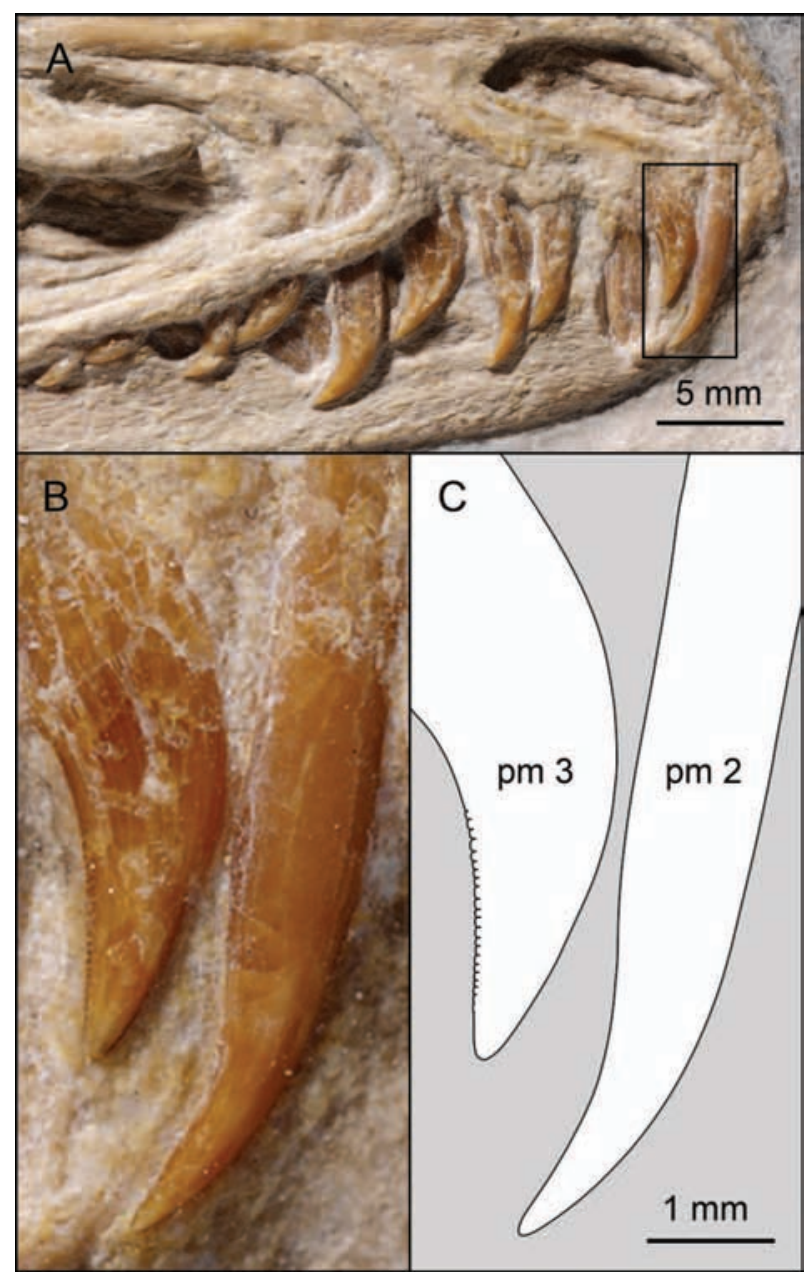

Fig. 11. Dentition of Juravenator starki (JME Sch 200). Tooth row (A) and detail (B, C) of middle premaxillary teeth. These teeth are interpreted to occupy the second and third positions of a probably four-toothed premaxilla.

sognathus (PEYER 2006) than that of Sinocalliopteryx (JI et al. 2007a), Sinosauropteryx (GMV 2124; pers. obs.), and basal tyrannosauroids (XU et al. 2004; SERENO et al. 2009), in which the dorsocaudal corner extends more caudally (i.e., it has a more "T"-shaped appearance) (Fig. 9). On the lateral surface, a minute swell marks the caudodorsal corner of the bone and anterior to this swell there is a small pit that we interpret as a pneumatopore (lacrimal fenestra), a feature widely distributed among non-avian theropods (RAUHUT 2003). If our interpretation is correct, the presence of a pneumatic lacrimal in Juravenator would distinguish this taxon from basal coelurosaurs such as Compsognathus (PEYER 2006), Sinosauropteryx (Currie \& CHen 2001), Scipionyx (DAL SAsso, pers. comm.) and apparently Sinocalliopteryx (Ji et al. 2007a), in which the lacrimal is apneumatic.

The nasal (horizontal) ramus of the lacrimal is subequal in length to the jugal (vertical) ramus; this condition is similar to that of Compsognathus (MNHM CNJ 79) but different from those of Scipionyx (DAL SASSO \& SignORE 1998) and Sinosauropteryx (GMV $2124)$ in which the nasal ramus is either shorter or longer than the jugal ramus, respectively (Fig. 9). The nasal ramus gradually tapers rostrally, ending in a sharp tip. This ramus articulates medially with the nasal, and laterally forms the dorsal margin of the caudal half of the antorbital fenestra. The jugal ramus is stout and hourglass-shaped, with expanded dorsal and ventral ends. This overall appearance of the ramus is comparable to those in Scipionyx and Compsognathus but clearly stouter than the slender jugal ramus of Sinosauropteryx (Fig. 9). The ventral half of the jugal ramus is laterally concave; the surface is excavated by an ample trough caudally defined by a broad and prominent rim that forms the caudal margin of the bone. Such a trough marks the caudal extension of the antorbital fossa, a condition also present in a variety of other non-avian theropods (e.g., Ostrom 1978; Currie \& Zhao 1993; Xu et al. 2004, 2006; CARPEnTER et al. 2005a; Coria \& CURrie 2006). The medial surface of the lacrimal is essentially flat. The contact between the lacrimal and the jugal is a subhorizontal suture.

The right jugal is exposed in lateral view; a fragment of what appears to be the left element, probably in medial view, is visible in the caudal corner of the left orbit. The jugal is slender; it is dorsoventrally thinner at the center of the orbit (Fig. 8). The dorsal and ventral margins of this bone are concave and straight, respectively. Caudally, the postorbital ramus is well developed and projected dorsocaudally at a 120 degree angle with respect to the horizontal body of the jugal (i.e., the suborbital ramus). The postorbital ramus tapers to a sharp end at the midheight of the orbit. The anterior margin of this ramus forms a slightly concave contact with the jugal ramus of the postorbital. Caudally, the jugal ends in a tapering process (subtemporal ramus) shortly behind the base of the postorbital ramus. There is no apparent evidence of jugal pneumaticity. The overall morphology of the jugal agrees well with that described for Compsognathus (Ostrom 1978; Michard 1991), Sinosauropteryx (Currie \& Chen 2001), Scipionyx (Currie \& CHen 2001), and Huaxiagnathus (HwANG et al. 2004). However, the subtemporal ramus of this bone is shor- 
ter than those of Huaxiagnathus and Sinosauropteryx.

We interpret a slender bone rimming the dorsocranial half of the right orbit as the prefrontal. Although it is unclear how much of this bone is actually preserved, if our interpretation is correct, this bone prevents most, if not all, contribution of the frontal to the orbit (Fig. 8). Comparable ossifications are preserved rimming the orbits of Compsognathus and Scipionyx (Fig. 10).

The two frontals are preserved in dorsal view. This bone is long and dorsally flat, has a transversal contact with the nasal and a straight suture with its counterpart (Fig. 8). Caudally, the width of the frontal increases gradually, however, its contact with the parietal is not clear on either side - we have interpreted a transversal line, roughly perpendicular to the interfrontal suture, as the frontoparietal contact (Fig. 8). If this is correct, the frontal participates extensively of the supratemporal fenestra, a condition similar to that apparently present in Huaxiagnathus (HwANG et al. 2004). At the same time, the frontoparietal suture interpreted here more closely resembles the sigmoid suture of the French Compsognathus (MNHM CNJ 79) than the very forked frontoparietal suture featured by Ostrom (1978) for the holotype (BSPG AS I 563).

The postorbital is exposed on lateral (right element) and medial (left element) views. This T-shaped bone has a frontal ramus slightly longer than the squamosal ramus (Fig. 8). These two rami are not at the same level; while the squamosal ramus points caudally, the frontal ramus is somewhat dorsorostrally directed. The dorsal margin of the right element, at the junction of these two rami, exhibits a small indentation. Such an indentation is absent in Scipionyx, in which the postorbital also differs by having the frontal and squamosal rami essentially aligned. The tapering jugal ramus is longer than the other two rami and it gently curves rostroventrally; its convex caudal margin contacts nearly the entire length of the postorbital ramus of the jugal and its rostral margin forms the concave caudal margin of the orbit.

Portions of both squamosals are preserved. The right element is exposed laterally and partially dorsally - this bone appears to be displaced caudoventrally - and the left element is represented only by its postorbital process exposed in medial view. The squamosal is a multibranched bone, and its complex morphology is best interpreted under UV light (Fig. 8). Two subvertical processes define a broad ventral notch, most probably for the articulation of the qua- drate. The caudalmost of these projections is a pointed process that presumably contacted the paraoccipital process, although the latter is not preserved. The other process, the quadratojugal process, is a longer and also tapering projection, the tip of which is overlapped by a fragment of a bone interpreted as a remnant of the quadratojugal. A third process projects mediodorsally from the caudal margin of the squamosal and appears to abut the skull roof; this process probably forms the caudal margin of the supratemporal fenestra. A fourth process is directed rostrally. This postorbital process is best preserved on the left element, even if viewed medially. The postorbital process ends in a fork that receives the squamosal ramus of the postorbital bone and together with this ramus forms the intertemporal bar (division between supra and infratemporal fenestrae).

Less certain anatomical information is available for the quadratojugal. Only what we interpret as the tips of the squamosal and jugal processes of the right element are preserved (Fig. 8). If correctly identified, the preserved fragment of the squamosal process would suggest that the quadratojugal contacted the squamosal behind the infratemporal fenestra. Likewise, if this interpretation is correct, it would indicate that the squamosal process of the quadratojugal of Juravenator is much thinner than the broad equivalent of Sinosauropteryx (GMV 2124; pers. Obs.). The portion interpreted as the jugal process is slender and together with the squamosal process gives the bone an "L" shape (Fig. 9).

The parietals are also poorly preserved, with both of them in dorsal view. The length of this bone appears to be roughly one-third the length of the frontal (Fig. 8). Dorsally, it is slightly convex; as in Compsognathus (Ostrom 1978; Michard 1991; PeYer 2006) and Scipionyx (DAL SASSO \& SignORE 1998), a sagittal crest running along the skull roof was clearly absent. The caudal margin of both parietals is defined by a thick rim that forms the nuchal crest, which appears to be stronger than the weak crest of Compsognathus (BSPG AS I 563).

A long and very poorly preserved bone situated in the caudolateral corner of the left portion of the skull is interpreted as a portion of the quadrate (Fig. 8). This bone exhibits a concave outer surface and under UV light, what appears to be a terminal articulation. Our identification of this bone is based on both its location and its elongate shape.

The vaulted, rostral portions of the palatines (vomerine processes) are among the few portions of 
the palate that can be determined with certainty. These bones, preserved within the antorbital fenestra, are best seen under UV light (Fig. 8). The vomerine process of the right palatine is in place and situated within the caudal half of the fenestra. Its left counterpart is displaced, protruding towards the right side of the skull at the center of the antorbital fenestra. As in other non-avian theropods (e.g., MADSEN 1976; Currie \& Zhao 1993; Dal Sasso \& Signore 1998; Norell \& MAKOVICKY 2004), the vomerine processes of the palatines have a strongly concave rostral margin that forms the caudal border of the choana, and a caudorostrally expanded dorsal (top) margin. These processes most likely contacted each other but this cannot be ascertained due to the displacement of the left one. A long and slender bone rostrocaudally crossing the orbit probably represents a portion of one of the pterygoids, although no morphological details of these bones are visible.

Very little anatomical information is available for the braincase, which is partially exposed in dorsal view. The supraoccipital has a pronounced midline ridge and the paroccipital processes are robust and tall. The latter project posteroventrally at approximately 45 degrees, and their posterior surface extends over a single plane. A thin sliver of bone, which may represent the stapes, anteriorly lines each paraoccipital processes.

Mandibular bones. - Only the lateral side of the right mandible is exposed and its dorsal border is overlapped by the ventral margin of the cranium. However, portions of some mandibular teeth have been exposed by preparation of the lateral surface of the dentary. The first exposed tooth is aligned with the broken base of the last premaxillary tooth (Figs. 8, 10), and the latter covers the tip of the former. The last exposed dentary tooth lies in front of the last two maxillary teeth; however, it is not possible to determine whether the mandibular dentition ended in front (as in many non-avian theropods) or behind (as in Scipionyx) the upper tooth row. Although the number of mandibular teeth cannot be ascertained with precision, the size of the few exposed suggest a tooth count significantly smaller than the 18 teeth counted by Ostrom (1978) or the 21-22 counted by Michard (1991) and PEYER (2006), for Compsognathus. Assuming the mandibular tooth row to be slightly shorter than the upper tooth row, as in Compsognathus (Ostrom 1978) and most other theropods (e.g., MADSEN 1976; COLBERT 1989; WEISHAMPEL et al. 2004), we estimate that the number of dentary teeth did not exceed 11 , a number that more closely resembles our estimate of the tooth count of Scipionyx (12-14). Likewise, the lower number of dentary teeth of Juravenator when compared to Compsognathus can also be inferred by the fact that the length of the dorsal margin of its dentary is significantly shorter; Ostrom (1978) reconstructed the dorsal margin of the dentary of Compsognathus as more than half the length of the skull while it is less than half the length of the skull in Juravenator (and in Scipionyx). Allometric studies on tyrannosaurids (CURRIE 2003) and other non-avian theropods (e.g., MADSEN 1976; COLBERT 1989) have failed to provide evidence indicating an increase in the number of teeth in relation with either size or age. However, the number of dentary teeth increases from 18 to 21-22 in Compsognathus, when the smaller holotype is compared to the larger French specimen (Ostrom 1978; Michard 1991; Peyer 2006). Individual variations notwithstanding (Colbert 1989; CURrie 2003; Peyer 2006) - and taking into account that the increment in tooth count in Compsognathus may suggest a similar increment in Juravenator - we still regard this difference as taxonomically important.

The lateral height of the rostral portion of the mandible is approximately two-thirds the mandibular height at the level of the orbit (Fig. 8); this ratio is about one-third in Sinosauropteryx (GMV 2124; pers. obs.), and one-half in Scipionyx and basal tyrannosauroids (Xu et al. 2004, 2006) The lateral surface of the mandible is essentially flat along its rostral half and slightly convex more caudally. The lower jaw lacks a mandibular foramen, a condition similar to that in Compsognathus (Ostrom 1978), Huaxiagnathus (Hwang et al. 2004), Sinosauropteryx (CURRIE \& Chen 2001), Sinocalliopteryx (Ji et al. 2007a), and Scipionyx (DAL SASSO, pers. comm.). The ventral margin of the dentary is nearly straight (Fig. 8). A gently and long caudoventrally slanting suture separates this bone from the surangular and the angular. Although the postdentary portion of the mandible is partially covered by the jugal, it can be seen that the dorsoventral width of the surangular is about three times that of the angular. The ventral margin of the surangular bears a faint longitudinal rim that forms a ledge at the contact with the angular. The latter bone is narrowly exposed laterally. The rear portion of the mandible is missing beyond the surangular and angular, and it is difficult to evaluate whether the caudal portions of these bones are missing as well. 
Cranial openings. - The external nares are defined by the premaxilla dorsally, anteriorly, and ventrally, and the nasal posteriorly. They are subelliptical in shape with a straight ventral margin and concave dorsal margin (Figs. 8). The external nares of Juravenator end substantially in front $(\sim 4 \mathrm{~mm})$ of the anterior margin of the antorbital fossa. This condition seems to contrast with that of other "compsognathids". The caudal end of the nares of Scipionyx (DAl SAsso \& Signore 1998) and Compsognathus (PEYER 2006) is aligned with the anterior margin of the antorbital fossa and HwANG et al. (2004) described the long nares of Huaxiagnathus as overlapping posteriorly the antorbital fossa (yet, this is not entirely apparent in the illustrations provided by HwANG et al. 2004).

The antorbital fossa contains what appear to be a round and small maxillary fenestra and a large antorbital fenestra. Whether Juravenator also possessed a promaxillary fenestra is uncertain. The latter is bordered by the lacrimal and nasal dorsally, the maxilla rostrally and ventrally, and the lacrimal caudally; whether or not the jugal contributed to the antorbital fossa, and perhaps the fenestra, is unclear (Fig. 8). The antorbital fenestra is suboval, although its vertical caudal margin defines a nearly $90^{\circ}$ angle with its ventral counterpart. The length of this fenestra is approximately three-fourths the length of the antorbital fossa - proportionally longer than in Scipionyx and Compsognathus (fenestra/fossa ratio is about 2/3) and Sinosauropteryx (fenestra/fossa ratio is between $2 / 3$ and 1/2) (Fig. 11).

Both orbits are preserved; the left one is incomplete and the right one is slightly collapsed by the ventral displacement of the right frontal. However, it is clear that the orbit was round and bordered by equal contributions of the lacrimal, jugal, postorbital, and what we interpreted as the prefrontal (Figs. 8, 11). It is not clear if the frontal comprised part of the dorsal margin of the orbit, or whether a postorbital-prefrontal contact prevented a frontal contribution. Most remarkable is the fact that the length of the orbit is approximately the same as that of the antorbital fenestra, a condition similar to that of basal tyranosauroids (XU et al. 2004, 2006) but an obvious difference with Sinosauropteryx (CURrie \& Chen 2001), Compsognathus (BIDAR et al. 1972; Ostrom 1978; Michard 1991), Ornitholestes (Osborn 1916), and Scipionyx (DAL SASSo \& SignORE 1998), in which the antorbital fenestra is substantially shorter (Fig. 11). The rostral half of the sclerotic ring is preserved within the right orbit but neither the shape nor the number of the scleral oscicles can be determined.

Both of the temporal fenestrae are distorted. Our interpretation of the quadratojugal suggests an infratemporal fenestra enclosed caudally by a squamosal-quadratojugal bar and with a subrectangular shape, taller than wide (Fig. 8). On the left side, the skull roof and the squamosal-postorbital bar surround a large fenestra. This opening is likely the supratemporal fenestra in dorsal view but its shape and size may be modified by the fact that the latter bar is clearly displaced and viewed medially.

Dentition. - As stated above (see Cranial bones), three premaxillary and eight maxillary teeth are preserved in the upper jaw; the premaxilla may have carried an additional tooth but this is unlikely to be the case for the maxilla. The tooth count of the dentary is unknown (see Mandibular bones) but we estimate it to be no more than 11 .

The first preserved premaxillary tooth (here interpreted as occupying the second position) is less compressed than the others (Fig. 10), like the "incisiform" premaxillary teeth of other non-avian theropods (SANDER 1997). The third maxillary tooth is the largest of the upper series. This tooth aligns with the rostral margin of the antorbital fossa (Figs. 8, 10). Similarly large teeth located at the rostral margin of the antorbital fossa are present in Huaxiagnathus and Compsognathus (MNHM CNJ 79). This large tooth is followed by two other large teeth, thus indicating that the largest teeth are located in the middle portion of the maxilla, similar to the condition in Scipionyx (DAL SASSO \& SignORE 1998) (Fig. 10).

All preserved teeth (from both the upper and lower jaws) lack mesial serrations. The first preserved premaxillary tooth also lacks distal serrations but these are present in the second preserved premaxillary tooth (the third one is highly incomplete) (Fig. 10). Among basal coelurosaurs, serrated premaxillary teeth are known in the "compsognathid" Sinocalliopteryx (JI et al. 2007a) and tyrannosauroids (Xu et al. 2004), although the premaxillary teeth of many basal coelurosaurs (and a number of tetanurans) lack serrations (OSTrom 1978; CURRIE \& CHEN 2001). The serrations of the premaxillary teeth of Juravenator and Sinocalliopteryx are much finer $(\sim 13 / \mathrm{mm})$ than those of the maxillary teeth $(\sim 8 / \mathrm{mm})$. All other exposed teeth of Juravenator also have distal serrations. As in Compsognathus (BSPG AS I 563), basal tyranosauroids (XU et al. 2004, 2006; SERENo et al. 2009), and possibly 


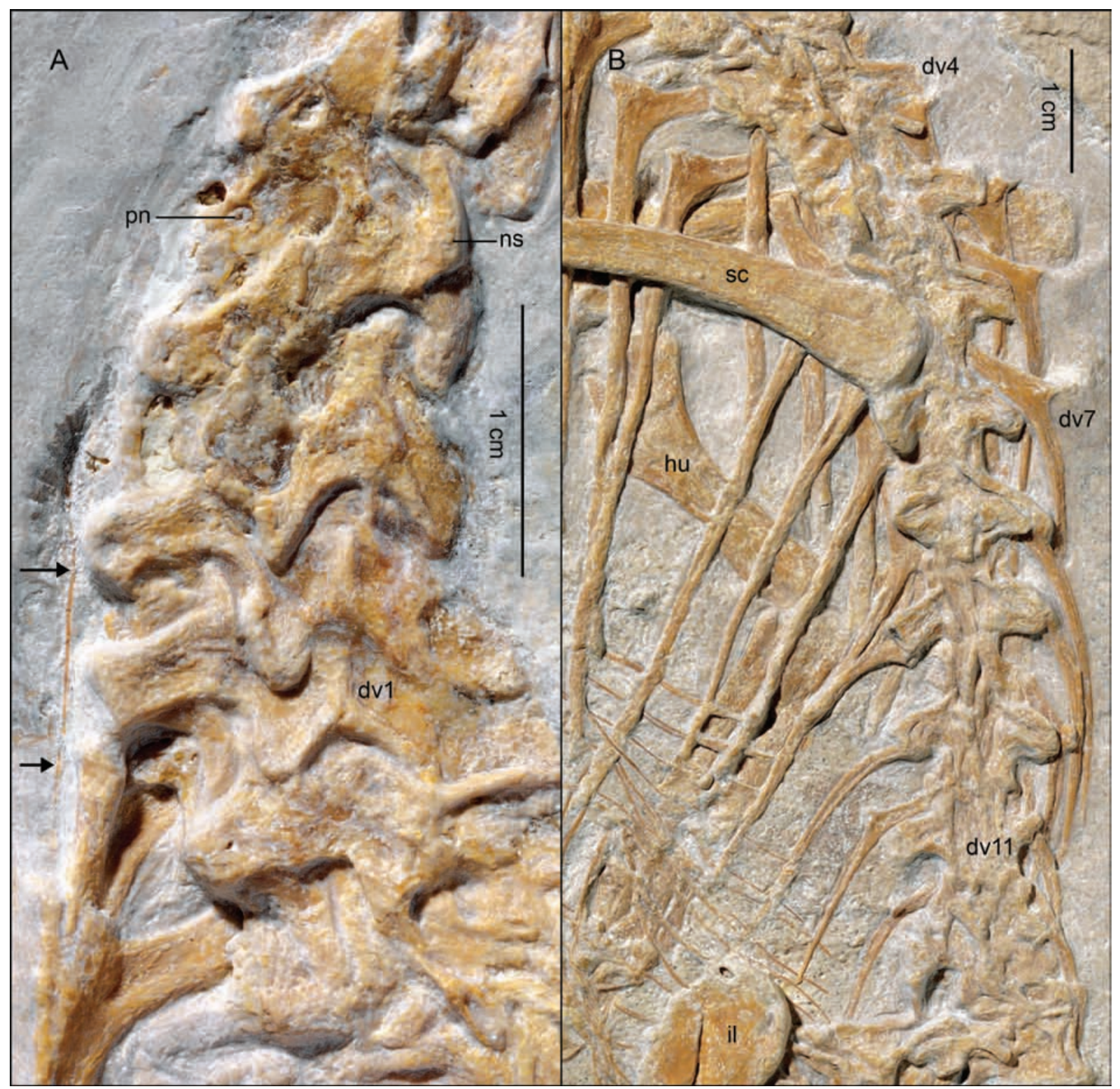

Fig. 12. Cervical (A) and dorsal (B) vertebral series of Juravenator starki (JME Sch 200). Arrows point to a very thin cervical rib. Abbreviations: dv, dorsal vertebrae; hu, humerus; il, ilium; ns, neural spine; pn, pneumatic pore; sc, scapula.

Huaxiagnathus (HwANG et al. 2004) and Sinocalliopteryx (JI et al. 2007a), the maxillary and posterior dentary teeth of Juravenator are more recurved than the premaxillary teeth (however, minimal information is available for the dentary teeth). This appears to be a difference between these taxa and either Sinosauropteryx or Scipionyx, where the teeth are more homogenous in shape.

\subsection{Postcranium}

Axial skeleton. - The vertebral column is essentially complete and articulated from the skull to the distal third of the tail. The cervical and dorsal series are exposed primarily in dorsal view (Fig. 12), the sacral region is dislocated due to the rotation of the skeleton at this region, and the caudal series is exposed on right lateral view. 


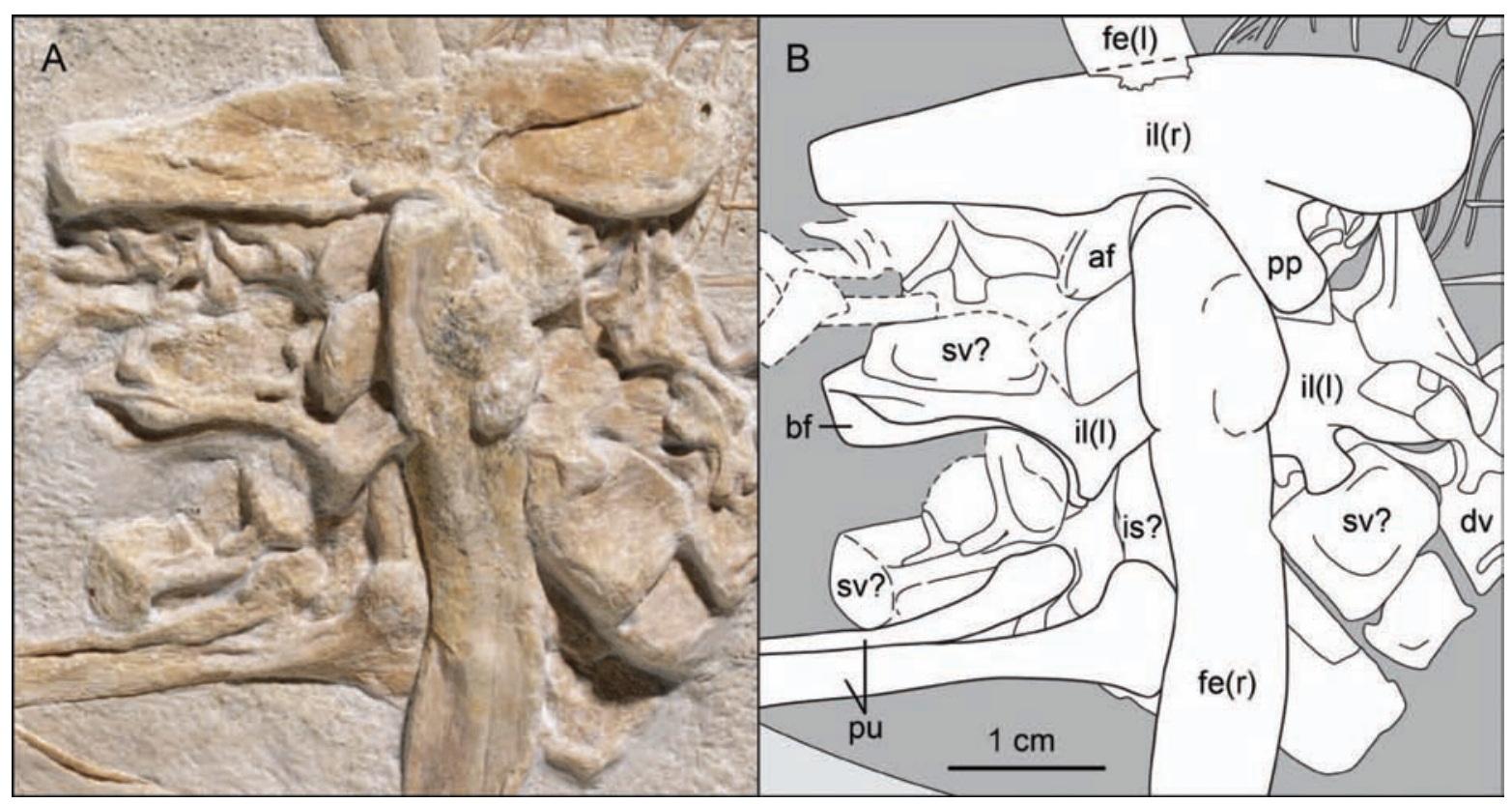

Fig. 13. Photograph (A) and interpretive drawing (B) of the pelvic region of Juravenator starki (JME Sch 200). Abbreviations: af, antitrochanteric facet; bf, brevis fossa; dv, dorsal vertebra; fe, femur; il, ilium; is, ischium; pp, pubic pedicel; pu, pubis; sv, sacral vertebra; $r$ and $l$ refer to the right and left element.

The cervical region is not well-preserved, especially its cranial half. The number of cervicals cannot be established with precision because no sternum has been preserved (thus, the separation between cervical and dorsal vertebrae cannot be determined on the basis of the articulation of ribs to this bone) and because most cervical ribs are missing. Seven vertebrae are preserved between the first one preserving a long rib of thoracic (dorsal) morphology (Figs. 3-5, 12) and a fragmentary element (presumably a cranialmost cervical) adjacent to the caudal portion of the skull. However, the possibility of an unaccounted cervical at the junction of the skull block with the body block cannot be ruled out; this region was damaged as a result of the breakup of the entire slab in two blocks (Fig. 3). All of this suggests the presence of nine to ten cervicals including the atlas, which it is not discernable from the mass of bones exposed immediately behind the skull.

When visible, the cervical vertebrae have short and low neural spines (Fig. 12). However, those in the middle (for example, the third vertebra in front of the first dorsal) appear to have taller neural spines that the caudalmost elements. The diapophyses are welldeveloped. The lengths of these processes increase gradually from the cranialmost elements to the caudal- most ones. Each zygapophysis (pre- and postzygapophyses) is well-spaced with respect to its counterpart. In the caudal portion of the series, the postzygapophyses decrease in length towards the back. The third cervical in front of the first dorsal exhibits a small, round foramen piercing the center of the centrum this is the only possible evidence of pneumaticity in the cervical series (Fig. 12). There is no information available about the central articular surfaces.

There are at least 13 dorsal vertebrae, all of them exposed dorsally with the exception of the last one, which is exposed on its right side. The dorsal vertebrae have well-developed transverse processes that slightly angle posteriorly (Fig. 12). The neural spines of these vertebrae are generally poorly preserved. A few vertical ridges crushed against the center of some centra are interpreted as remains of neural spines but these provide minimal anatomical information. Nonetheless, the craniocaudal extension of the neural spines of the posterior dorsals appears to be large; in some instances these ridges are preserved projecting caudally between the postzygapophyses. The morphology of the neural spine is clearer in the last dorsal vertebra. In this vertebra, the caudal margin of the neural arch and the posterior portion of the neural spine are exposed in lateral view, apparently over- 
lapping the anteriormost portion of the left preacetabular wing. Although the neural spine of this vertebra is not exposed completely, the observable portion shows the distal expansion characteristic of the neural spines of the posterior dorsals of Compsognathus (Ostrom 1978, Peyer 2006), Huaxiagnathus (Hwang et al. 2004), Scipionyx (DAL SASSO, pers. comm.), Sinosauropteryx (CURRIE \& CHEN 2001), Sinocalliopteryx (JI et al. 2007a), and the Brazilian compsognathid Mirischia (NAISH et al. 2004). The caudal articular surface of the last dorsal centrum is flat, thus suggesting that dorsal vertebrae had amphiplatyan centra. The exposure of the vertebrae prevents us from determining whether there is any evidence of pneumaticity.

The number and general morphology of the sacral vertebrae is also problematic (Fig. 13). The sacrum appears to be disarticulated and is partially covered by other bones. A number of unidentifiable bones are also exposed in this area. The fact that none of the bones identified as sacral centra are coossified to one another suggests that the sacrum was not fused at the time the animal died - the complete lack of fusion between sacral vertebrae may be another feature suggesting an early ontogenetic age for the holotype of Juravenator. A laterally exposed centrum located immediately caudal to the thirteenth dorsal vertebra is regarded as part of the first sacral vertebra. The centrum is substantially larger than that of the last dorsal and it has a subquadrangular shape. The interpretation of this centrum as that of the first sacral is based on the fact that (1) it already lies within the realm of the ilia and (2) its lateral surface is broadly recessed, resembling the condition of a centrum lying between the two ilia (a vertebra more clearly identified as sacral). The latter centrum is crushed against the medial surface of the postacetabular wing of the left ilium. The lateral surface of this centrum is distinctly recessed and a ridge defines the periphery of the centrum. A disarticulated centrum of similar morphology lies ventral to the postacetabular wing of the left ilium. The lateral recess of this centrum is very distinct and its caudal articular surface is rounded and flat. It is unclear whether this centrum corresponds to another sacral vertebra or to the first caudal. A gap between the articulated portion of the tail and the sacral centrum crushed against the medial surface of the postacetabular wing suggests that the disarticulated centrum beneath the left ilium could belong to the first caudal (Fig. 13). However, if this is accepted, the centrum of the first caudal would have greatly differed from those of the succeeding tail vertebrae. Comparisons with "compsognathids" and other basal coelurosaurs are problematic because pelvic bones often cover the sacral vertebrae. Nonetheless, the subquadrangular shape of the first sacral vertebra of Juravenator and the fact that its sacrals are substantially bigger than both dorsal and caudal vertebrae resembles the condition present in Scipionyx. However, these features contrast with those in Mirischia, in which the sacrals are smaller than the dorsals (centra are shorter and more depressed) and their centra are not laterally recessed (NAISH et al. 2004).

All preserved caudals are articulated and exposed in right lateral view (Figs. 3-5, 14). The tail includes 44 vertebrae preserved in articulation but it is unclear whether the centrum of the first caudal is missing (see above). Comparisons of the number of caudal vertebrae and relative tail length with other basal coelurosaurs are hampered by the incomplete nature of the tail of most taxa (e.g., Ostrom 1978; Dal SASSO \& SignORE 1998; KirKLAND et al. 1998; De KLERK et al. 2000; HwANG et al. 2004; NAISH et al. 2004). However, meaningful comparisons can be established with the tail of the holotype of Sinosauropteryx (NIGP 127586, CHEn et al. 1998; CuRrie \& CHEN 2001). The nearly complete tail of NIGP 127586 preserves 64 caudal vertebrae. In this specimen, the last 20 vertebrae represent approximately $44 \%$ of the total length of the tail and the entire length of the tail is approximately $170 \%$ of the snout-vent length (measured from the tip of the snout to the caudal end of the ilium). The preserved portion of the tail of Juravenator is approximately $125 \%$ of the snout-vent length but when the proportions observed in Sinosauropteryx (i.e., that the last 20 vertebrae constitute $44 \%$ of the tail) are extrapolated to the Schamhaupten fossil, the length of the tail of Juravenator is estimated to represent about $180 \%$ of the snout-vent length. This extrapolation is warranted by the fact that the ratio between the combined length of the first 43 caudal vertebrae and the snout-vent length of NIGP 127586 is approximately $118 \%$, a value slightly shorter than the one observed in Juravenator. All of this suggests that the tail of Juravenator was probably as long, if not longer, than the tail of Sinosauropteryx - the proportionally longest known tail within theropods (CHEN et al. 1998).

The length of the caudal centra remains more or less constant $(<1 \mathrm{~mm}$ in difference $)$ until the $17^{\text {th }}$ caudal, when the length of the centrum starts increasing (Fig. 14). At the level of the $27^{\text {th }}$ caudal, the length of the centrum reaches a maximum plateau and 


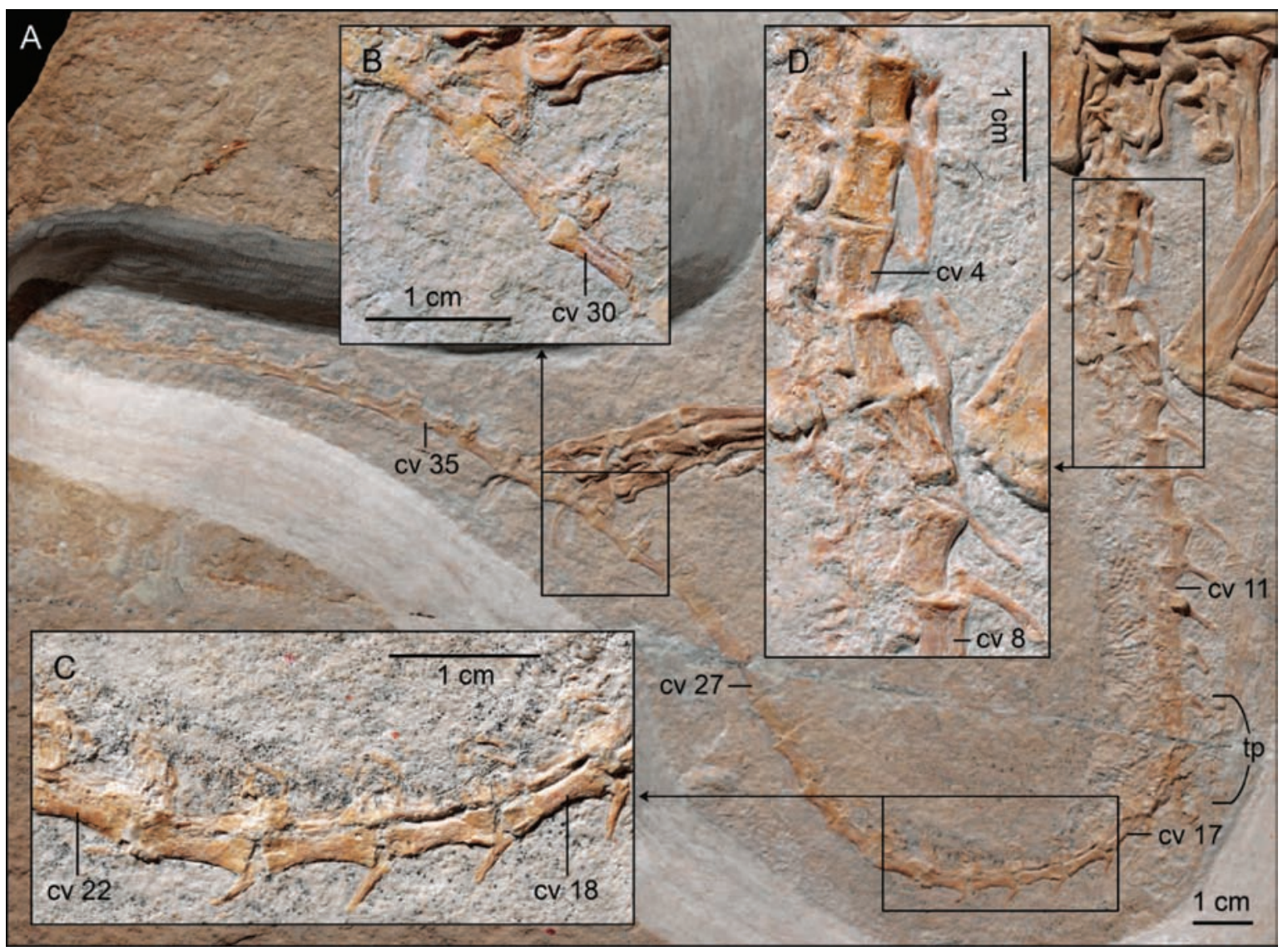

Fig. 14. Caudal vertebral series (A) of Juravenator starki (JME Sch 200) with close-ups of the distal (B), middle (C), and proximal (D) portions of the tail. Abbreviations: cv, caudal vertebrae; tp, transition point.

it remains as long with minor variance until the $35^{\text {th }}$ caudal. Distal from this point, the length of the caudal centra becomes gradually shorter, but the last preserved vertebra is still longer than any of the first seventeen elements of the tail. This pattern is similar to that of Huaxiagnathus, in which the length of the caudal centra remains more or less constant until the $14^{\text {th }}$ caudal and then increases to a higher plateau for the subsequent 11 caudals (only 25 caudals are preserved in this taxon [HwANG et al. 2004]). It also approaches that of the compsognathid Sinocalliopteryx (JI et al. 2007a) in which the longest caudals are between the $20^{\text {th }}$ and the $23^{\text {rd }}$ vertebrae. This trend, however, is markedly different from that of Sinosauropteryx, in which the length of the centra increases until the sixth caudal but then decreases until the end of the tail (CURRIE \& CHEN 2001). It is also different from the one observed in Compsognathus (BSPG AS I 563 and MNHN CNJ 79 preserve approximately
15 [Ostrom 1978] and 30 [Michard 1991] elements, respectively) and Scipionyx (less than 10 vertebrae preserved) in which the length of the centra gradually increases throughout the preserved portion of the tail.

The centra are elongated and morphologically very similar throughout the entire length of the tail (Fig. 14). The height of the centrum decreases gradually throughout the tail in such a way that in the proximal caudals the mid-height of the centrum is approximately half the length of the centrum (with an average of $55 \%$ for the first five preserved caudals) and in the distal caudals the height is nearly one-quarter of the central length (with an average of $27 \%$ for the first five preserved caudals). The general depression of the caudal centra towards the tail's distal end is shared by Compsognathus (PEYER 2006) but not by Huaxiagnathus, in which the caudal centra remain approximately the same relative height throughout the 25 preserved elements of its tail (HwANG et al. 2004). The 

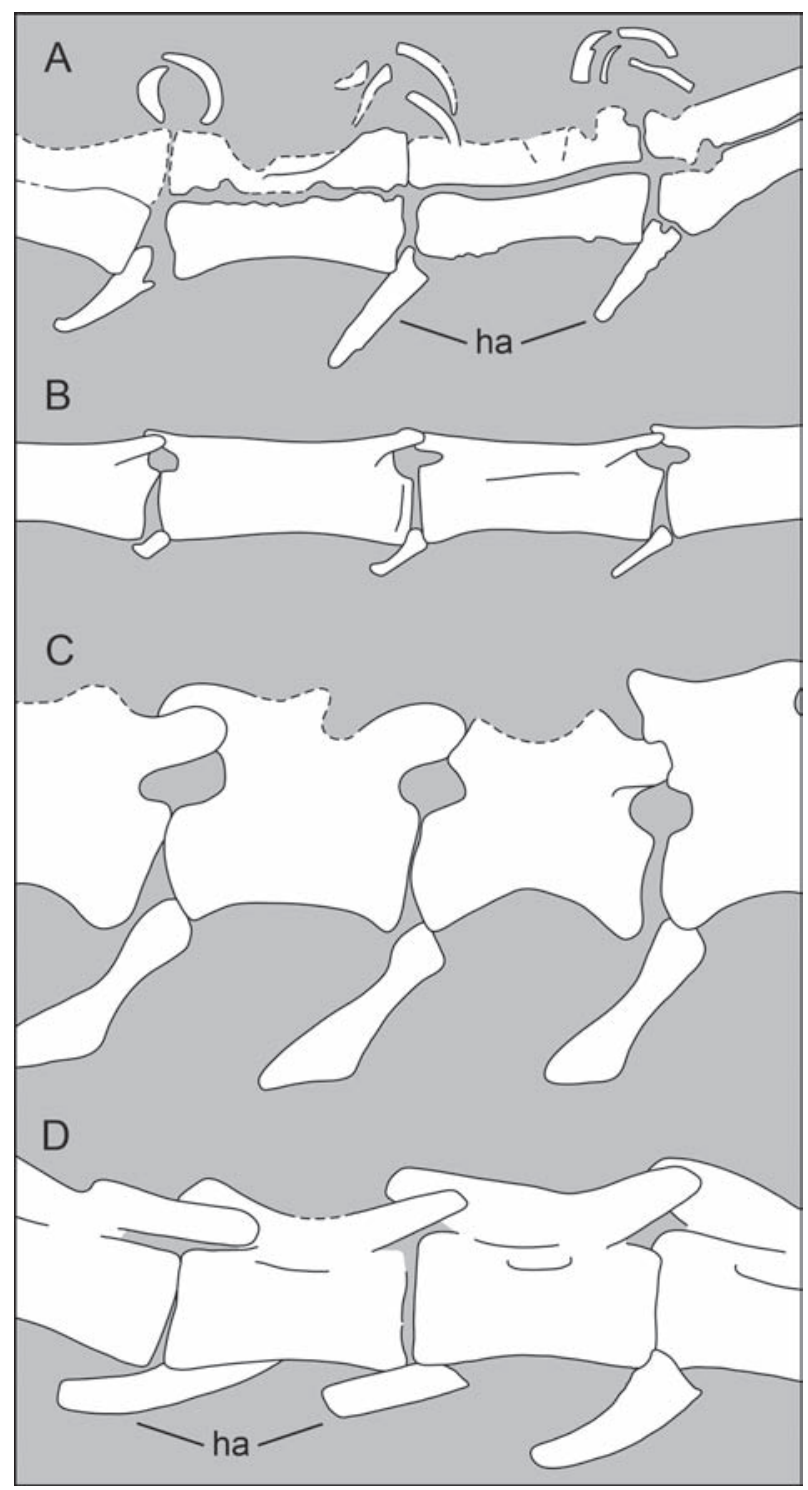

Fig. 15. Comparisons of middle caudals (vertebrae 19 and 20) of Juravenator starki (A), Compsognathus longipes (B, based on Peyer 2006), Sinosauropteryx prima (C, based on CURRIE \& CHEN 2001), and Huaxiagnathus orientalis (D, based on photographs of CAGS-IG02-301 provided by S. Hwang). Abbreviations: ha, haemal arch.

neural spines are long and caudally oriented in the first three caudals of Juravenator - the neural spine of the third caudal extends back to the middle of the fourth caudal. The neural spine of the latter vertebra is shorter but still somewhat inclined; its morphology transitions with the shorter and vertically oriented neural spines of the subsequent vertebrae. The neural spine of the fifth caudal is dorsally expanded and fan- shaped, and this condition appears to remain present in more distal neural spines (however, the morphology of some of these processes is not clear in every vertebra). The transverse processes are poorly preserved. They appear to be well-developed in the proximal caudals but their presence in more distal caudals cannot be determined. The poor preservation of the transverse processes and limited preparation in areas covered by soft tissue (see Soft tissue below) complicates the assessment of the transition point. However, remnants of a moderately tall neural spine are visible down to the $14^{\text {th }}$ caudal. It is difficult to determine if a neural spine of any significant height was present in the $15^{\text {th }}$ caudal but it seems clear that the neural spines were reduced from the $16^{\text {th }}$ caudal onwards. Thus, we regard the transition point to be around the $14^{\text {th }}$ or $15^{\text {th }}$ caudal vertebrae (Fig. 14), an estimate more or less comparable to that provided for Compsognathus (MichARD 1991), Huaxiagnathus (HwANG et al. 2004), and other basal coelurosaurs (HoLtz et al. 2004). None of the centra exhibit evidence of pneumaticity.

The proximal zygapophyses are not well-preserved. However, it seems apparent that they were short. The morphology of the zygapophyses can be better observed in the middle and distal portion of the tail. Although still difficult to determine, the morphology of the zygapophyses of the middle caudals (roughly between the $16^{\text {th }}$ and the $35^{\text {th }}$ element) is strikingly unique (Figs. 14, 15). These zygapophyses are tall and slender, relatively short, and remarkably arched, forming a "bow" over the intercentral articulation. The exact contribution of the pre- and postzygapophyses to this bow-like articulation is unclear but both zygapophyses seem to participate in this joint. The morphology of the zygapophyses becomes more conventional from the $36^{\text {th }}$ caudal onwards, when the prezygapophyses gradually become straighter and longer, overlapping substantially (but less than half) the length of the preceding centrum.

The chevrons are elongate and rod-shaped throughout the tail (Fig. 14). There are 25-26 chevrons in articulation with the first $25-27$ vertebrae - the last ones are very small and difficult to see but a chevron appears to be present between the $31^{\text {st }}$ and the $32^{\text {nd }}$ caudal. The length of the chevrons decreases gradually towards the distal part of the tail. The last few chevrons are approximately one-third the length of the proximal ones (e.g., the $6^{\text {th }}$ chevron is $8.8 \mathrm{~mm}$ long and the $22^{\text {nd }}$ chevron is $3.0 \mathrm{~mm}$ long). While the proximal chevrons tend to be caudally bowed, the middle 


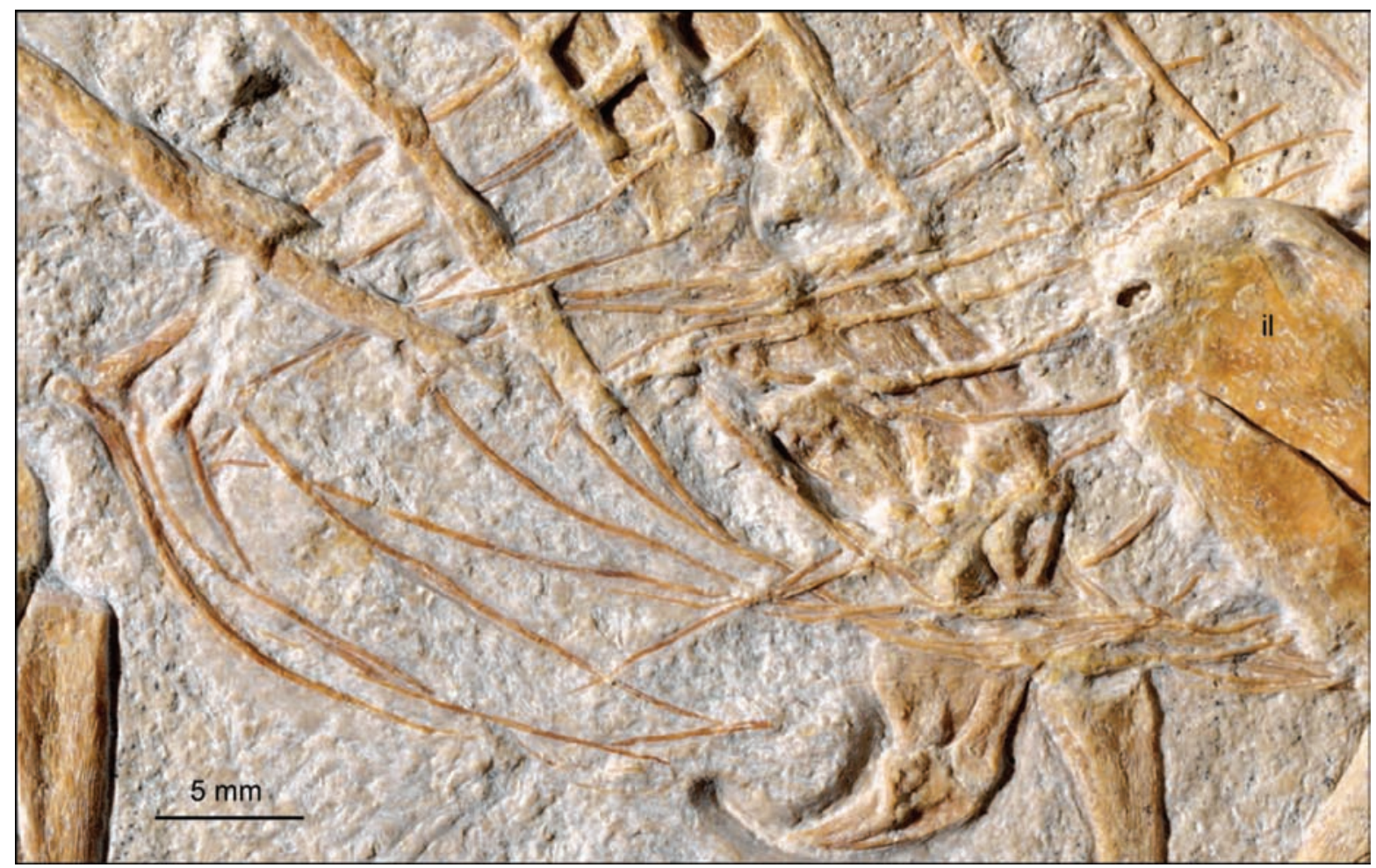

Fig. 16. Close-up of the gastralia of Juravenator starki (JME Sch 200). Abbreviations: il, ilium.

ones are straight. These bones are articulated obliquely until the $20^{\text {th }}$ chevron but they lay parallel to the vertebral central onwards. The morphology and orientation of the chevrons of Juravenator is comparable to that of Huaxiagnathus (HwANG et al. 2004), Compsognathus (MichARD 1991), Sinocalliopteryx (JI et al. 2007a), and as far as it can be compared, Scipionyx (DAL SASso \& Signore 1998). The chevrons of Huaxiagnathus and Compsognathus differ somewhat from the more spatulated ones of Sinosauropteryx (CURRIE \& CHEN 2001) - the middle chevrons of the latter taxon are also hooked as opposed to straight as in Juravenator.

Only a few cervical ribs are preserved, although the one corresponding to the penultimate element of the series is best exposed. These long and extremely thin ribs exhibit the characteristic "hair-like" condition (Fig. 12) of the cervical ribs of Sinosauropteryx (Currie \& Chen 2001), Compsognathus (PEyer 2006), Sinocalliopteryx (JI et al. 2007a), and Scipionyx (DAL SAsso, pers. comm.). Twelve pairs of thoracic ribs are preserved in near articulation, possibly representing the complete ribcage (Figs. 3-5, 12). The ribs are composed of a single element (i.e., without sternal segments) and they show no evidence of ossified uncinate processes. They become thinner and shorter towards the caudal portion of the ribcage. Although those from the left cranial half are straight, the gently curved outline of the ribcage is better insinuated on the right side.

A full set of partially articulated gastralia is preserved in front of the pelvis (Figs. 3-5, 16). There are more than 13 rows of gastralia, a condition approaching the 15 or so described for Sinocalliopteryx (JI et al. 2007a). The first row is the thickest and a pair of single gastralia forms it. These elements connect at their medial end forming a short cranial process. Two pairs of filament-like segments articulated in a zigzag pattern form subsequent rows of gastralia. Like in all other theropods (CLAESSENS 2004), each of these pairs is formed by two overlapping elements. When visible, the medial segments are longer than the lateral one, a condition similar to that reported in Sinocalliopteryx (JI et al. 2007a) and Huaxiagnathus (HwANG et al. 2004). 
Appendicular skeleton. - Both scapulae are preserved in approximately their life-orientation - nearly perpendicular to the vertebral column and with the blade diagonally crossing the rib cage (Figs. 3-5, 17). The left scapula is entirely exposed in lateral view. Its counterpart is beneath several ribs, the left scapular blade, and the vertebral column, and only portions of its medial surface can be seen between these bones. The scapula is a slender and elongate bone, and the blade expands gradually towards its dorsal end (Fig. 17). Its length is approximately ten times its width at mid-shaft and 1.5 times the length of the humerus (Fig. 18) - while the former proportion is comparable to Sinosauropteryx and Compsognathus, the latter is much greater than that in Compsognathus (scapula: humerus is 1 in BSPG AS I 563; OsTrom 1978) but similar to that in Sinosauropteryx (Fig. 19). The proportion of the length of the scapula to that of the humerus is 1.3 in Sinocalliopteryx, a ratio thus intermediate between Juravenator and Compsognathus (JI et al. 2007a). Unlike these taxa, Scipionyx has a stouter scapula - with an estimated length of about seven times the width of the mid-shaft - even if the proportion of this bone with respect to the humerus is comparable to that of Compsognathus. The scapula of Juravenator differs from that of Sinosauropteryx as well as from that of other "compsognathids" by the fact that the narrowest portion of the scapula is at the neck as opposed to near the mid-shaft - in this respect the scapula of Juravenator resembles more that of the basal coelurosaurs Nqwebasaurus (DE KLERK et al. 2000) and Tyrannosaurus [BROCHU 2003; but not basal tyrannosauroids such as Dilong (Xu et al. 2004) in which the scapula is very robust. The lateral surface of the scapula is virtually flat, although it is more concave in cross-section along the ventral third of its blade (its basal portion). Based on what is exposed of the right scapula, the medial surface (at least in its basal portion) appears to be convex. In lateral view, the scapular blade is curved caudally; its cranial and caudal margins are convex and concave, respectively (Fig. 17). In this respect, Juravenator also differs from other basal coelurosaurs (e.g., Scipionyx, Sinosauropteryx, Sinocalliopteryx, Compsognathus, Nqwebasaurus, ornithomimids, tyrannosauroids), where the scapular blade is straight or less visibly curved (Fig. 19). The scapula is more abruptly expanded ventrally to form the glenoid and the coracoidal articular surface. The former is well-exposed on the left side and directed caudally as in "compsognathids" (CURRIE \& Chen 2001; Hwang et al. 2004) and basal theropods
(Madsen 1976; Currie \& Zhao 1993; Weishampel et al. 2004). The glenoid is a concave facet, about onefifth of the width of the ventral end of the scapula, surrounded by a distinct rim, which is more pronounced laterally. The acromion is prominent - much more so than in Sinosauropteryx - and subtriangular in shape. Unlike Sinosauropteryx, Sinocalliopteryx, and Huaxiagnathus, this process projects abruptly from the scapular blade and its dorsal margin is distinctly concave, a condition that best approaches that of Scipionyx (DAL SASSo \& Signore 1998). The lateral margin of the articulation for the coracoid is partially weathered, offering no information.

Neither of the two coracoids is well exposed (Fig. 17). The left element is incomplete and only a portion of it is articulated with the left scapula. The right coracoid appears to be better preserved but the left scapula and ribs unfortunately cover it. Nonetheless, the medial surface of this coracoid exhibits a distinct concavity and a rounded, convex caudoventral margin.

We interpret two tiny (approximately $5 \mathrm{~mm}$ long), S-shaped, and rod-like bones preserved in disarticulation next to the cranioventral end of the left scapula as clavicles (Fig. 17). The ventralmost of these bones exhibits a hook-like end that is possibly a preservational artifact. Although the same end is somewhat recurved in the dorsalmost preserved element, it is clearly not hooked as in its counterpart. We interpret this extremity to be the articulation with the scapulocoracoid and the opposite, medially curved end as the median contact between these bones. If this is correct, these tiny bones would have formed a U-shaped, albeit not fused, "furcula". Fused clavicles forming a furcula have been reported in a great variety of non-avian theropods (RAUHUT 2003; WeISHAMPEL et al. 2004; NesBitT et al. 2009), including basal coelurosaurs (HwANG et al. 2004; Ji et al. 2007a), but unfused clavicles are also known for the ceratosaur Segisaurus (CAMP 1936; CARRANO et al. 2005; but see RAUHUT [2003] for a different interpretation) (unfused clavicles are also known for the Cretaceous bird Hesperornis [MARSH 1880] and a number of modern birds [BAUMEL \& WiTMER 1993]). The absence of clavicular fusion in Juravenator could well be ontogenetic, although the relation between furcular formation and age is not well understood in non-avian theropods (e.g., the early juvenile Scipionyx has clavicles fused into a furcula). Regardless, if our interpretation of these bones is correct, the "furcula" of Juravenator would have been much more U-shaped - with a substantially narrower interclavicular angle - than those 


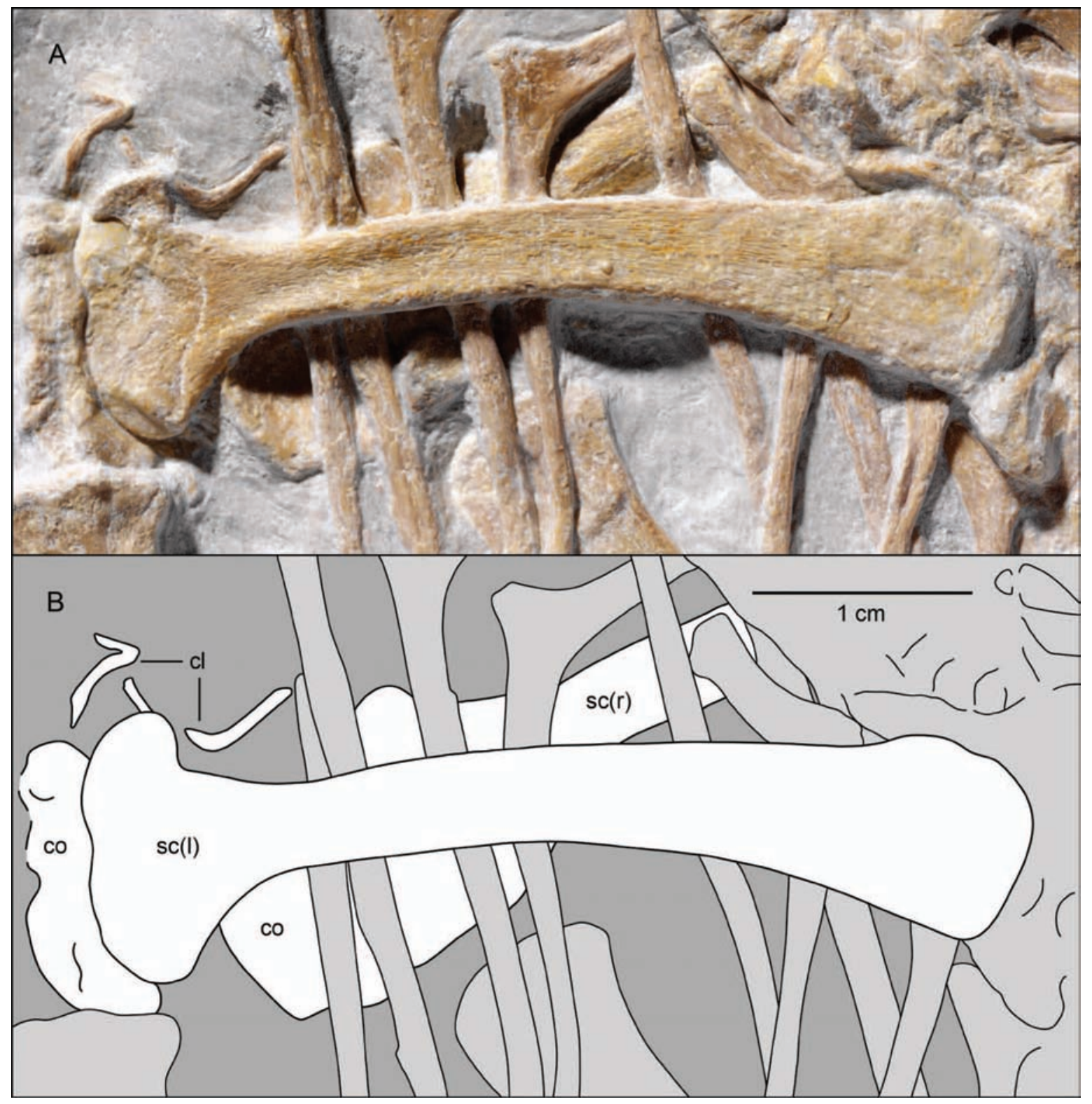

Fig. 17. Photograph (A) and interpretive drawing (B) of the shoulder girdle and clavicles of Juravenator starki (JME Sch 200). Abbreviations: cl, clavicles; co, coracoid; sc, scapula. Note the intense pitting and grooving of the bone surface of the scapula (A). $r$ and 1 refer to the right and left element.

of other non-avian theropods (e.g., Norell et al. 1997; Makovicky \& Currie 1998; Dal Sasso \& SignORE 1998; Clark et al. 1999; HwANG et al. 2002; RauHut 2003).

The forelimb is $50 \%$ the length of the hindlimb (measured along their longest digit and including their corresponding claws) (Figs. 3-5), a ratio comparable to that of Huaxiagnathus (48\% according to HwANG et al. [2004]) and Sinocalliopteryx (Ji et al. 2007a) and smaller than that of the basal tyrannosauroid Guanlong (XU et al. 2006). This proportion is substantially greater than the forelimb: hindlimb ratio of Compsognathus and Sinosauropteryx (39\% and $36 \%$, respectively, according to HwANG et al. [2004]). The ratio between humerus + radius and femur + tibia of Juravenator is 0.43 , slightly greater than that of Huaxiagnathus (0.39; HwANG et al. 2004), Compsognathus (0.41 for BSPG AS I 563 [HwANG et al. 2004] 


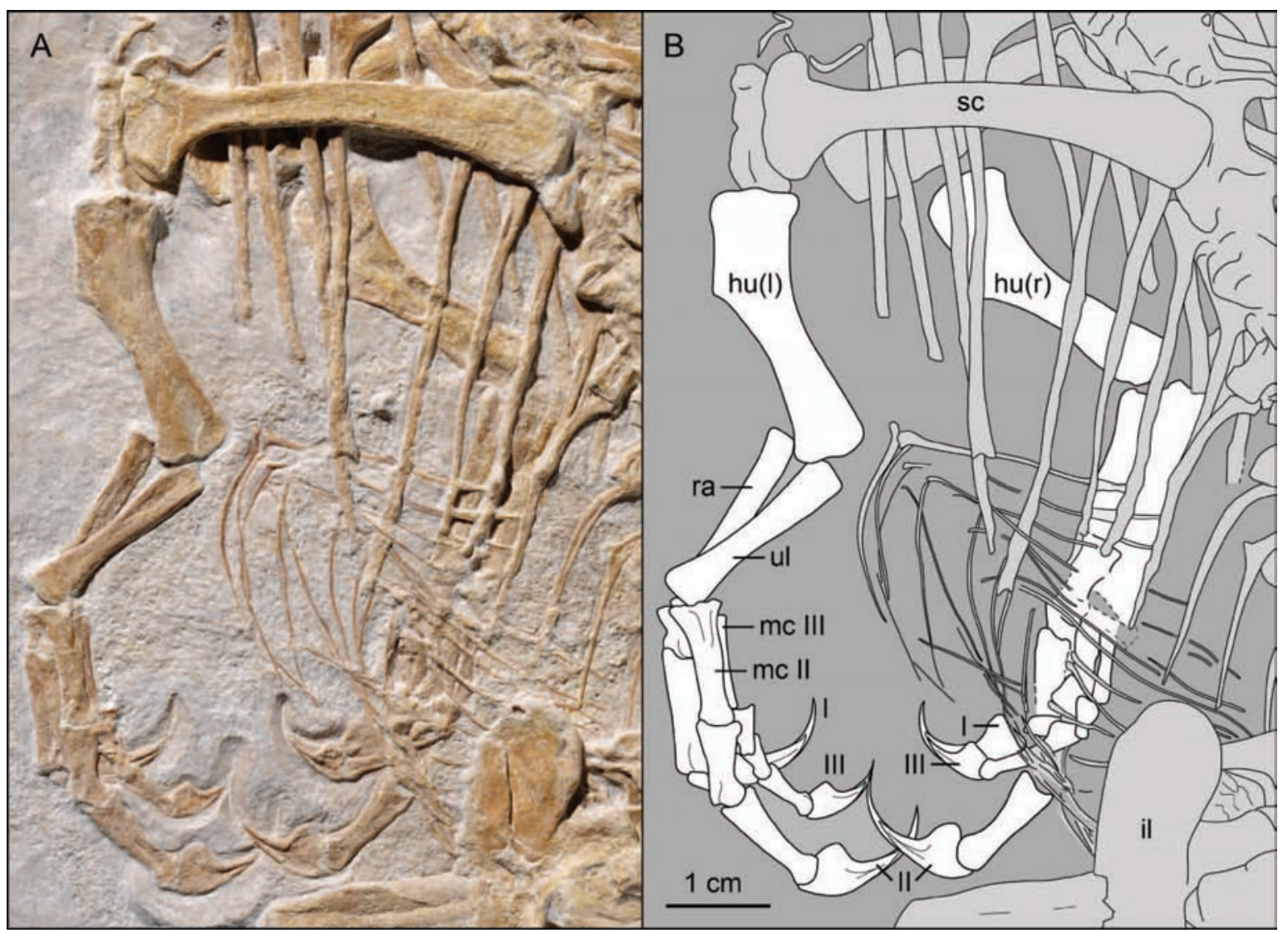

Fig. 18. Photograph (A) and interpretive drawing (B) of the forelimbs of Juravenator starki (JME Sch 200). Abbreviations: mcII-III, metacarpals II-III; hu, humerus; il, ilium; ra, radius; sc, scapula; ul, ulna; I-III, manual digits I-III. R and 1 refer to the right and left element.

and 0.38 for MNHN CNJ 79), and Nqwebasaurus (0.40 using humeral and femoral length estimations of DE KLERK et al.[2000]), and much greater than that of Sinosauropteryx (0.29 and 0.31 for NIGP 127586 and NIGP 127587, respectively [JI et al. 2007b]). Thus, Juravenator has the longest forelimb among "compsognathids" and such a difference does not seem to be related to the elongation of the hand as in Huaxiagnathus (HwANG et al. 2004). The smaller contribution of the hand to the length of the forelimb in Juravenator can also be noticed when the length of the manus is compared to the rest of the forelimb (Figs. 18-19). While the ratio between the manus and the (humerus + radius) is 0.87 for Juravenator, 0.84 for Sinosauropteryx (NIGP 127587; HwANG et al. 2004), and 0.74 for Compsognathus (holotype; HwANG et al. 2004), it is 1.03 for Huaxiagnathus (HwANG et al. 2004).

Both humeri are preserved (Fig. 18). The left one is exposed in caudal view and the right one in cranial view, however the latter is more flattened and partially covered by the ribcage. The proximal end of the humerus bears a convex head (in caudal view) and a weak internal tuberosity. The deltopectoral crest is short and triangular in shape, with its caudal surface being distinctly concave. Unlike the long deltopectoral crest of Sinosauropteryx that originates at the proximal end and extends for more than half the length of the humerus (CURRIE \& CHEN 2001; Ji et al. 2007b), the deltopectoral crest of Juravenator expands for less than $15 \%$ the length of the humerus and it does not reach the proximal end of the bone. The humerus of Compsognathus is not well preserved in any of the specimens - the French specimen seems to have a more pronounced crest - but the deltopectoral crest does not appear to be like the short, triangular crest of Juravenator. The abbreviated deltopectoral crest of Juravenator sets this species aside from the majority of non-avian theropods, in which the deltopectoral 


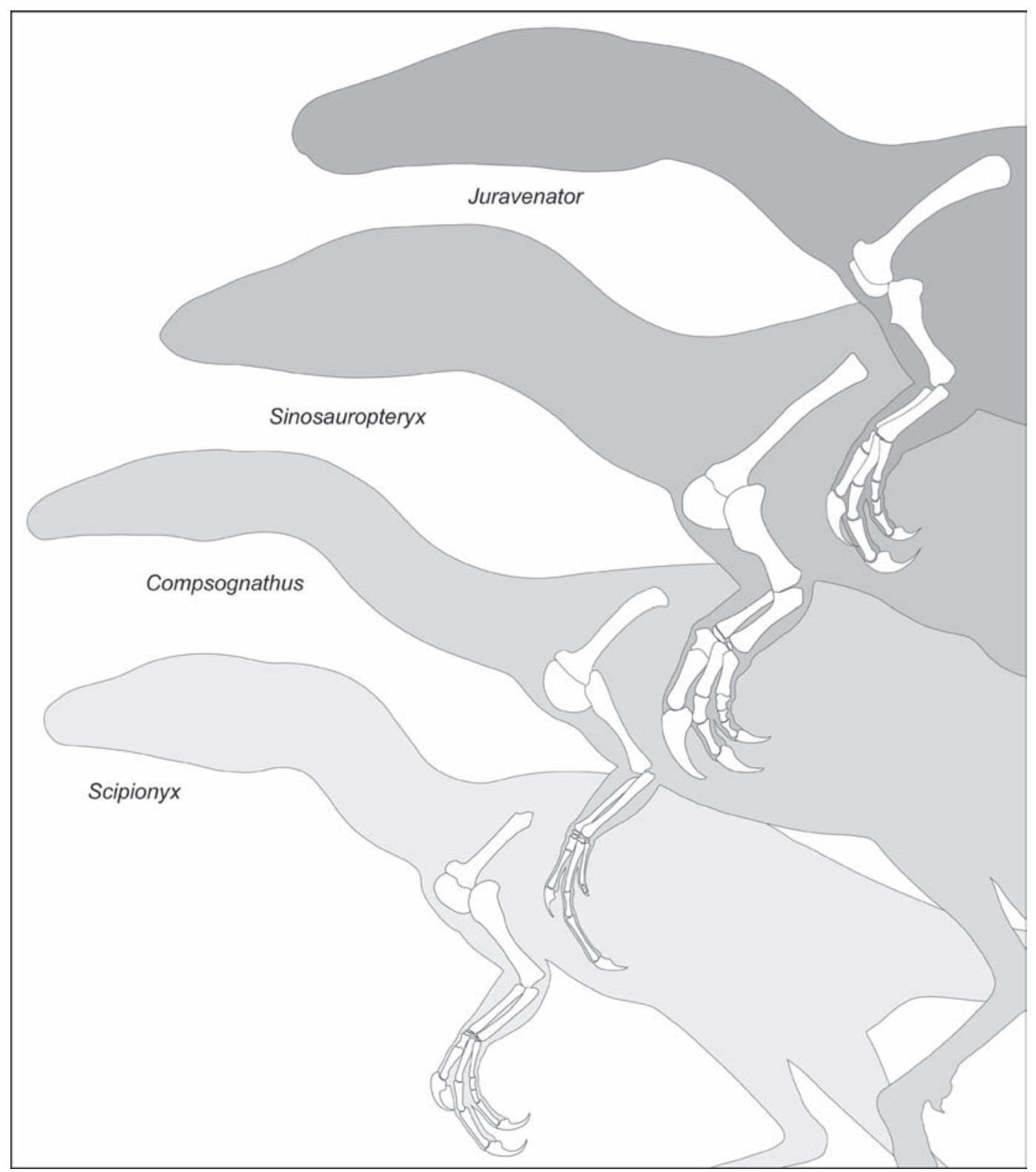

Fig. 19. Comparisons between the shoulder girdle and forelimb of Juravenator, Sinosauropteryx (based on CURRIE \& CHEN 2001), Compsognathus (based on Peyer 2006), and Scipionyx (based on Dal SAsso \& Signore 1998), scaled to the length of the humerus.

crests often extend for a third or more of the length of the humerus (e.g., MADSEN 1976; Ostrom 1978; DE Klerk et al. 2000; Currie \& Chen 2001; Brochu 2003; RAUHUT 2003). However, we cannot be sure as to the extent to which this condition may be related to immaturity since the early juvenile holotype of Scipionyx (thus far the only know specimen) also exhibits a faint deltopectoral crest.
A few millimeters distal to the deltopectoral crest, on the caudolateral margin of the shaft, there is a short, ridge-like structure that could have been the insertion of the humeroradialis muscle (MADSEN 1976). The distal end expands gradually from the midshaft. This end exhibits a slight degree of torsion with respect to the proximal end (both ends are not expanded on the same transversal plane). This torsion 


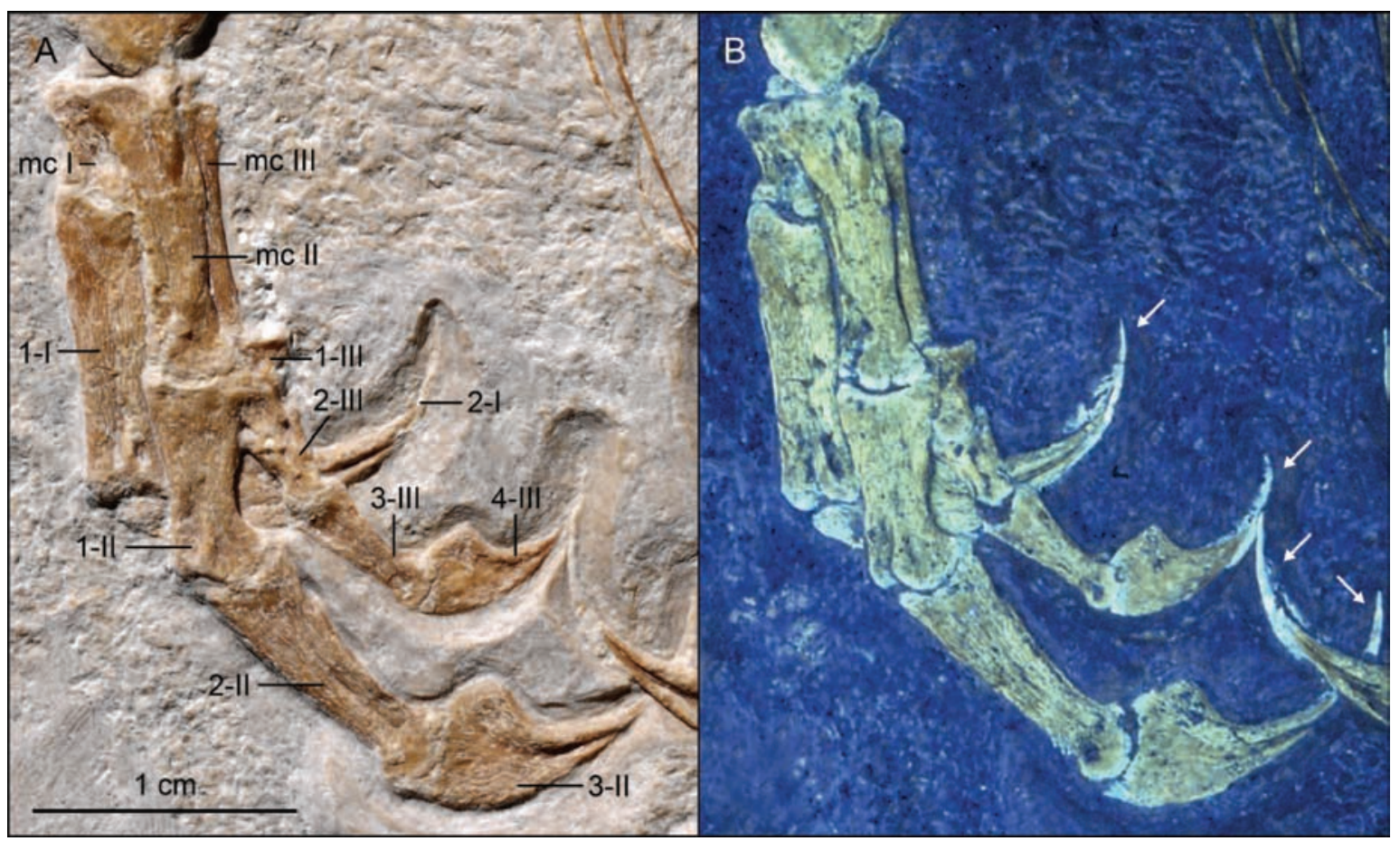

Fig. 20. Photographs of the right hand of Juravenator starki (JME Sch 200) under normal (A) and ultraviolet (B) light. Arrows (B) point to the keratinous sheaths of the manual claws. Abbreviations: mcI-III, metacarpals I-III; 1-I, first phalanx of digit I, 2-I, second phalanx of digit I; 1-II, first phalanx of digit II; 2-II, second phalanx of digit II; 3-II, third phalanx of digit II; 1-III, first phalanx of digit III; 2-III, second phalanx of digit III; 3-III, third phalanx of digit III; 4-III, fourth phalanx of digit III.

may account for the presence of an inflated margin on the distal end of the right humerus, which constitutes the medial margin of the bone itself. Comparing the degree of humeral torsion with that of other basal coelurosaurs is hampered by the bi-dimensional preservation of most of these fossils. However, CURRIE \& CHEN (2001) described the humerus of Sinosauropteryx as lacking any kind of torsion and a similar condition appears to be the case in Scipionyx (DAL SASSO \& SignORE 1998). The caudal surface of the distal end is slightly excavated by a triangular fossa. The external (ulnar) condyle is well developed and hemispheric; the internal (radial) condyle is not sufficiently exposed to be described.

Both ulnae and radii are preserved (Fig. 18) but those from the right side are largely covered by ribs and gastralia. The radius and ulna are straight bones shorter than the humerus (approximately two-thirds the length of the humerus). The shafts of these bones are essentially of the same width, although that of the ulna appears to be slightly thicker. However, although judging from the more weathered right element, the proximal end of the ulna appears to be more expanded than that of its counterpart. Unlike Compsognathus and Sinosauropteryx (Ostrom 1978; CURRIE \& CHEN 2001), the ulna of Juravenator lacks a prominent olecranon, thus resembling the condition of Huaxiagnathus and Sinocalliopteryx, whose ulna seems to have a small olecranon. On the distal end, the ulna of Juravenator bears a rounded articular surface.

Both manus are preserved in articulation with the left one completely exposed in dorsolateral view digit I is mostly exposed on dorsal view and digits II and III are more laterally exposed (Figs. 17, 19). Only the ends of the digits of the right hand are clearly visible - the rest is largely covered by gastralia - and they appear to be exposed medially. There is no evidence of any carpal bone, even if the entire forelimb is preserved in articulation. Probably the carpalia have not been ossified yet - another indication of the juvenile/immature age of the specimen. The hand of Juravenator carries three digits (Fig. 19). Metacarpal I is approximately $40 \%$ the length of metacarpal II. Such a ratio agrees well with that of Sinosauropteryx 


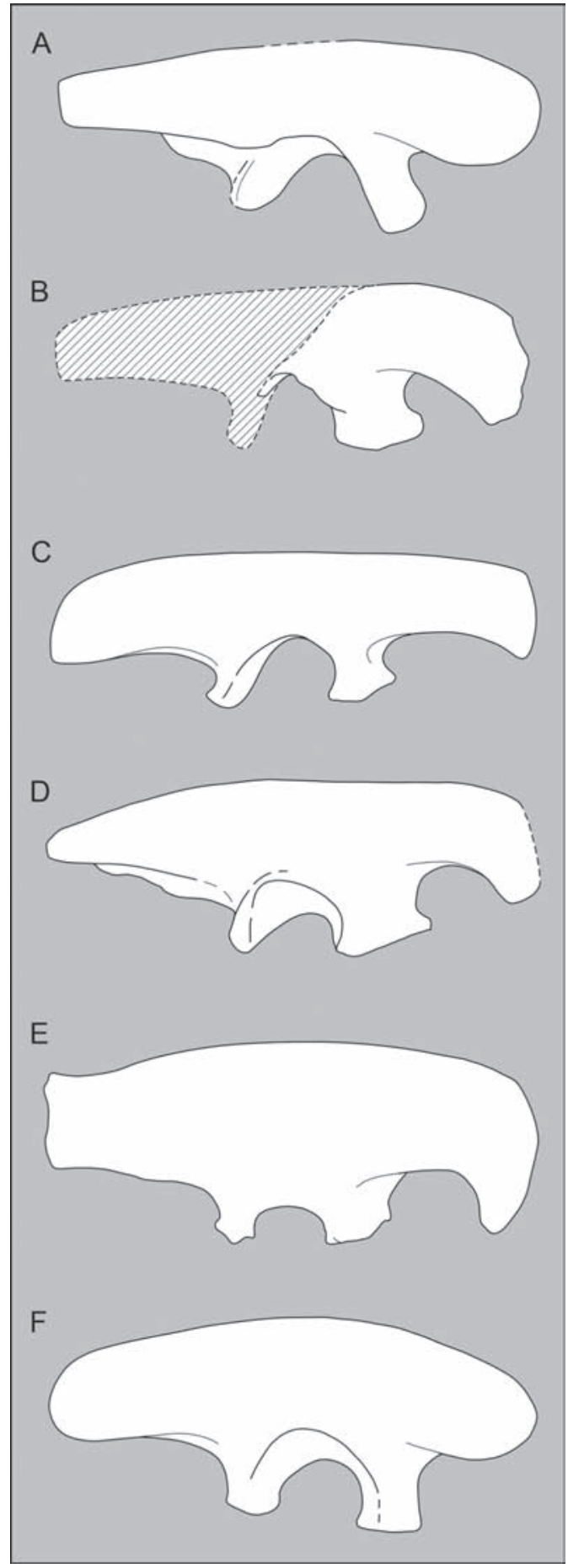

Fig. 21. Comparison between the right ilia of Juravenator starki (A), Mirischia asymmetrica (B, based on SMNK 2349), Sinosauropteryx prima (C, based on CURRIE \& CHEN 2001), Ornitholestes hermanni (D, based on AMNH 619), Gallimimus bullatus (E, based on BARSBOLD \& OSMÓLSKA 1990), and Huaxiagnathus orientalis (F, based on HwANG et al. 2004). Hatched areas indicate missing portions of the skull. Drawings not to scale.
(CURrie \& Chen 2001), Huaxiagnathus (HwAng et al. 2004), Sinocalliopteryx (Ji et al. 2007a), and the basal tyrannosauroid Guanlong (Xu et al. 2006), but it differs from that of Scipionyx, which has a substantially lower ratio ( $27 \%)$. Metacarpal I of Juravenator more resembles that of Huaxiagnathus, Scipionyx, and Guanlong than that of Sinosauropteryx in that in the first four taxa, this bone is longer than it is wide and similar in width to metacarpal II. Yet, the proximomedial corner of the metacarpal I of Juravenator projects into a distinct flange similar to (but less prominent than) the one exhibited by Sinosauropteryx - a condition apparently unique to these theropods (CURRIE \& CHEN 2001). The trochlea of metacarpal I is asymmetric, with its lateral rim projecting distally more than its medial rim. The straight metacarpal II is thicker than metacarpal III. The latter is also straight but has $75 \%$ the length of metacarpal II, a proportion that falls within the range $(\sim 70-80 \%)$ exhibited by other basal coelurosaurs (e.g., Scipionyx, Huaxiagnathus, Sinosauropteryx, Guanlong) - Ji et al. (2007a) reported a relatively shorter metacarpal III (64\% the length of the metacarpal II) for Sinocalliopteryx. Although the left metacarpal III of Juravenator appears much thinner than the metacarpal II, such a difference may be explained by the fact that the latter overlaps the former (Fig. 20). Examination of the right hand confirms that metacarpal III is thinner than metacarpal II but the precise relation between these widths is difficult to establish with confidence. Our estimation, however, is that metacarpal III is about one half the width of metacarpal II, which agrees well with the relative widths of these bones in Sinosauropteryx and Huaxiagnathus (CURRIE \& CHEN 2001; HwANG et al. 2004) but differs from Scipionyx and Sinocalliopteryx, in which the metacarpal III is proportionally thicker and thinner, respectively. The metacarpals of Compsognathus (both specimens) are too poorly preserved to establish reliable comparisons but as highlighted elsewhere (e.g., Currie \& CHEN 2001; Peyer 2006; Gishlick \& Gauthier 2007), their morphology seems to compare well with the overall design (e.g., very short metacarpal I, slender metacarpal III) of the hand of other "compsognathids".

The three digits of Juravenator are robust and powerfully clawed (Fig. 20). The phalangeal formula is 2-3-4-x-x and when the digits are measured in articulation with their metacarpals, digit I is the shortest and digit II is the longest. Phalanx I-1 is the largest of all phalanges. This straight bone is as long as metacarpal II and has a similar width. The overall morpho- 


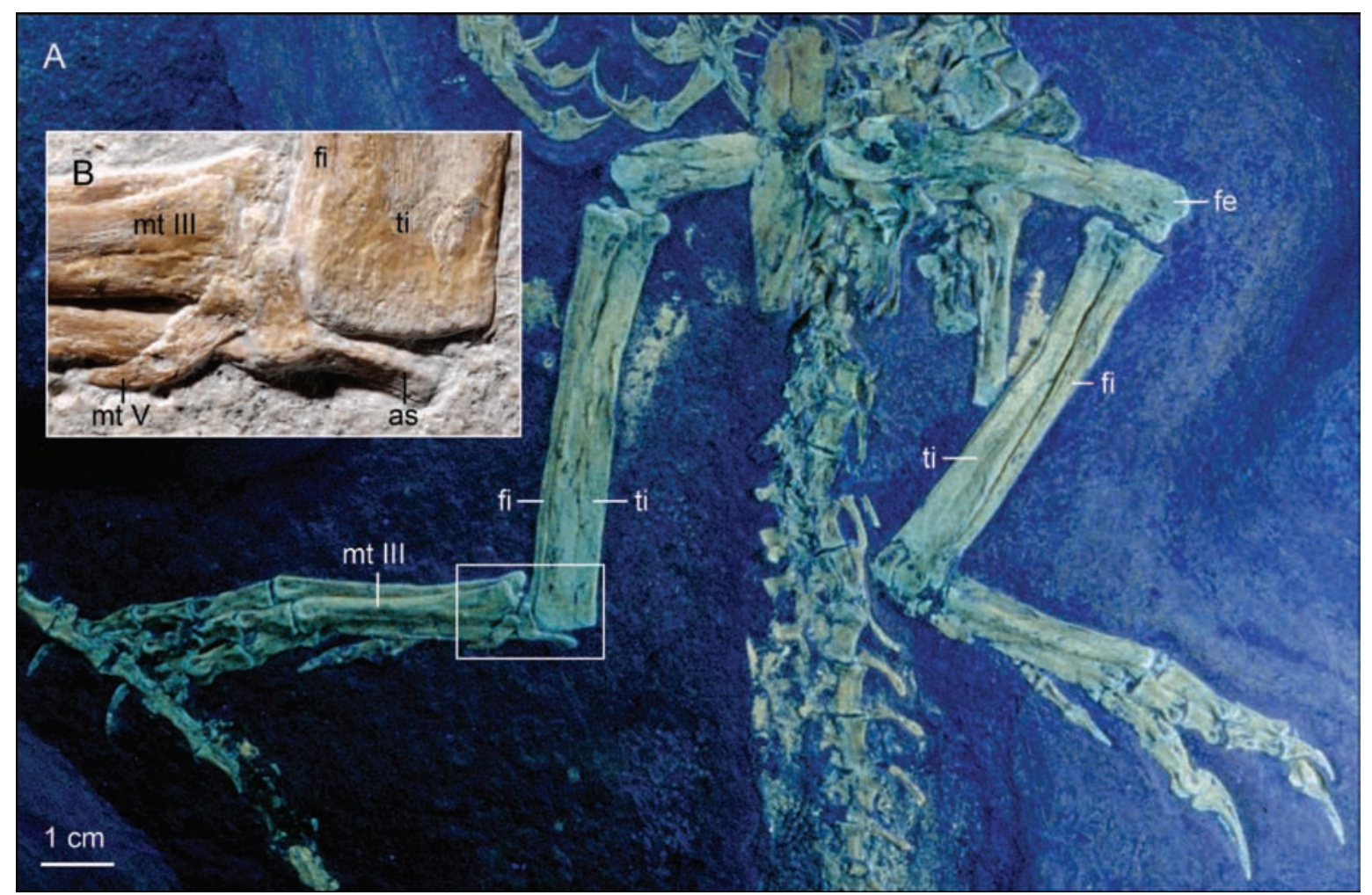

Fig. 22. Photograph of the hindlimbs of Juravenator starki (JME Sch 200) under UV light (A) and an inset of the left ankle photographed under normal light (B). Abbreviations: as, astragalus; fe, femur; fi, fibula; mt III, metatarsal III; mt V, metatarsal V; ti, tibia.

logy of this bone confirms previous statements (e.g., Michard 1991; Currie \& Chen 2001; Gishlick \& GAUTHIER 2007) indicating that the bone described by Ostrom (1978) as the metacarpal I of Compsognathus is indeed the phalanx I-1 of this animal. The relative size of phalanx I-1 of Juravenator compares well with that of Huaxiagnathus (HwANG et al. 2004), Scipionyx (Dal Sasso \& Signore 1998), Compsognathus (Gishlick \& GAUTHIER 2007), and Sinocalliopteryx (JI et al. 2007a) but drastically differs from that of Sinosauropteryx. In this latter taxon, phalanx I-1 is much longer and wider than metacarpal II and it is as long as the radius (CURRIE \& CHEN 2001). This unusually large phalanx I-1 appears to be unique to Sinosauropteryx since such proportions - in particular, a length subequal to that of the radius -are not shared by other basal coelurosaurs (e.g., Huaxiagnathus, Compsognathus, Sinocalliopteryx, Juravenator, Scipionyx, Nqwebasaurus, tyrannosauroids, ornithomimids) (Fig. 18). The claw supported by phalanx I-1 is subequal in length to the latter - this claw is the largest of the hand. Like all other manual claws, its curvature is moderate and its proximal end is very high. In lateral view, this and other manual claws taper abruptly around their midpoints. The abrupt transition between the proximal and distal ends of the manual claws markedly differs from the more gradual tapering of the unguals of Huaxiagnathus, Sinosauropteryx, Sinocalliopteryx, Scipionyx, Nqwebasaurus, Ornitholestes, and other basal coelurosaurs (Fig. 19). The lateral surfaces of the manual claws are excavated by a deep longitudinal groove and the horny sheaths extending the length of the unguals are visible under UV light (Fig. 20). Phalanx II-1 is approximately $80 \%$ the length of phalanx II-2. The latter is slightly bowed along the dorsoventral plane. The dorsal surface of the distal end of phalanx II-1 has a marked central depression and the sides of the distal end of this phalanx and of phalanx II-2 are excavated by shallow fossae for the attachment of collateral ligaments. The length of the ungual phalanx of digit II is subequal to that of phalanx II-2 and about a third longer than the claw 
of digit III. The latter digit has two short proximal phalanges (III-1 and III-2) that have approximately almost the same length and that are about two-thirds the length of phalanx III-3. The claw (III-4) is the longest phalanx of this digit (see Appendix I for specific measurements of manual phalanges).

The pelvis is complete with its sides exposed, although its bones are disarticulated (Fig. 13). The right ilium is exposed in lateral view and the left ilium is exposed in medial view; however, other bones cover most of the left ilium. The ilium is essentially a straight, laterally concave, long, and low bone, with its dorsal and ventral margins gently tapering caudally. The preacetabular process is slightly shorter and much higher - more than twice in depth - than the postacetabular process; its cranial margin is round, lacking the hooked outline of some other theropods (e.g., Allosaurus, Mirischia, Gallimimus, Ornitholestes, Sinocalliopteryx, Guanlong) (Fig. 21). The caudal end of the postacetabular process is distinctly square in lateral view, a design similar to that of many basal tetanurans (including other basal coelurosaurs; Weishampel et al. 2004). This design, however, shows a significant departure from the pointed end of Ornitholestes (CARPENTER et al. 2005 b) and more advanced coelurosaurs (e.g., dromaeosaurids, therizinosaurids; WeIsHAMPEL et al. 2004). The difference between the heights of the pre- and postacetabular processes is strikingly different from the more subequal height of these processes in Huaxiagnathus, Sinocalliopteryx, Sinosauropteryx, and Guanlong. This feature is difficult to ascertain in the poorly preserved pelves of Scipionyx, Mirischia, and the two specimens of Compsognathus.

The acetabular contribution of the ilium is ample, between one-third and one-fourth the entire length of the bone. The dorsal margin of the acetabulum projects laterally forming a distinct ledge over the head of the femur (Fig. 13); similar supracetabular crests are found in a variety of other theropods including basal coelurosaurs. The pubic peduncle is robust, projecting cranioventrally, and distally a bit beyond the distal projection of the ischiadic peduncle. The lateral side of the pubic peduncle is craniocaudally concave and its craniodistal end approximates the mid-level of the preacetabular process. The proportion between the size of the pubic peduncle and that of the preacetabular process resembles more the condition in Huaxiagnathus (Hwang et al. 2004), Sinocalliopteryx (JI et al. 2007a), Mirischia (NAISH et al. 2004), and the

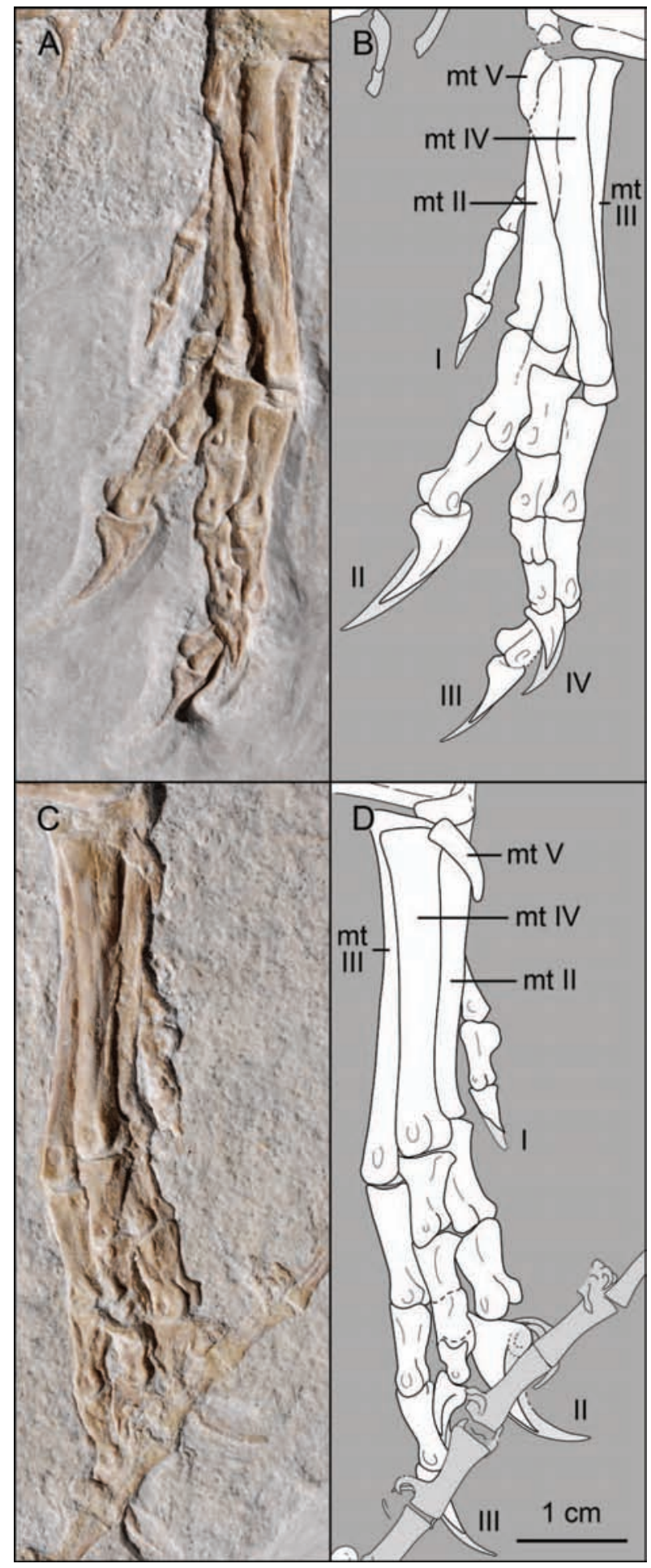

Fig. 23. Close-ups (A, C) and interpretive drawings (B, D) of the right (A, B) and left (C, D) foot of Juravenator starki (JME Sch 200). Abbreviations: mt II-V, metatarsals II-V; I-IV, pedal digits I-IV. 
basal tyrannosauroid Guanlong (XU et al. 2006) than that of Sinosauropteryx (CURRIE \& CHEN 2001) or Ornitholestes (CARPENTER et al. 2005b) (Fig. 21). A small and slightly recessed area at the cranial base of the pubic peduncle corresponds to a minute preacetabular ("cuppedicus") fossa (HUTCHINSON 2001). This fossa is also small in Mirischia (NAISH et al. 2004). The ischiadic peduncle is much smaller than the pubic peduncle. Its acetabular portion develops into a flat antitrochanteric facet. The ventral margin of the postacetabular process is excavated by the brevis fossa. In side view, the lateral (iliac blade) and medial (medial shelf) margins of this fossa are straight and concave, respectively, but the caudal end of the medial shelf tapers distally instead of having a squared off end like the iliac blade. Although the compression of the ilium prevents us from assessing the width of the brevis fossa, it is clear that the base of the medial shelf projects ventrally more than the iliac blade.

The other elements of the pelvis are of difficult interpretation (Fig. 21) - this area has been affected by the postmortem rotation of the hindquarters with respect to the presacral portion of the skeleton (Figs. 3-5). The long and slender shafts of two bones lying parallel to the ilium and pointing backwards are interpreted as proximal halves of the pubes, possibly exposed in caudolateral view. This interpretation is primarily based on the absence of a distinct obturator process. If correct, this interpretation suggests a substantial postmortem rotation of the bones towards the back - assuming that the pubes were oriented either rostroventrally or vertically as in other basal coelurosaurs (e.g., CURRIE \& CHEN 2001; HwANG et al. 2004; WEISHAMPEL et al. 2004; CARPENTER et al. 2005 b; XU et al. 2006; JI et al. 2007a). These two bones are still partially connected to one another, but their distal portions are missing. The proximal end of the bone interpreted as the right pubis is expanded and bears a distinct swell. An elongated bone running along the caudal margin of the right femur and dorsal to this swell cannot be identified with precision but it may be a portion of an ischium. Portions of other bones are exposed beneath the right pubis, and between the cranial margin of the right femur and a pair of vertebral centra located in front of this femur. The identification of these bones remains unclear.

The hindlimbs are robust and twice as long as the forelimb (Appendix 1) (Figs. 3-5). Both femora are preserved and exposed in lateral-caudolateral view but the pelvis covers the proximal half of the left element. The femur is slightly bowed craniocaudally, convex cranially, and concave caudally (Fig. 22). A notable step on the proximocranial edge of the right femur is interpreted as the dorsal margin of the lesser trochanter. This margin is approximately $5 \mathrm{~mm}$ distal to the proximal end of the bone. Opposite to the base of the lesser trochanter is a crest-like structure, perhaps corresponding to the posterior trochanter; among "compsognathids", a knob-like posterior trochanter is present in at least Mirischia. The distal end bears two distinct condyles that are exposed in caudolateral view. There is no evidence of an ectocondylar tuber and there does not seem to be any significant groove separating both condyles. The caudal margin of the right femur does not show any definitive evidence of a fourth trochanter but the more lateral exposure of this bone may prevent this structure from being visible. A crest-like ridge present on the distal half (dorsal to the proximal end of the tibia) is possibly a preservational artifact. This structure is too distal to be considered a fourth trochanter and its crest-like appearance seems enhanced by the overlapping of the tibia on the caudal margin of the distal fourth of the bone.

The complete tibiae are exposed in caudal view and articulated to the fibulae (Fig. 22). The tibia exceeds the length of the femur by $10 \%$. This ratio resembles that of Huaxiagnathus (HwANG et al. 2004), Sinocalliopteryx (Ji et al. 2007a), Sinosauropteryx (CURrie \& CHEN 2001), and the basal tyrannosauroid Dilong (XU et al. 2004), but is greater in Nqwebasaurus (tibia is $20 \%$ longer than femur; DE KLERK et al. 2000) and Compsognathus (tibia is 20-30 \% longer than femur; Ostrom 1978; Michard 1991). The tibia is essentially straight although the medial margin of its proximal half is slightly concave; this condition appears to be absent in other basal coelurosaurs (e.g., KiRKLAND et al. 1998; De KLERK et al. 2000; CURRIE \& CHEN 2001). The caudal extensions of the proximal articulations are visible, and their shape suggests that as in other theropods, the articulations were convex. No other details of the proximal articular surface can be observed. Likewise, nothing can be said about the shape of the fibular crest, which is in both cases overlapped by the fibula. However, the presence of a longitudinal depression in the proximal third of the lateral margin of the right tibia, next to the fibula, suggests that the crests were developed. Both fibulae are also complete and caudally exposed. They are straight and relatively strong, and their shafts gradually taper towards the distal end. There is no obvious sign of a fibular tubercle but the development of this structure may be obscured by the caudal exposition of the 


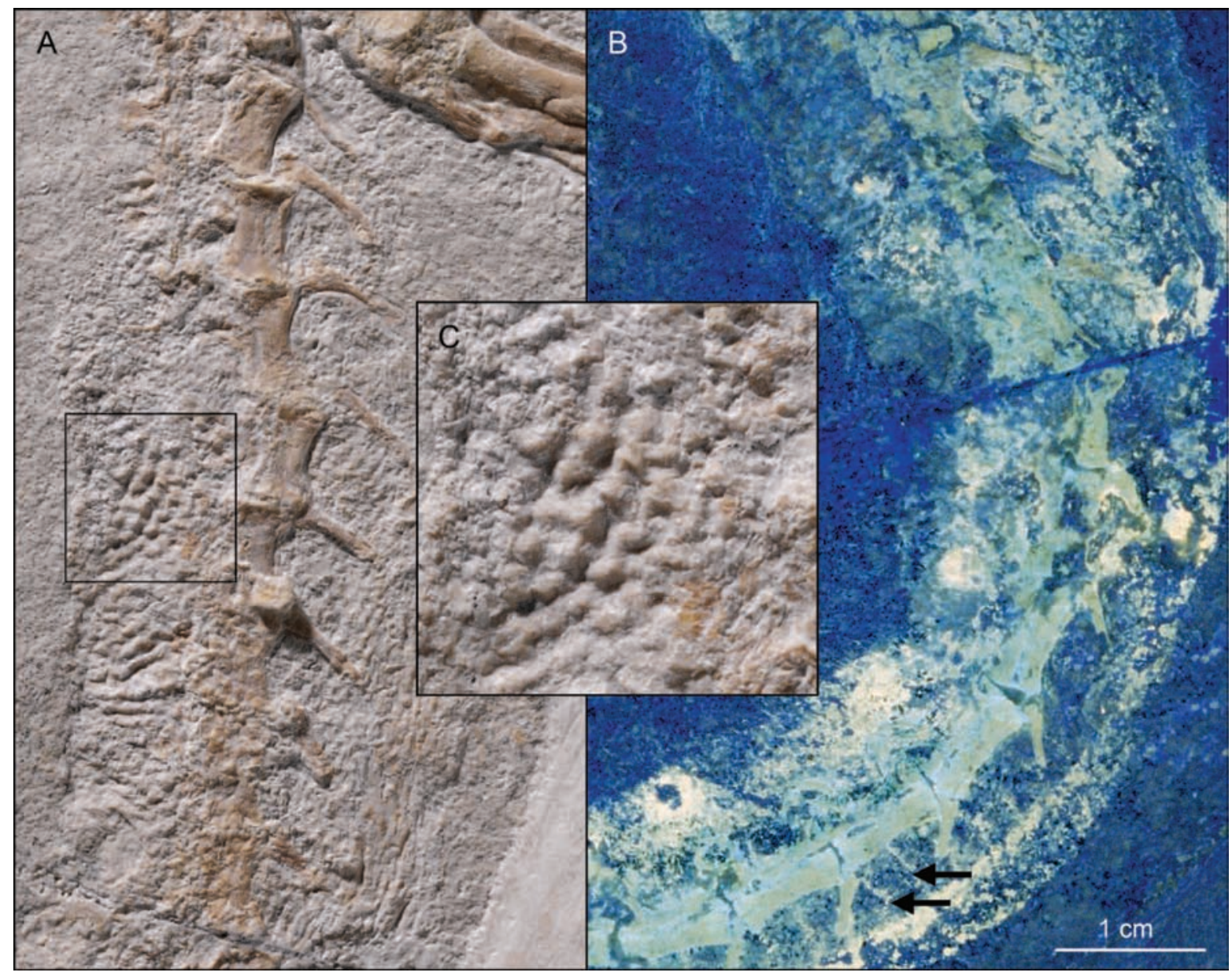

Fig. 24. Soft tissue structures of Juravenator starki (JME Sch 200) under normal (A, C) and ultraviolet (B) light. Inset highlighting details of the soft tissue $(\mathrm{C})$. Arrows point at vertical stripes in between chevrons.

bones. Proximally, the width of the fibula is about three-quarters the width of the tibia; on its distal half, it is one-fourth to one-third the width of the tibia. Distally, the fibula ends about $3 \mathrm{~mm}$ before the distal end of the tibia. Very little can be said about the proximal tarsals, which are partially exposed in caudal view (Fig. 22). These bones are most clearly visible on the left hindlimb. They do not seem to be fused to each other and the astragalus is clearly not coossified with the tibia. What is preserved of the astragalus suggests a rather shallow bone.

Both pedes are complete, in articulation, and laterocaudally exposed (Figs. 22-23). The foot is proportionally shorter than in other "compsognathids". For example, the length of the metatarsal III plus its digit (including claw) is approximately $10 \%$ longer than the tibia in Juravenator, $12 \%$ in Compsognathus,
$16 \%$ in Sinosauropteryx (NIGP 127587), and $27 \%$ in Huaxiagnathus. This ratio is mostly influenced by the size of the metatarsal III, which while in Juravenator is approximately half the length of the tibia, it is more than $60 \%$ in all these other taxa. All five metatarsals are preserved and neither is coossified to each other (Fig. 23). Metatarsal V is short, distally pointed, and somewhat bent medially. This metatarsal is approximately one-fifth of metatarsal III, thus being relatively shorter than Huaxiagnathus (one-fourth; HwANG et al. 2004) and Compsognathus (one-fourth to one-third; OSTROM 1978; MichARD 1991). The shorter nature of this metatarsal also gives it a more stout appearance when compared to the more gracile metatarsals of the latter two taxa. Metatarsal IV is completely exposed on both feet of Juravenator. This metatarsal is robust, straight, shorter than metatarsal III but longer than 
metatarsal II. The lateral rim of its distal trochlea projects laterocaudally into a distinct flange. A weak collateral fossa excavates the lateral surface of the trochlea of the left metatarsal IV but this fossa is not evident on the right element. Metatarsal IV largely overlaps metatarsal III. However, it can be seen that the latter is the longest, reaching the proximal end of the metatarsus (i.e., lacking the arctometatarsalian condition of many other coelurosaurs). The distal trochlea of this metatarsal lacks the lateral flange of metatarsal IV but its lateral collateral fossa is deeper. Metatarsal II is also partially overlapped by the other metatarsals. Unlike Huaxiagnathus (HwANG et al. 2004), Nqwebasaurus (De KLERK et al. 2000), Sinosauropteryx (CURRIE \& CHEN 2001), Compsognathus (Ostrom 1978, MNHN CNJ 79), and Ornitholestes (CARPENTER et al. 2005b), the metatarsal II of Juravenator is distinctly shorter than the metatarsal IV (Fig. 23). Distally, the trochlea of this metatarsal forms a ginglymus, in which the lateral rim appears to be more distally projected than the medial rim. The lateral surface of this trochlea is excavated by a well-developed collateral fossa. The short metatarsal I articulates at the mid-shaft of metatarsal II as in Compsognathus (Ostrom 1978) and apparently Huaxiagnathus (HwANG et al. 2004); this metatarsal articulates more distally in Nqwebasaurus (DE KLERK et al. 2000).

All pedal phalanges are preserved in articulation (Fig. 23). Digit III is the longest followed by digits IV, II, and I. The phalangeal formula is $2-3-4-5-\mathrm{X}$ as is common for most dinosaurs. All non-ungual phalanges exhibit deep collateral fossae on the sides of their trochleae and the unguals bear a single lateral groove on each side. The two phalanges of digit I are longer than their metatarsal; this digit ends in a very small claw. On digit II, the proximal phalanx is slightly longer than the intermediate phalanx. The claw of digit II is much greater than the others and it has a prominent flexor tubercle. The proximal phalanx of digit III is distinctly longer than the other nonungual phalanges of this digit. Its claw also bears a prominent flexor tubercle. Like in digit III, the proximal phalanx of digit IV is longer than the other nonungual phalanges. However, the claw of this digit does not appear to carry a strong flexor tubercle.

\subsection{Soft tissue}

Soft tissue is preserved surrounding several parts of the skeleton and is particularly evident under ultra- violet illumination (GöHLICH et al. 2006) (Fig. 24). Under ultraviolet light, soft tissue preservation is visible dorsal to the rostrum, along both tibiae, and between the $8^{\text {th }}$ and the $22^{\text {nd }}$ caudal vertebrae, where it defines the outline of the tail. Furthermore, the ultraviolet illumination perfectly visualizes the long horny sheets especially on the manual but also on the pedal claws. In the caudal region, the preserved soft tissue is also apparent under normal light (Fig. 24). The caudal integument is formed of uniformly sized, smooth tubercles (about 15 tubercles per $25 \mathrm{~mm}^{2}$ ) similar in appearance to the small, conical and non-imbricated tubercles of many other non-avian dinosaurs (BROWN 1916; Czerkas 1997; Anderson et al. 1998; Coria \& CHIAPPE 2007).

GÖHLICH \& CHIAPPE (2006) reported the absence of both feathers and skin follicles in the caudal portion of the skeleton of Juravenator, thus suggesting that unlike some other basal coelurosaurs (CHEN et al. 1998; Ji et al. 1998; XU et al. 1999a, 1999b, 2004, 2009; Norell \& Xu 2005; Zhang et al. 2006), the central portion of the tail of Juravenator was devoid of plumage. However, new, technically improved, detailed ultraviolet photography by H. TISCHLINGER (Stammham, Germany) has revealed evidence of tiny filament-like structures that may be similar to those interpreted as the plumage of Sinosauropteryx (CHEN et al. 1998) and other non-avian theropods (XU et al. 1999a, 1999b, 2004, 2009; Norell \& Xu 2005; ZHANG et al. 2006). These structures, apparently representing the tips of very slender and parallelarranged filaments that are angled slightly caudally from the longitudinal mid axis of the vertebral column, are visible along the edge of the soft tissue preserved around caudal vertebrae 18-20 (Fig. 25). If these structures were found to be traces of plumage, the holotype of Juravenator starki would stand out among other specimens of feathered non-avian theropods in preserving both plumage and extensive portions of a scaly integument covering main portions of the body (e.g., tail) (XU 2006). The coexistence of scaly skin and bristle-like integumentary structures has been reported for other non-avian dinosaurs albeit not theropods (e.g., Psittacosaurus; MAYR et al. 2002) - but it remains highly unusual. Nonetheless, such coexistence is not at odds with a wealth of laboratory experiments that have demonstrated that small groups of stem cells in scales can be stimulated by molecular perturbation to form active feather follicles that develop feathers (DHOUAILly et al.1980; Widelitz et al. 2000, 2003; CHANG et al. 2009). In 


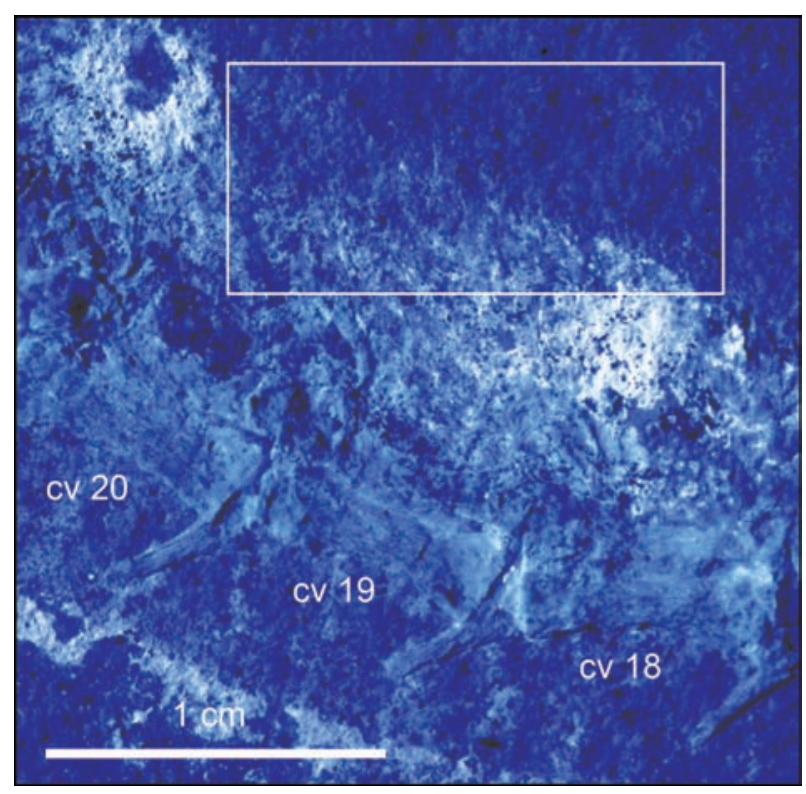

Fig. 25. Extremely thin filaments at the edge of the preserved soft tissue (inside box) are visible at high magnification and under ultraviolet light in some areas of the mid-caudal region.

fact, such "feathery scales" are regularly envisioned as an intermediate stage of models of feather evolution (CHANG et al. 2009).

The apparent presence of filament-like integumentary structures in Juravenator is consistent with similar structures, often regarded as primitive feathers, in the basal coelurosaurs Sinosauropteryx (CHEN et al. 1998; Ji et al. 2007 b) and Dilong (Xu et al. 2004); and the combination of these structure with large portions of scaly skin along its body suggest that these structures may not have completely surrounded the bodies of these theropods.

Besides integumentary structures, internal elements of soft tissue are preserved along the proximal portion of the tail. Under ultra-violet illumination, a distinct longitudinal band of about $2 \mathrm{~mm}$ in width is visible, which runs immediately ventral to the tips of the chevrons of the mid-proximal caudals (between the $14^{\text {th }}$ and $23^{\text {rd }}$ caudal) (Fig. 24). In between the chevrons of the $17^{\text {th }}$ and $21^{\text {st }}$ caudals, vertical illuminating stripes arranged in regular intervals of about $3 \mathrm{~mm}$ are observable. These vertical structures might reflect external or internal segmentation of the tail (Fig. 24B). Under normal light, a series of fibers, also ventral to the chevrons of the $10^{\text {th }}$ to $14^{\text {th }}$ caudals and parallel to the axis of the tail, is also visible. These structures may either represent tendinal elements of the $\mathrm{m}$. ilioischiocaudalis or remnants of a reinforced seam of the vertical septum ventral to the chevrons, a condition present in the terminal portion of the crocodilian tail (Frey 1988). DAL SASSO \& Signore (1998) similarly interpreted a series of comparable soft structures associated with the skeleton of Scipionyx, although such structures could also correspond to bundles of subcutaneous collagen fibers (LINGHAMSOLIAR 2003).

\section{Conclusions}

The exquisitely preserved holotype of Juravenator starki is one of the most complete non-avian theropod skeletons described to date for Europe, and a significant addition to the scant worldwide record of smallbodied Late Jurassic theropods. This specimen provides evidence of morphologies - from details of the skull to the epidermis - that are poorly known in other theropods interpreted as basal coelurosaurians and thus it contributes significantly to our understanding of the anatomical disparity and evolutionary history of this clade. Juravenator exhibits a number of similarities (e.g., hair-like cervical ribs, extremely long tail) to other coelurosaurians often regarded as having evolved either at the base or near the divergence of this clade. The discovery of Juravenator augments the diversity of predatory dinosaurs known for the Late Jurassic basins of southern Germany (Fig. 26) and it documents that during this time the nearby, recently emerged lands were inhabited by diverse small-bodied non-avian coelurosaurians of presumably similar lifestyles.

\section{Acknowledgements}

We are especially grateful to the finders of the specimen, Hans and Klaus-Dieter Weiss (Kelkheim-Fischbach), to PINO VÖLKL (Jura-Museum Eichstätt) for the spectacular preparation of the specimen, and to Helmut Tischlinger (Stammham) and GEORG JANSSEN (Bayerische Staatssammlung für Paläontologie und Geologie, Munich) for the invaluable UV and normal light photographs, respectively. We are also very grateful to MARTINA KöLBL-Ebert (JuraMuseum Eichstatt) and Franz STARK (Schamhaupten) for access to the specimen. We thank Stephanie Abramowicz, William Evans and Emma Freeman (Natural History Museum of Los Angeles County), for preparing the illustrations and for editorial assistance, respectively. JAMES Clark (George Washington University), Cristiano Dal SAsso (Museo Civico di Storia Naturale di Milano), EberHARD FREY (Staadliches Museum für Naturkunde Karlsruhe), Daniel Goujet (Muséum National d'Histoire Natur- 


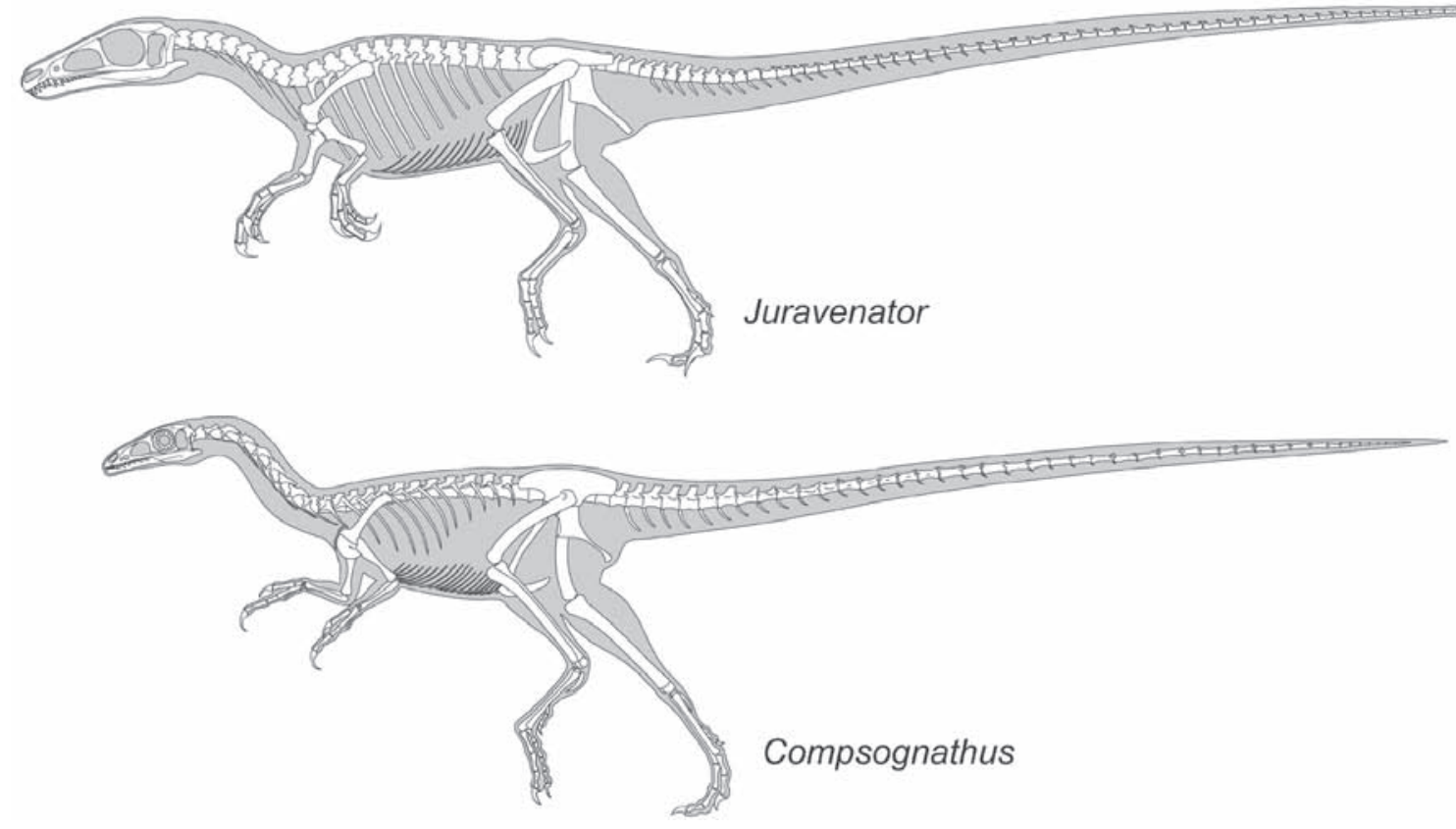

Fig. 26. Reconstructed skeletons of Juravenator starki compared to Compsognathus longipes (based on MNHM CNJ 79; PEYer 2006, Gishlick \& GAUthier 2007). These animals, the only non-avian theropod skeletons known from the Late Jurassic Solnhofen Archipelago, are among the most informative non-avian theropods from the European fossil record. Drawings not to scale.

elle, Paris), Sunny Hwang (American Museum of Natural History, New York), Martina Kölbl-Ebert, Reinhold LEINFELDER (Museum für Naturkunde Berlin), MARKus Moser (München), Mark Norell (American Museum of Natural History), Oliver RAUHut (Bayerische Staatsammlung für Paläontologie und Geologie), MARTIN RÖPER (Museum Solnhofen), Helmut TISChlinger, GÜNTER VIOHL (Jura Museum Eichstätt), DAVID VARRICCHIO (Montana State University), Pino VölkL, Peter Wellnhofer and Winfried WERNER (Bayerische Staatssammlung für Paläontologie und Geologie), and $\mathrm{XU}_{\mathrm{U}} \mathrm{X}_{\mathrm{ING}}$ and ZHOU ZHONGHE (Institute of Vertebrate Paleontology and Paleoanthropology, Beijing) provided access to specimens or unpublished photographs, logistics, and/or valuable discussions, and StePhen Brusatte (American Museum of Natural History) and Roger BENSON (Cambridge University) provided invaluable assistance during their reviews of the manuscript. Finally, LUIS CHIAPPE wishes to thank very especially Martina KöLBL-EBERT, ReINHOLd LeINfelder, Oliver Rauhut, Peter Wellnhofer, and WinFRIED WERNER for the wonderful hospitality offered during his visits to the Jura-Museum Eichstätt and the Bayerische Staatssammlung für Paläontologie und Geologie. This research was made possible by the Alexander von Humboldt Foundation (Friedrich Wilhelm Bessel Award) and supported also by the Jurassic Foundation, Synthesys Program, Antorchas Foundation, Bayerische Staatssammlung für Paläontologie und Geologie, Department of Geo- and Environmental Sciences (Munich University), Jura-Museum Eichstätt, and Natural History Museum of Los Angeles
County. The Alexander von Humboldt Foundation is also acknowledged for funding the color printing of the figures.

\section{References}

Anderson, B. G., Lucas, S. G., Barrick, R. E., Heckert, A. B. \& Basabilvazo, G. T. (1998): Dinosaur skin impressions and associated skeletal remains from the upper Campanian of Southwestern New Mexico: New data on the integument morphology of hadrosaurs. Journal of Vertebrate Paleontology, 18: 739-745.

Barthel, K. W., Swinburne, N. H. M. \& Conway Morris, S. (1990): Solnhofen - A study in Mesozoic palaeontology. - 236 pp.; Cambridge (Cambridge University Press).

BARsBold, R. \& Olmoska, H. (1990): Ornithomimosauria, - In: Weishampel, D. B., Dodson, P. \& Osmólska, H. (Eds.): The Dinosauria, 225-244; Berkeley (University of California Press).

BAumel, J. J. \& WitMer, L. M. (1993): Osteologia. - In: Baumel, J. J. , King, A. S., Breazile, J. E., Evans, H. E.\& VANDEN Berge, J. C. (Eds.): Handbook of avian anatomy: Nomina Anatomica Avium. - Publications of the Nuttall Ornithological Club, 23: 45-132.

Bidar, A., Demay, L. \& Thomel, G. (1972): Compsognathus corallestris, nouvelle espèce de dinosaurien théropode du Portlandien de Canjuers (Sud-Est de la France). - Annales du Muséum d'Histoire Naturelle, Nice, I (1): 3-34. 
Brochu, C. A. (1996): Closure of neurocentral sutures during crocodilian ontogeny: implications for maturity assessment in fossil archosaurs. - Journal of Vertebrate Paleontology, 16: 49-62.

- (2003): Osteology of Tyrannosaurus rex: Insights from a nearly complete skeleton and high-resolution computed tomographic analysis of the skull. - Journal of Vertebrate Paleontology, 22 (Suppl. 4): 1-138.

Brown, B. (1916): Corythosaurus casuarius: Skeleton, musculature and epidermis. - American Museum of Natural History Bulletin, 35: 709-716.

Butler, R. \& UpChURCH, P. (2007): Highly incomplete taxa and the phylogenetic relationships of the theropod dinosaur Juravenator starki. - Journal of Vertebrate paleontology, 27 (1): 253-256.

CAMP, C. L. (1936): A new type of small theropod dinosaur from the Navajo Sandstone of Arizona. - Bulletin of the University of California, Department of Geological Sciences, 24: 39-65.

Carpenter, K., Miles, C. \& Cloward, K. (2005a): New small theropod from the Upper Jurassic Morrison Formation of Wyoming. - In: CARPENTER, K. (Ed.): The Carnivorous Dinosaurs, 23-48; Bloomington (Indiana University Press).

Carpenter, K., Miles, C., Ostrom, J. H. \& Cloward, K. (2005 b): Redescription of the small maniraptoran theropods Ornitholestes and Coelurus from the Upper Jurassic Morrison Formation of Wyoming. - In: CARPENTER, K. (Ed.): The Carnivorous, 49-71; Bloomington (Indiana University Press).

Carrano, M. T., Hutchinson, J. R. \& Sampson, S. D. (2005): New information on Segisaurus halli, a small theropod dinosaur from the Early Jurassic of Arizona. Journal of Vertebrate Paleontology, 25 (4): 835-849.

Chang, C., Wu, P., Baker, R. E., Maini, P. K., Alibardi, L. \& ChuONG, C.-M. (2009): Reptile scale paradigm: EvoDevo, pattern formation and regeneration. - International Journal of Developmental, 53: 813-826

Chen, P.-J., Dong, Z.-M. \& Zhen, S.-N. (1998): An exceptionally well-preserved theropod dinosaur from the Yixian Formation of China. - Nature, 391: 147-152.

Chiappe, L. M. (2007): Glorified Dinosaurs. - 263 pp.; New York (Wiley \& Sons).

Chitappe, L. M., Coria, R. A., Dingus, L., Jackson, F., Chinsamy, A. \& Fox, M. (1998): Sauropod dinosaur embryos from the Late Cretaceous of Patagonia. Nature, 396: 258-261.

Choiniere, J. N., Xu, X., Clark, J. M., Forster, C. A., Guo, Y. \& HAN, F. (2010): A basal alvarezsauroid theropod from the Early Late Jurassic of Xinjiang, China. Nature, 327: 571-574.

Clark, J. M., Norell, M. A. \& Chiappe, L. M. (1999): An oviraptorid skeleton from the Late Cretaceous of Ukhaa Tolgod, Mongolia, preserved in an avianlike brooding position over an oviraptorid nest. - American Museum Novitates, 3265: 1-36.

Claessens, L. (2004): Dinosaur gastralia: Origin, morphology, and function. - Journal of Vertebrate Paleontology, 24 (1): 89-106.
Colbert, E. H. (1989): The Triassic dinosaur Coelophysis. - Bulletin of the Museum of Northern Arizona, 57: 1-160.

Codorniú, L. \& Chiappe, L. M. (2004). Early juvenile pterosaurs (Pterodactyloidea: Pterodaustro guinazui) from the Lower Cretaceous of central Argentina. - Canadian Journal of Earth Sciences, 41: 9-18.

CORIA, R. A. \& CHIAPPE, L. M. (2007): Embryonic skin from Late Cretaceous sauropods (Dinosauria) of Auca Mahuevo, Patagonia, Argentina. - Journal of Paleontology, 81 (6): 1528-1532.

Coria, R. A. \& CuRrie, P. J. (2006): A new carcharodontosaurid (Dinosauria, Theropoda) from the Upper Cretatious of Argentina. - Geodiversitas, 28 (1): 71-118.

CuRrie, P. J. (2003): Cranial anatomy of tyrannosaurids from the Late Cretaceous of Alberta, Canada. - Acta Palaeontologica Polonica, 48: 191-226.

Currie, P. J. \& Chen, P.-J. (2001): Anatomy of Sinosauropteryx prima from Liaoning, northeastern China. Canadian Journal of Earth Sciences, 38: 1705-1727.

CuRRIE, P. J. \& ZHAO, X. (1993): A new carnosaur (Dinosauria, Theropoda) from the Jurassic of Xinjiang, People's Republic of China. - Canadian Journal of Earth Sciences, 30: 2037-2081.

Czerkas, S. (1997): Skin. - In: Currie, P. J. \& Padian, K. (Eds.): Encyclopedia of Dinosaurs, 669-675; San Diego (Academic Press).

Dal Sasso, C. \& Signore, M. (1998): Exceptional softtissue preservation in a theropod dinosaur from Italy. Nature, 392: 383-387.

De Klerk, W. J., Forster, C. A., Sampson, S. D., ChinSAMY, A. \& Ross, C. F. (2000): A new coelurosaurian dinosaur from the Early Cretaceous of South Africa. Journal of Vertebrate Paleontology, 20 (2): 324-332.

DeSMOND, A. (1982): Archetypes and Ancestors. - 287 pp.; Chicago (University of Chicago Press).

Dhouallly, D., Hardy, M. H. \& Sengel, P. (1980): Formation of feathers on chick foot scales: A stage-dependent morphogenetic response to retinoic acid. - Journal of Embryology and Experimental Morphology, 58: 63-78.

FreY, E. (1988): Anatomie des Körperstammes von Alligator mississippiensis DAUDIN. - Stuttgarter Beiträge zur Naturkunde, (A), 424: 1-106.

GAUTHIER, J. (1986): Saurischian monophyly and the origin of birds. - In: PADIAN, K. (Ed.): The origin of birds and the evolution of flight. - Memoires of the California Academy of Sciences, 8: 1-55.

Gishlick, A. D. \& Gauthier, J. (2007): On the manual morphology of Compsognathus longipes and its bearing on the diagnosis of Compsognathidae. - Zoological Journal of the Linnean Society, 149: 569-581.

Göhlich, U. B. \& ChiAppe, L. M. (2006): A new carnivorous dinosaur from the Late Jurassic Solnhofen archipelago. - Nature, 440: 329-332.

GÖHLich, U. B., TisChlingeR, H. \& ChiAPPE, L. M. (2006): Juravenator starki (Reptilia, Theropoda), ein neuer Raubdinosaurier aus dem Oberjura der südlichen Frankenalb (Süddeutschland): Skelettanatomie und Weichteilbefunde). - Archaeopteryx, 24: 1-26. 
Holtz, T. R., Molnar, R. E. \& Currie, P. J. (2004): Basal Tetanurae. - In: Weishampel, D. B., Dodson, P. \& OsmóPlsKa, H. (Eds.): The Dinosauria, 71-110; Berkeley, Los Angeles \& Oxford (California University Press).

Horner, J. R. (1997): Behavior. - In: CurRie, P. \& PAdian, K. (Eds.): Encyclopedia of Dinosaurs, 45-50; San Diego (Academic Press).

Hutchinson, J. R. (2001): The evolution of pelvic osteology and soft tissues on the line to extant birds (Neornithes). - Zoological Journal of the Linnean Society, 131: $123-168$.

HuENE, F. v. (1914): Das natürliche System der Saurischia. - Zentralblatt für Mineralogie, Geologie und Paläontologie, (B), 1914: 154-158.

Hwang, S. H., Norell, M. A., Qiang, J. \& Keqin, G. (2002): New specimens of Microraptor zhaoianus (Theropoda: Dromaeosauridae) from northeastern China. - American Museum Novitates, 3381: 1-44.

Hwang, S. H., Norell, M. A., Qiang, J. \& Keqin, G. A. (2004): Large compsognathid from the Early Cretaceous Yixian Formation of China. - Journal of Systematic Paleontology, 2 (1): 13-30.

JI, Q. \& JI, S. 1996. On discovery of the earliest bird fossil in China and the origin of birds. - Chinese Geology, 10 (233): 30-33.

Ji, S., Ji, Q., LÜ, J. \& Yuan, C. (2007a): A New Giant Compsognathid Dinosaur with Long Filamentous Integuments from Lower Cretaceous of Northeastern China. - Acta Geologica Sinica, 81 (1): 8-15.

Ji, S., Gao, C., Liu, J., Meng, Q. \& Ji, Q. (2007b): New material of Sinosauropteryx (Theropoda: Compsognathidae) from Western Liaoning, China. - Acta Geologica Sinica, 81 (2): 177-182.

JI, Q., Currie, P. J., Norell, M. A. \& JI, S.-A. (1998): Two feathered theropods from the Upper Jurassic/Lower Cretaceous strata of northeastern China. - Nature, 393: 753-761.

Kirkland, J. I., Britt, B. B. Whittle, C. H., Madsen, S. K. \& Burge, D. L. (1998): A small coelurosaurian theropod from the Yellow Cat Memeber of the Cedar Mountain Formation (Lower Cretaceous, Barremian) of Eartern Utah. - In: LuCAs, S. G., Kirkland, J. L. \& Estep, J. W. (Eds.): Lower and Middle Cretaceous Terrestrial ecosystems. - Science Bulletin of the New Mexico Museum of Natural History, 14: 239-248.

LingHAM-Soliar, T. (2003): Evolution of birds: ichthyosaur integumental fibers conform to dromaeosaur protofeathers. - Naturwissenschaften, 90: 428-432.

Madsen, J. H. (1976): Allosaurus fragilis: A revised osteology. - Bulletin of the Utah Geological and Mineral Survey, 109: 1-163.

MAKovicky, P. J. \& CURRIE, P. J. (1998): The presence of a furcula in tyrannosaurid theropods, and its phylogenetic and functional implications. - Journal of Vertebrate Paleontology, 18: 143-149.

MARsh, O. C. (1880). Odontornithes: a monograph on the extinct toothed birds of North America. - United States Geological Exploration of the 40th Parallel. - 201 pp.; Washington, DC (U.S. Government Printing Office).
- (1881): Principal characters of American Jurassic dinosaurs; Part V. - American Journal of Sciences, Series 3, 21: 417-423.

Marshall Faux, C. \& Padian, K. (2007): The opisthotonic posture of vertebrate skeletons: postmortem contraction or death throes? - Paleobiology, 33 (2): 201-226.

Martill, D. M., Frey, E. Sues, H.-D. \& Cruickshank, A. R. I. (2000): Skeletal remains of a small theropod dinosaur with associated soft structures from the Lower Cretaceous Santana Formation of northeast Brazil. Canadian Journal of Earth Sciences, 37: 891-900.

Mayr, G., Peters, D. S., Plodowski, G. \& Vogel, O. (2002): Bristle-like integumentary structures at the tail of the horned dinosaur Psittacosaurus. - Naturwissenschaften, 89: 361-365.

MichARD, J.-G. (1991): Description du Compsognathus (Saurischia, Theropoda) de Canjuers (Jurassique Supérieur du Sud-Est de la France): Position phylogénetique, relation avec Archaeopteryx et implications sur l'origine Théropodienne des oiseaux. - Unpublished Ph.D. thesis.-328 pp.; Paris (Muséum National d'Histoire Naturelle).

Naish, D., Martill, D. M. \& Frey, E. (2004): Ecology, systematics and biogeographical relationships of dinosaurs, including a new theropod, from the Santana Formation (Albian, Early Cretaceous) of Brazil. - Historical Biology, 2004: 1-14.

Nesbitt, S. J., Turner, A. H., Spaulding, M., Conrad, J. L. \& Norell, M. A. (2009): The theropod furcula Journal of Morphology, 270: 856-879.

Norell, M. A., MAKOVICKY, P. J. \& ClaRK, J. M. (1997): A Velociraptor wishbone. - Nature, 389: 447.

- (2004): Dromaeosauridae. - In: WEISHAMPEL, D. B., Dodson, P. \& Osmólska, H. (Eds.): The Dinosauria, p. 196-209; Berkeley, Los Angeles \& Oxford (California University Press).

Norell, M. A. \& XU, X. (2005): Feathered Dinosaurs. Annual Revue of Earth and Planetary Sciences, 33: 277 299.

OsBoRn, H. F. (1916): Skeletal adaptations of Ornitholestes, Struthiomimus, Tyrannosaurus. Bulletin of the American Museum of Natural History 19: 459-464.

Ostrom, J. H. (1978): The osteology of Compsognathus longipes WAGNER. - Zitteliana, 4: 73-118.

Owen, R. (1842): Report on British fossil reptiles; part II. Report of the British Association for the Advancement of Science, 1841: 60-204.

Peyer, K. (2006): A reconsideration of Compsognathus from the Upper Tithonian of Canjuers, southeastern France. - Journal of Vertebrate Paleontology, 26 (4): 879-896.

Raunut, O. W. M. (2003): The interrelationships and evolution of basal theropod dinosaurs. - Special Papers in Palaeontology, 69: 1-213.

Renesto, S. \& Viohl, G. (1997): A sphenodontid (Reptilia, Diapsida) from the Late Kimmeridgian of Schamhaupten (Southern Franconian Alb, Bavaria, Germany). Archaeopteryx, 15: 27-46.

SAnder, M. P. (1997): Teeth and claws. - In: Currie, P. J. \& Padian, K. (Eds.): Encyclopedia of Dinosaurs, 717-725; San Diego (Academic Press). 
Sanz, J. L., Chiappe, L. M., Pérez-Moreno, B. P., Moratalla, J. J., Hernández-Carrasquilla, F., Buscalioni, A. D., Ortega, F., Poyato-Ariza, F. J., Rasskin-Gutman, D. \& Marínez-Delclós, X. (1997): A nestling bird from the Lower Cretaceous of Spain: Implications for avian skull and neck evolution. Science, 276: 1543-1546.

Sanz, J. L., Chiappe, L. M., Fernández-Jalvo, Y., Ortega, F., SÁnchez-Chillón, B., Poyato-Ariza, F. J. \& PérezMoreno, B. P. (2001): An early Cretaceous pellet. Nature, 409: 998-999.

SCHWEIGERT, G. (2007): Ammonite biostratigraphy as a tool for dating Upper Jurassic Lithographic limestones from Southern Germany - first results and open questions. Neues Jahrbuch für Geologie und Paläontologie, Abhandlungen, 245 (1): 117-125

SENTER, P. (2007): A new look at the phylogeny of Coelurosauria (Dinosauria: Theropoda). - Journal of Systematic Palaeontology, 5 (4): 429-463.

Sereno, P., Tan, L., Brusatte, S. L., Kriegstein, H. J., ZHAO, X. \& CLOWARD, K. (2009): Tyrannosaurid skeletal design first evolved at small body size. - Science, 326: 418-422.

TherRIEN, F. \& Henderson, D. M. (2007): My theropod is bigger than yours ... or not: Estimating body size from skull length in theropods. - Journal of Vertebrate Paleontology, 27 (1): 108-115.

Tischlinger, H., Göhlich, U. B. \& Chiappe, L. M. (2006): Borsti, der Dinosaurier aus dem Schambachtal: Erfolgsstory mit Hindernissen. - Fossilien, 2006 (5): 277-287.

VioHL, G. (1999): Fund eines neuen kleinen Theropoden. Archaeopteryx, 17: 15-19.

VIOHL, G. \& ZAPP, M. (2006): Die Fossil-Lagerstätte Schamhaupten (oberstes Kimmeridgium, Südliche Frankenalb, Bayern). - Archaeopteryx, 24: 27-78.

- (2007): Schamhaupten, an outstanding Fossil-Lagerstätte in a silicified Plattenkalk around the Kimmeridgian-Tithonian boundary (Southern Franconian Alb, Bavaria). - Neues Jahrbuch für Geologie und Paläontologie, Abhandlungen, 245: 127-142.

WAGNER, A. (1861): Neue Beiträge zur Kenntnis der urweltlichen Fauna des lithographischen Schiefers. V. Compsognathus longipes WAGNER. - Abhandlungen der Bayerischen Akademie der Wissenschaften, 9: 30-38.

Weishampel, D. B., Dodson, P. \& Osmólska, H. (2004): The Dinosauria (2 ${ }^{\text {nd }}$ ed.). - 861 pp.; Berkeley (University of California Press).

Wellnhofer, P. (2008): Archaeopteryx - Der Urvogel von Solnhofen. - 256 pp.; München (Pfeil).

Widelitz, R. B., Jiang, T.-X., Lu, J.-F. \& Chuong, C.-M. (2000). Beta catenin in epithelial morphogenesis: Conversion of part of avian foot scales into feather buds with a mutated beta catenin. - Developmental Biology, 219: 98-114.

Widelitz, R. B., JiAnG, T.-X., Yu, M., Wu, P., Yue, Z. \& ChuOng, C.-M. (2003). Molecular biology of feather morphogenesis: A testable model of Evo-Devo research. - Journal of Experimental Zoology, 298B: 109-222.

XU, X. (2006): Scales, feathers and dinosaurs. - Nature, 440: 287-288.
Xu, X., Clark, J. M., Forster, C. A., Norell, M. A., Erickson, G. M., Eberth, D. A., Jia, C. \& Zhao, Q. (2006): A tyrannosauroid dinosaur from the Late Jurassic of China. - Nature, 439: 715-718.

Xu, X, Clark, J. M., Mo, J., Choniere, J., Forster, C. A., Erickson, G. M., Hone, D. E., Sullivan, C., Eberth, D., Nesbitt, S., ZhaO, Q., Hernandez, R., Jia, C., Han, F. \& Guo, Y. (2009): A Jurassic ceratosaur from China helps clarify avian digital homologies. - Nature, 459: 940-944.

Xu, X., Norell, M. A., Kuang, X., Wang, X., Zhao, Q., AND C. JIA., (2004): Basal tyrannosauroids from China and evidence for protofeathers in tyrannosauroids. Nature, 431: 680-684.

Xu, X., WanG, X.-L. \& Wu, X.-C. (1999a): A dromaeosaurid dinosaur with a filamentous integument from the Yixian Formation of China. - Nature, 401: 262-266.

Xu, X., TANG, Z.-L. \& WANG, X.-L. (1999b): A therizinosauroid dinosaur with integumentary structures from China. - Nature, 399: 350-354.

Xu, X., Zheng, Z. \& You, H. (2009): A new feather type in a non-avian theropod and the early evolution of feathers. - Proceedings of the National Academy of Sciences, 106 (3): 832-834.

ZeIss, A. (2001): Wenig bekannte Ammoniten aus dem Grenzbereich Oberkimmeridgium/Untertithonium der Südlichen Frankenalb. - Archaeopteryx, 19: 57-70.

Zhang, F., Zhou, Z., \& Dyкe, G. (2006): Feathers and 'feather-like' integumentary structures in Liaoning birds and dinosaurs. - Geological Journal, 41: 1-6.

Manuscript received: July 23rd, 2009.

Revised version accepted by the Stuttgart editor: July 8th, 2010 .

\section{Addresses of the authors:}

Luis M. Chiappe, The Dinosaur Institute, Natural History Museum of Los Angeles County, 900 Exposition Boulevard, Los Angeles, CA 90007, USA;

e-mail: chiappe@nhm.org

Ursula B. GöHLICH, Naturhistorisches Museum Wien, Geologisch-paläontologische Abteilung, Burgring 7, A-1010 Vienna, Austria;

e-mail: ursula.goehlich@nhm-wien.ac.at 


\section{Appendix: Measurements of the skeleton of Juravenator starki (in $\mathrm{mm}$ )}

\section{Left Right}

\section{Skull and Mandible}

Skull length

Orbit length

Orbit height

Antorbital fossa length

Antorbital fossa height

Antorbital fenestra length

Supratemporal fenestra length

Mandible length

\section{Shoulder and Forelimb}

Coracoid length

Scapula length

Humerus length

Ulna length

Radius length

Metacarpal I length

Metacarpal II length

Metacarpal III length

Phalanx I-1 length

Phalanx II-1 length

Phalanx II-2 length

Phalanx III-1 length

Phalanx III-2 length

Phalanx III-3 length

Phalanx I-2 (claw) length

Phalanx II-3 (claw) length

Phalanx III-4 (claw) length

\section{Pelvis and Hindlimb}

Ilium length

Femur length

Tibia length

Fibula length

Metatarsal I length

Metatarsal II length

Metatarsal III length

Metatarsal IV length

Metatarsal V length

Phalanx I-1 length

Phalanx II-1 length

Phalanx II-2 length

Phalanx III-1 length

Phalanx III-2 length

Phalanx III-3 length

Phalanx IV-1 length

Phalanx IV-2 length

Phalanx IV-3 length

Phalanx IV-4 length

Phalanx I-2 (claw)*

Phalanx II-3 (claw)*

Phalanx III-4 (claw)*

Phalanx IV-5 (claw)*

$\begin{array}{ll}- & 82 \\ - & 18.4 \\ - & 14 \\ - & 24 \\ - & 9 \\ - & \sim 19.5 \\ 7.5 & - \\ \sim 77 & -\end{array}$

- $\quad-$

$42-$

$20.5 \quad 20.5$

$-5$.

$11.5-$

$10.5-$

$8-$

$10 \quad 10$

$4 \quad-$

4.5
5.5

$\sim 12 \quad-$

$9 \quad 10$

$\begin{array}{ll}5.5 & 7\end{array}$

- 40

- 52

$58.1 \quad 58.1$

$55.3 \quad 56$

$26.5-$

$34 \quad 32$

$29.6 \quad 29.8$

$8 \quad 6.8$

$5.8 \quad 6$

$10.4 \quad 11.4$

98

$11.9 \quad 11.5$

$8.1 \quad 8$

$\begin{array}{ll}7.4 & 7.7\end{array}$

$7.4 \quad 7$

$5.5 \quad 6.5$

$5.3 \quad 4.5$

4.24

$6.0 \quad 3.5$

$10.7 \quad 11.5$

$7.4 \quad 6.6$

$7.2 \quad 5.8$
$27 \quad 27.5$

9 -

$4.6 \quad 4.5$
Length/mid-height

caudal centra

Caudal 1

Caudal 2

Caudal 3

Caudal 4

Caudal 5

Caudal 6

Caudal 7

Caudal 8

Caudal 9

Caudal 10

Caudal 11

Caudal 12

Caudal 13

Caudal 14

Caudal 15

Caudal 16

Caudal 17

Caudal 18

Caudal 19

Caudal 20

Caudal 21

Caudal 22

Caudal 23

Caudal 24

Caudal 25

Caudal 26

Caudal 27

Caudal 28

Caudal 29

Caudal 30

Caudal 31

Caudal 32

Caudal 33

Caudal 34

Caudal 35

Caudal 36

Caudal 37

Caudal 38

Caudal 39

Caudal 40

Caudal 41

Caudal 42

Caudal 43

6.2

6.5

$\begin{array}{ll}6.5 & 3.3\end{array}$

$\begin{array}{ll}6.4 & 3.2\end{array}$

$\begin{array}{ll}6.9 & 3.5\end{array}$

$6.5 \quad 3.5$

$\begin{array}{ll}6.4 & 3.2\end{array}$

$6.4 \quad 3.1$

$\begin{array}{ll}6.1 & 2.8\end{array}$

$6.8-$

$6.8-$
-

$-$

6.5

$-$

$-$

$6.8-2.5$

$\begin{array}{ll}7.2 & 2.4\end{array}$

$\begin{array}{ll}7.5 & 2.6\end{array}$

$\begin{array}{ll}7.5 & 2.7\end{array}$

$\begin{array}{ll}7.6 & 2.4\end{array}$

$\begin{array}{ll}7.6 & 2.3\end{array}$

$\begin{array}{ll}7.9 & 2.7\end{array}$

$7.7-$

$8.0 \quad 2.2$

$8.0 \quad 2.6$

$8.4-$

$8.4 \quad 2.6$

$8.3 \quad 2.3$

$8.3 \quad 2.1$

$8.2 \quad 2.3$

$8.3 \quad 2.3$

$8.3-$

$8.3 \quad 2.3$

$8.3 \quad 2.7$

$8.0 \quad 2.5$

$\begin{array}{ll}7.9 & 1.9\end{array}$

$\begin{array}{ll}7.7 & 1.7\end{array}$

$\begin{array}{ll}7.6 & 2.0\end{array}$

$\begin{array}{ll}7.6 & 1.9\end{array}$

$\begin{array}{ll}7.5 & 1.7\end{array}$

$\begin{array}{ll}7.5 & 2.2\end{array}$

Caudal 44

$7.2 \quad 2.2$

* claws were measured from the dorsoproximal corner to the osseous tip 